\title{
On Melting of High Carbon Steel by Oxygen Converter Process*
}

\author{
Panel Discussion at the 66th Grand Lecture Meeting, \\ Held at Nagoya University on Oct. 18, 1963
}

\section{- Attendance}

Chairman:

Lectures \&

lecturers :

Debators :
Jō Doi (Kawasaki Iron Works, Nippon Kokan Kabushiki Kaisha)

Outline of LD Converter Process (On the High Carbon Steelmaking)

By Jō Doi** (Kawasaki Iron Works, Nippon Kokan Kabushiki Kaisha)

On Melting of High Carbon Steel by Oxygen Converter Process

By Katsushige Nagami, Kichinosuke Matsunaga \& Motohiko Nakatani** (Kokura Iron Works, Sumitomo Metal Industries, Ltd.)

On Melting of High Carbon Steel by Oxygen Converter Process

By Hideo Sugizawa, Osamu Saeki \& Shōzō Mitsushima** (Kobe Works, Kobe Steel Works, Ltd.), Kiichi Narita \& Akitsu Tomita (Central Research \& Development Laboratory, Kobe Steel Works, Ltd.)

On Melting of High Carbon Steel by Oxygen Converter Process

By Yoshimasa Aoyama, Hiroharu Usui**, Akira Matsunaga \& Seiji Kobayashi (Amagasaki Iron Works, Amagasaki Iron \& Steel Mfg. Co., Ltd.)

On Melting of High Carbon Steel by Oxygen Converter Process (Some Problems on Dephosphorization)

By Jō Doi, Takashi Itaoka** \& Katashi Saitō (Kawasaki Iron Works, Nippon Kokan Kabushiki Kaisha)

Tōru Araki, Dr. Eng. (National Research Institute for Metals)

Tasuku Fuwa, Prof.-Dr. Eng. (Tohoku University)

Yūshirō Fukao (Daido Steel Co., Ltd.)

Shinkichi Koike (North Japan Special Steel Co., Ltd.)

Keiichi Komota (Kawasaki Steel Corporation)

Akira Matsunaga (Amagasaki Iron \& Steel Mfg. Co., Ltd.)

Yukio Matsushita, Prof.-Dr. Eng. (University of Tokyo)

Kiyoshi Mizui (Nippon Kokan Kabushiki Kaisha)

Kōkichi Sano, Prof.-Dr. Eng. (Nagoya University)

Kazuo Wakabayashi (Yawata Iron \& Steel Co., Ltd.)

Zensaku Yamamoto (Fuji Iron \& Steel Co., Ltd.)

\section{OUTLINE OF LD CONVERTER PROCESS ON THE HIGH CARBON STEELMAKING)}

\section{By Jō Doi \\ (Nippon Kokan Kabushiki Kaisha)}

The LD converter process was first industrialized in Austria in 1952 after World War II and the process has come to spread throughout the world on account of its excellency.

Now it is becoming important as a representative steelmaking process. Especially the aptitude in the way of raw materials and the advantages for operation of this process are most suitable to conditions in Japan. It showed such promising terms for the future that the system was keenly watched and introduced relatively early and has been in operation since the end of 1957 .
- Lectures

Nowadays the amount of crude steel produced by the LD process has already come to occupy more than half of the whole output of Japan and 13 companies have adopted the process in steelmaking.

The LD process was jointly originated by Vöest Co., Ltd. in Linz and Alpine Co., Ltd. in Donavitz as the name shows, and has been made prevailing through the patent technical compact of BOT Group and the reciprocal technical assistance pact is made not only locally but throughout the world. Also in Japan we have been making efforts to improve techniques through the regular meetings of the LD Conference. We have been disclosing the results thereof in the meetings of The Iron and Steel Institute of Japan, as far as feasible.

Now the LD technique in Japan is highly appreciated by the world. Today we decided to have

* This article was published with the kind permission of Brassert Oxygen Technik AG in Austria. Japanese text was printed in Tetsuto-Hagané (Journal, Iron \& Steel Institute, Japan), 50 (1964), 2, 216-248.

** Representative lecturers. 
a Panel Discussion "On Melting of High Carbon Steel by LD Process " in response to a request by The Iron and Steel Institute of Japan. To make it more successful and effective, we have made a careful preparation and therefore we heartily appreciate the kindness of the Institute.

As the LD process originally belongs to a converter process, we are apt to consider it a furnace only for low carbon steel making. But the different points between the LD process and the classical basic converter are that in the case of the LD process, both dephosphorization and decarburization occur simultaneously from the start of blowing. Furthermore, provided with suitable conditions, both dephosphorization and desulphurization can be completed even if refining is stopped within high carbon range, while in the classical converter such reactions do not occur; that is to say, the LD process provides easy feasibility of manufacturing high carbon steel. These points have been recognized since the LD process came into existence, particularly in Germany and Austria, wherein there are many factories that have adopted the LD process as a steelmaking technique not only in high carbon steel manufacturing but also in special steel manufacturing. It has been steadily put into operation to produce tool steel of one per cent carbon, and special steel with total alloy elements up to over 10 per cent. It is remarkable that the smelting test of 18-8 stainless steel was also successfully made.

In Japan the LD plants were originally set up to produce low carbon steel, especially for thin plates, and many plants have thereafter come to produce high carbon steel also. It is just a matter of time before the LD process will take part in the field of alloy steel. The LD process is a technical success and it promises to have a large portion in the steel production and a great influence upon the steel industry, because of its good economical yield. In these circumstances the manufacture of high carbon steel, especially machine structural steel, has gradually come to be recognized by JIS (Japan Industrial Standards).

The important point in producing high carbon steel by the LD process is, in short, how to control the reaction of decarburization, dephosphorization and desulphurization. It is also very important to clarify the mechanism " how molten steel is directly oxidated by gaseous oxygen as its motive force". The fact that a highly reactable slag is produced from the beginning of blowing while the bath temperature is still low, on account of a high temperature occurring at the point of oxygen colliding with the bath, is a favorable condition.

Regarding dephosphorization, sound high carbon steel can be easily produced even from hot metal with a high phosphor content by means of the double slag method in the LD process as in the open hearth furnace, by which almost all the phosphor in hot metal can be eliminated in the first slag at the melt-down period. The degree of dephosphorization in the early period is influenced by the bath temperature, oxygen consumption, kind and shape of flux and its shooting method. Accordingly many practical procedures may be considered, as we can see in the LDAC process. If phosphor in the hot metal is less than 0.1 per cent, high carbon steel can be easily produced with a rather high efficiency by the single slag method.

Regarding desulphurization, it is expected that the peculiar reaction will occur by direct oxidation in the LD process, that is to say, the effect by direct combustion to $\mathrm{SO}_{2}$ gas.

The oxygen included in molten steel influences the nonmetallic inclusion in steel, which is the most important element regarding mechanical properties. The LD process has such advantages that refining in this process relies on direct oxidation irrespective of the $\mathrm{FeO}$ potential in the slag. It is easy to produce good conditions such that the refining can be done in a reducing atmosphere by the energetic occurrence of $\mathrm{CO}$ gas. Therefore, we can produce steel with little oxygen by the LD process in spite of using pure oxygen.

The technique concerning these points is not yet perfectly completed and studies are steadily continuing. On the other hand it is a problem for further study to establish a direct oxidation refining theory, which has not yet be clarified by the classical metallurgy. When we consider that the LD process has a possibility of manufacturing sound carbon steel, and that we are investigating the technique of heat adjustment for alloying and improving the deoxidation practice, the manufacture of special steel is theoretically prospective and its realization is not so difficult.

As mentioned above, we have a great expectation for the LD process in melting of not only high carbon steel but special steel, and we are making efforts to put it into practice one by one. Now we are to have the four lectures talk about their experiences, then have a discussion on the subjects of their lectures between the eleven interrogators here as representatives, from their own specialistic points of view.

I hope this discussion will be a great aid to the development of the LD technique. 


\section{ON MELTING OF HIGH GARBON STEEL BY OXYGEN CONVERTER PROGESS}

\section{By Katsushige Nagami, Kichinosuke Matsunaga and Motohiko Nakatani}

(Sumitomo Metal Industries, Ltd.)

\section{Introduction}

In our converter plant, mainly low carbon capped steel was melted at the beginning of the operation, and afterward a melting test for medium carbon steel and high carbon steel was gradually made to increase the variety of manufacturing steel. Using the double slag method for melting medium carbon steel, we investigated ways of promoting slag-formation of lime, and the method and time of deslagging, and at the same time we studied also the single slag method of melting to simplify the operation practices and to shorten the refining time. We gained the prospect and ability to melt high carbon steel by a single slag method, as such we report in the following on the progress of the operation and the results of the examination.

\section{On the Standards of Steelmaking Practice}

The objectives of steel composition and tap temperature in our works are shown in Table 1. As the melting method, we adopted the catch-carbon method, by which the final carbon content could be remained within the standard limit, and the quality of steel can be improved. Pouring practice is bottom pouring and ingot is 4.2 ton weight with hot-topping.

\section{On the Progress of Refining Practice and Its Results}

Since the first trial, various refining methods have been investigated to improve the dephosphorization efficiency, and the transition of processes is shown in Table 2.

\section{The First Period}

In the first trial, we adopted the double slag method, considering that an intermediate deslagging is necessary for dephosphorization according to some reports and from our own experiences.

Taking the dephosphorization equilibrium and some others' reports into consideration, the time for deslagging was decided at $8 \mathrm{~min}$. after the blowing was started, because the dephosphorization was effective while the bath temperature was still low and while the slag basicity was as high as possible after the end of the silicon blow.

\section{The Second Period}

In the first period, the slag was so sticky that it was laborious and took long time to slag off. So we delayed the deslagging time in order to promote the slagging of lime and to make the slag more fluid by increasing the slag temperature, and thus make it possible for the slag to flow out by foaming. The deslagging time was decided $13 \mathrm{~min}$. after the beginning of blowing. At the same time we tried to promote slagging in order to elevate the dephosphorization efficiency by increasing the lime, scale and fluorspar consumption. The result was that at the time of deslagging the slag gushed out from the vessel immediately after blowing out, and the deslagging was performed smoothly by self-flowing.

\section{The Third Period}

In the first and second periods we adopted the double slag method from the view point of dephosphorization efficiency. But in this system the refining time is long and the yield is lower for the sake of intermediate deslagging, and furthermore the blowing time is so short that the slagging of lime is not always satisfactory, even if the consumption of the flux is increased. So to solve these problems, we tested the single slag method, considering the following points:

(1) Lime consumption is to be less than the total amount used in the double slag method; fluorspar

Table 1. Private specification of chemical composition and temperature target at the end point

\begin{tabular}{|c|c|c|c|c|}
\hline Item & Class. & A & B & C \\
\hline $\mathrm{C}$ & $(\%)$ & $0.30 \sim 0.40$ & $0.40 \sim 0.50$ & $0.50 \sim 0.60$ \\
\hline $\mathrm{Si}$ & $(\%)$ & \multicolumn{3}{|c|}{$0.15 \sim 0.35$} \\
\hline Mn & $(\%)$ & \multicolumn{3}{|c|}{$0.60 \sim 0.85$} \\
\hline $\mathrm{P}, \mathrm{S}$ & $(\%)$ & \multicolumn{3}{|c|}{$\leq 0.030$} \\
\hline $\begin{array}{l}\text { End point } \\
\text { ture }\end{array}$ & $\begin{array}{l}\text { tempera- } \\
\left({ }^{\circ} \mathrm{C}\right)\end{array}$ & \multicolumn{3}{|c|}{$1,630 \pm 15$} \\
\hline
\end{tabular}

Table 2. Transition of refining method

\begin{tabular}{c|c|c|c|c}
\multirow{2}{*}{ Period } & Method & $\begin{array}{c}\mid c \\
\text { Time after } \\
\text { blowing-in }\end{array}$ & Method & Reference \\
\cline { 2 - 4 } & Double slag & $8 \mathrm{~min}$ & Forced & Deslagging after the end of silicon blowing \\
\hline 1 & Double slag & $13 \mathrm{~min}$ & Natural & To promote slagging of lime, scale and spar were increased. \\
\hline 3 & Single slag & - & - & $\begin{array}{c}\text { To reduce the ch.-tap time, single slag method was adopted. Spar was more in- } \\
\text { creased, and lime and spar were added in parts. }\end{array}$ \\
\hline
\end{tabular}


to be increased to make the slag-formation perfect.

(2) Separated injection of lime and fluorspar is done in order to promote the slagging of lime.

(3) An acid source is added according to the hot metal composition and pig rate in order to keep the basicity within $4.5 \sim 5.0$.

(4) Oxygen pressure is to be $6.7 \mathrm{~kg} / \mathrm{cm}^{2}$ for the first $5 \mathrm{~min}$. of blowing, same as in the case of low carbon steel, then it must drop to $6.0 \mathrm{~kg} / \mathrm{cm}^{2}$ in order to decrease the occurrence of slopping and to promote slagging.

(5) Lance height is to be fixed at 1,100 1,500 $\mathrm{mm}$ according to the lining life throughout the blowing period.

Table 3 shows operation results of each period.

\section{Consideration on the Results}

\section{On Pig Rate}

We used a large amount of flux, especially scale, to increase the amount of lime and its slagging, so that pig rate amounted to $96.5 \%$. But it was useless to add a heat source such as ferro-silicon from the point of heat balance. In the third period the pig rate could drop to $91.7 \%$, because the amount of lime and scale used was decreased and a lowering of the temperature did not occur by stopping the blowing.

\section{On the Refining Time}

As is shown in Table 3 and Fig. 1, there is almost no change in each period as far as the blowing time and the refining time are concerned. It is mainly the deslagging time that has influence upon the refining time. That is to say, in the first period it took about $10 \mathrm{~min}$. to slag off and the refining time amounted to $46 \sim 47$ min., which was the longest of the three periods. In the second period the refining time was reduced by $6 \sim 7 \mathrm{~min}$, which was mainly due to shortening of the deslagging time by self-flowing. In the third period when the single slag method was used, it was reduced to $35 \mathrm{~min}$., which was still $3 \sim 4 \mathrm{~min}$. longer than that of the low carbon steel melting. This is explained by the fact that the blowing time is one min. longer than that of low carbon steel, because the blowing pressure is $6.0 \mathrm{~kg} / \mathrm{cm}^{2}$ and it takes time to add ferro-alloy.

\section{On Yield of Refining}

Yield of refining was about $90 \%$, which scarecely changed through three periods. We expected the yield in the third period to be higher than other periods, for in the third period there was no iron loss by intermediate deslagging, and the pig rate was kept low, and massive return scarp was used. The yield in that period was not so high, the reason being that the iron loss was increased by an increase of the final slag volume

Table 3-1. Operating data at each period

\begin{tabular}{|c|c|c|c|c|c|c|c|c|c|c|c|}
\hline \multirow{2}{*}{ Period } & \multirow{2}{*}{\multicolumn{2}{|c|}{$\begin{array}{l}\text { Pig rate } \\
(\%)\end{array}$}} & \multicolumn{5}{|c|}{ Chemical composition of hot metal (\%) } & \multicolumn{4}{|c|}{ Flux for 1st stage $(\mathrm{kg} / \mathrm{t})$} \\
\hline & & & $\mathrm{C}$ & $\mathrm{Si}$ & $\mathrm{Mn}$ & $\mathrm{P}$ & $\mathrm{S}$ & Lime & Scale & Spar & $\mathrm{SiO}_{2}$ \\
\hline $\begin{array}{l}1 \\
2 \\
3\end{array}$ & & & $\begin{array}{l}4.27 \\
4.29 \\
4.25\end{array}$ & $\begin{array}{l}0.60 \\
0.62 \\
0.49\end{array}$ & $\begin{array}{l}0.89 \\
0.64 \\
0.81\end{array}$ & $\begin{array}{l}0.181 \\
0.179 \\
0.199\end{array}$ & $\begin{array}{l}0.037 \\
0.041 \\
0.038\end{array}$ & $\begin{array}{l}48 \\
53 \\
80\end{array}$ & $\begin{array}{l}11 \\
19 \\
23\end{array}$ & $\begin{array}{r}4 \\
8 \\
20\end{array}$ & $\frac{-}{-}$ \\
\hline \multirow[t]{2}{*}{ Period } & \multicolumn{4}{|c|}{ Flux for 2nd stage $(\mathrm{kg} / \mathrm{t})$} & \multicolumn{7}{|c|}{ Chemical composition at the end of 1 st stage (\%) } \\
\hline & Lime & Scale & Spar & Silica & C & $\mathrm{P}$ & $\mathrm{S}$ & $\mathrm{CaO}$ & $\mathrm{SiQ}_{2}$ & $\mathrm{FeO}$ & $\mathrm{P}_{2} \mathrm{O}_{5}$ \\
\hline $\begin{array}{l}1 \\
2 \\
3\end{array}$ & $\begin{array}{l}29 \\
42 \\
-\end{array}$ & $\begin{array}{r}6 \\
13 \\
-\end{array}$ & $\begin{array}{r}4 \\
8 \\
-\end{array}$ & $\begin{array}{c}6 \\
6 \\
-\end{array}$ & $\begin{array}{c}2.77 \\
1.78 \\
-\end{array}$ & $\begin{array}{c}0.118 \\
0.077 \\
-\end{array}$ & $\begin{array}{c}0.025 \\
0.015 \\
-\end{array}$ & $\begin{array}{c}46.71 \\
61.69 \\
-\end{array}$ & $\begin{array}{c}26.30 \\
17.90 \\
-\end{array}$ & $\begin{array}{c}5.97 \\
4.17 \\
-\end{array}$ & $\begin{array}{c}2.56 \\
2.22 \\
-\end{array}$ \\
\hline
\end{tabular}

Table 3-2. Operating data at each period

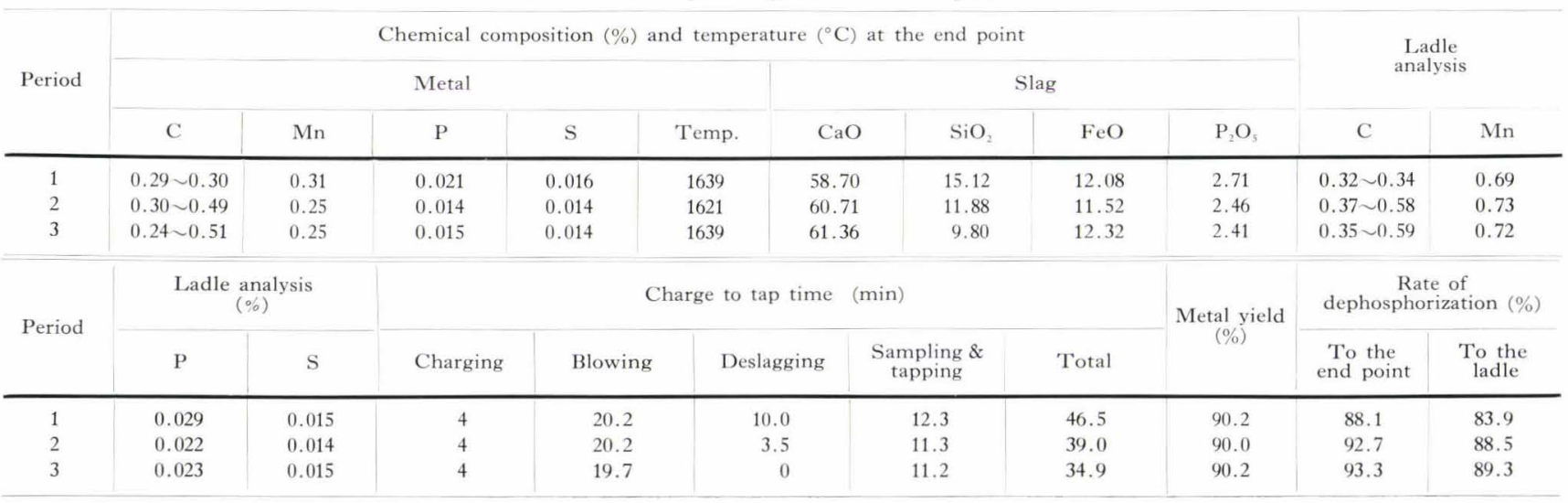




\begin{tabular}{|c|c|c|c|c|c|c|c|c|c|c|c|}
\hline \multirow{4}{*}{\begin{tabular}{|l} 
Lime $(\mathrm{kg} / \mathrm{t})$ \\
$\mathrm{Scale}(\mathrm{kg} / \mathrm{t})$ \\
$\mathrm{Spar}(\mathrm{kg} / \mathrm{t})$ \\
$\mathrm{SiO}_{2}(\mathrm{~kg} / \mathrm{t})$ \\
\end{tabular}} & \multirow{4}{*}{$\begin{array}{l}\text { Charg- } \\
\text { ing }\end{array}$} & \multicolumn{2}{|l|}{48} & \multirow{4}{*}{\multicolumn{2}{|c|}{ Deslagging }} & & \multicolumn{2}{|l|}{29} & \multirow{4}{*}{\multicolumn{3}{|c|}{$\begin{array}{l}\text { Sampling } \\
\text { and tapping }\end{array}$}} \\
\hline & & 11 & Blowing & & & & \multirow{2}{*}{\multicolumn{2}{|c|}{$\begin{array}{l}\text { Blowing } \\
\text { 2nd stage }\end{array}$}} & & & \\
\hline & & \begin{tabular}{|l|}
4 \\
\end{tabular} & 1st stage & & & & & & & & \\
\hline & & - & & & & & 6 & & & & \\
\hline 2nd period & & 5 & 10 & 15 & & & 25 & 30 & 35 & 40 & $4 \frac{1}{5}$ \\
\hline Lime $(\mathrm{kg} / \mathrm{t})$ & & 53 & & & & 40 & & & & & \\
\hline Scale $(k g / t)$ & Charg- & 19 & Blowing & & Desla & 13 & Blowing & Samp & $\mathrm{ng}$ & & \\
\hline Spar $(\mathrm{kg} / \mathrm{t})$ & ing & 8 & 1 st st. & & ging & 8 & 2nd st. & and $t$ & pping & & \\
\hline $\mathrm{SiO}_{2}(\mathrm{~kg} / \mathrm{t})$ & & - & & & & 6 & & & & & \\
\hline 3 rd period & 0 & 5 & 10 & 15 & & & 25 & 30 & 35 & 40 & 45 \\
\hline Lime $(\mathrm{kg} / \mathrm{t})$ & & 30 & 50 & & & & & & & & \\
\hline Scale $(\mathrm{kg} / \mathrm{t})$ & Charg- & 23 & & Blowi & & & & pling & & & \\
\hline Spar $(k g / t)$ & ing & 5 & 15 & & & & & d tapping & & & \\
\hline$\left[\mathrm{SiO}_{2}(\mathrm{~kg} / \mathrm{t})\right]$ & & - & 6 & & & & & & & & \\
\hline & 0 & 5 & 10 & 15 & & & 25 & 30 & 35 & 40 & 45 \\
\hline
\end{tabular}

Fig. 1.

Operating diagram at each period and occurrence of slopping due to a large quantity of scale and fluorspar used to promote slagging.

\section{On Dephosphorization Efficiency}

As the blowing standard was improved step by step since the first trial, dephosphorization was also improved with every period, and $\mathrm{P}$ in the products was kept less than $0.030 \%$ throughout the three periods. In killed steel, especially high carbon steel, rephosphorization occurs to a noticeable degree, while tapping. The amount is influenced by the conditions of refining, so we calculated the dephosphorization according to $\mathrm{P}$ in products. Dephosphorization efficiency in the third period using the single slag method, was better than that of other periods when the double slag method was adopted, in spite of the decreasing amount of lime.

For this reason the following is considered as owing to the increase in the fluorspar and its separated addition.

(1) Slagging of lime was promoted more effectively.

(2) Fluidity of slag was improved by lowering the melting point of slag.

(3) As activity of $(\mathrm{FeO})$ in slag was increased, dephosphorization was performed steadily.

Fig. 2 shows the relation between $[\mathrm{C}]$ and $[\mathrm{P}]$ at the end point and $[\mathrm{P}]$ in the ladle.

\section{On the Relation between Dephosphorization and Melting Condition of High Carbon Steel}

Many factors such as (FeO) in end point slag, basicity of end point slag, end point temperature, are considered to control the dephosphorization rate. But in this case we could not find any remarkable change in the slag volume and ladle analysis, so we made a multiple regression analysis between end point $[\mathrm{C}]$, end point temperature and $[\mathrm{P}]$ in products, and dephosphorization according to the data of the first period, and gained the following formula:

$$
z=149.185-0.1558 x * *-0.0336 y * *
$$

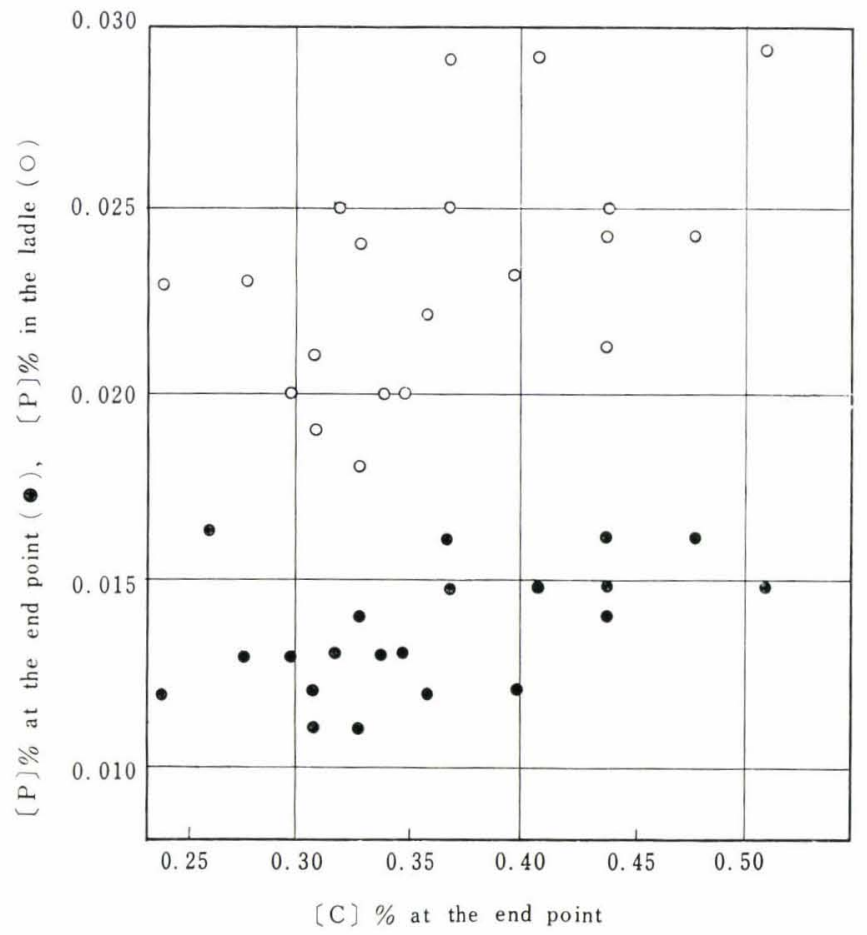

Fig. 2. Relation between $[\mathrm{P}] \%$ at the end point and in the ladle, and $[\mathrm{C}] \%$ at the end point by single slag method

Where, $z$ : dephosphorization rate to $\mathrm{P}$ in product $(\%)$

$x$ : end point $[\mathrm{C}]\left(\% \times 10^{2}\right)$

$y$ : end point temperature $\left({ }^{\circ} \mathrm{C}\right)$

Next we asked for the conditions necessary to make [P] in the products within the limits of the standard from the above formula. For example, in the case where [C] of the products is $0.55 \%,[\mathrm{P}]$ of the products less than $0.030 \%$, end point temperature $1,615^{\circ} \sim 1,645^{\circ} \mathrm{C}$, pig rate $96 \%$, provided that the end point [C] is $0.50 \%$ for $0.55 \% \mathrm{C}$ of products, and the end point temperature is $1,645^{\circ} \mathrm{C}$ which is the limit of disadvantage for dephosphorization, the dephosphorization rate is required to be about $86 \%$ and allowed $[\mathrm{P}] \%$ in hot metal must be about $0.200 \%$ in order to make [P] of products less than $0.030 \%$. So if $[\mathrm{P}]$ in the hot metal 
is less than $0.200 \%$, it is possible to melt high carbon steel up to the limit of $0.55 \% \mathrm{C}$ keeping $[\mathrm{P}]$ in the products less than $0.030 \%$ by the present melting standard of the single slag method.

\section{The Quality Test of Products}

Comparing with steel melted by other processes such as the open hearth furnace and the electric arc furnace, the results are as follows :

\section{Sulphur Print and Macro-Structure}

There are no remarkable differences between these three processes and no significant problems.

\section{Chemical Composition}

There is almost no difference between C, Si, Mn, $\mathrm{S}$ and $\mathrm{Cu}$, etc. but $\mathrm{P}$ in the steel by the open hearth furnace is less than $0.020 \%$, which is lower than the rest.

\section{Gas Analysis}

Fig. 3 shows the analysis of $\mathrm{N}_{2}$ and $\mathrm{O}_{2}$, and $\mathrm{N}_{2}$ of steel from a converter is slightly lower and that of the electric furnace is higher. About $\mathrm{O}_{2}$ there is almost no difference, but that of the converter is slightly lower.

\section{Nonmetallic Inclusion}

As is shown in Fig. 4, $\mathrm{SiO}_{2}$ of the converter steel is a little higher and $\mathrm{Al}_{2} \mathrm{O}_{3}$ of the converter is less than that of the electric furnace, the rest being lower in the order of open hearth, converter and electric furnace.

\section{Cleanliness in Microscopic Scale}

The results of inspection according to the JIS

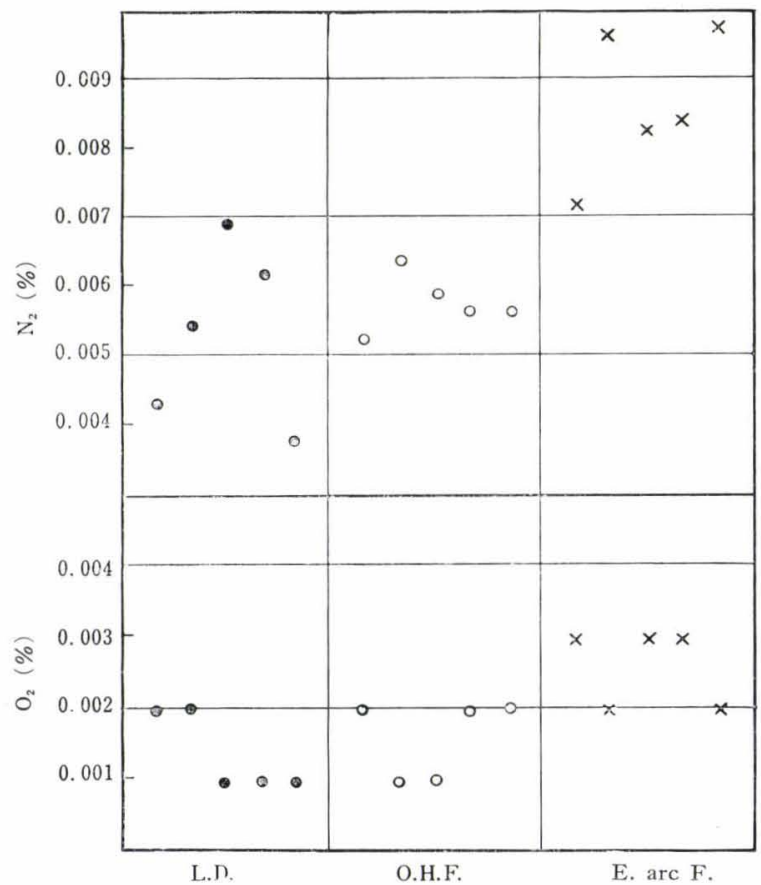

Fig. 3. Comparison of gas content in L.D., open hearth furnace and electric arc furnace steel method (PC method) showed that the quantities of $\mathrm{A}$ type or B type inclusions were much the same among the steels from the converter, the open hearth furnace and the electric arc furnace, while $\mathrm{C}$ type inclusions were least in converter steel. The total amount of these A, B and C type inclusions was found least in converter steel.

\section{Sand Mark}

The sand mark test consisting of three step cutting according to the JSPS (Japan Society for thePromotion of Science) method shows that the converter steel is never worse than the electric furnace steel, and that the open hearth furnace steel is the worst among them.

\section{Mechanical Properties}

Mechanical properties of round bar forged steel (as normalized state) are shown in Table 4 and Fig. 5. On mechanical properties according to the carbon equivalent of Rinebolt there was almost no difference, but considering them within a high carbon equivalent, tensile strength of electric furnace steel showed a slightly high value, and the elongation of converter

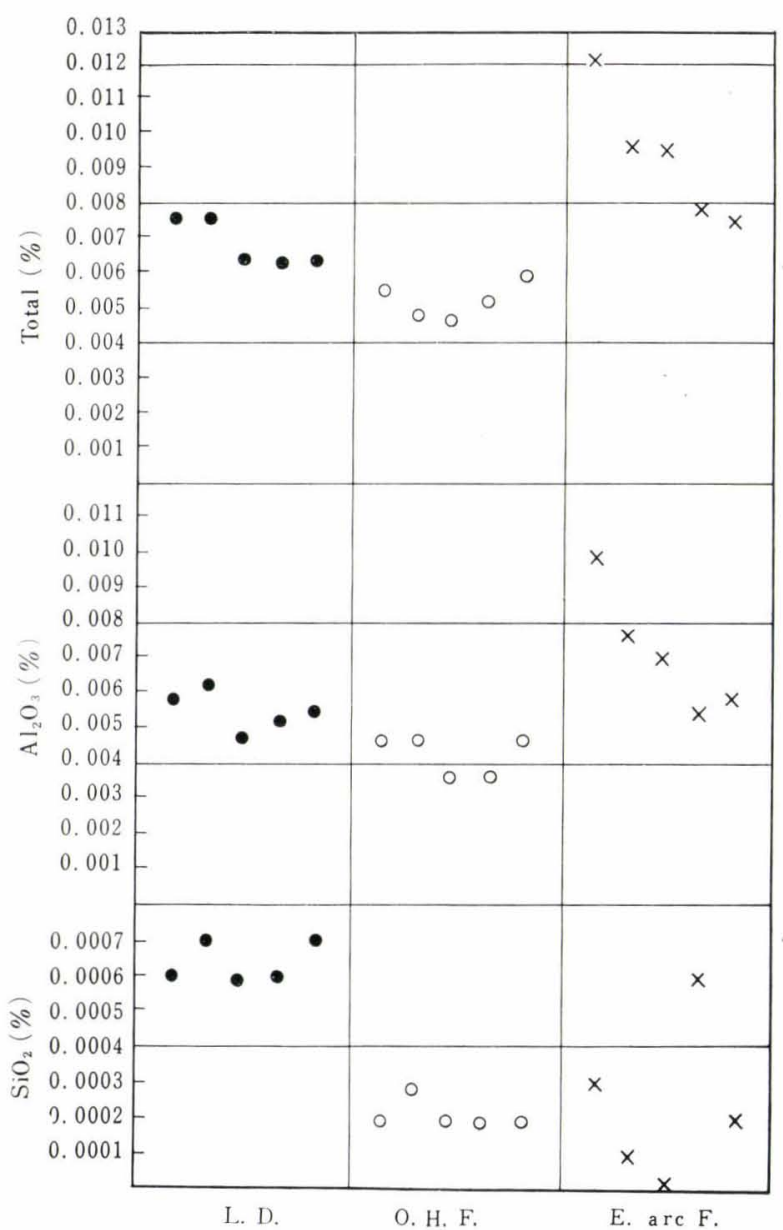

Fig. 4. Comparison of hot metel inclusion in L.D., open hearth furnace and electric arc furnace steel 
steel showed a slight drift to a higher value. On Charpy impact value and Rockwell hardness there was found no significant difference.

\section{Hardenability}

As hardenability is influenced by the chemical composition and the austenite grain size, we studied the relation between $A$ value in the $\mathrm{SAE}$ hardenability value and the ideal critical diameter $D_{I}$ which was calculated from the chemical composition and austenite grain size. The results showed, as we see in Fig. 6, there was no difference in three steelmaking processes. The reason why the converter steel shows a low hard-

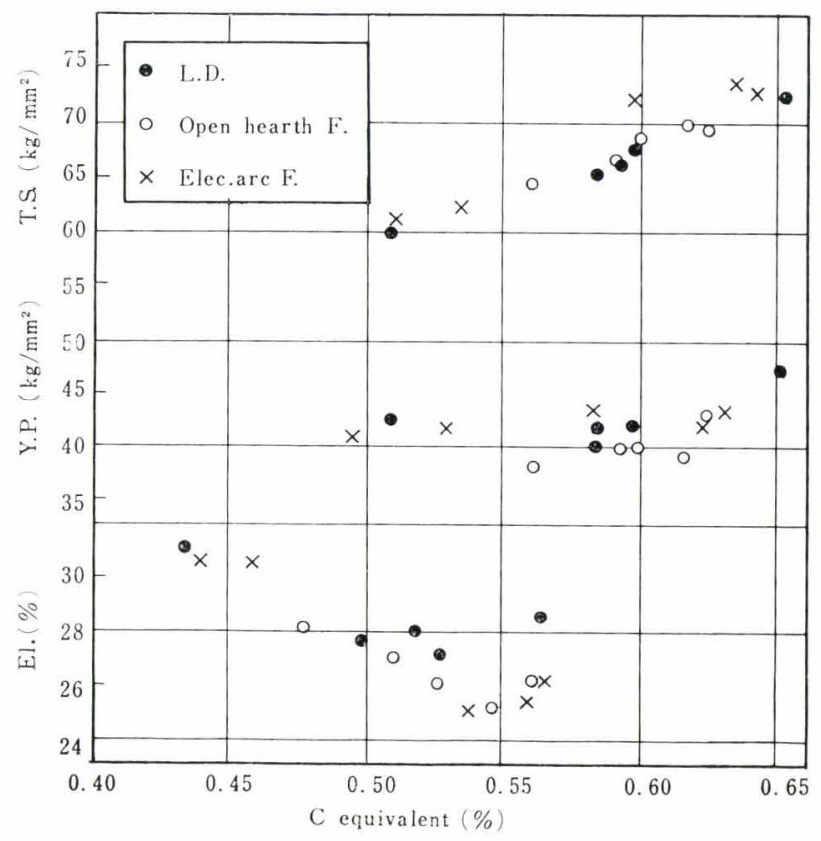

Fig. 5. Results of the tension test enability is considered to be not a matter of process but chemical composition, especially tramp-elements such as $\mathrm{Cr}$ or $\mathrm{Ni}$ which is negligible in converter steel.

\section{Conclusions}

Since the first trial, we have investigated the melting practice of high carbon steel step by step, and come to

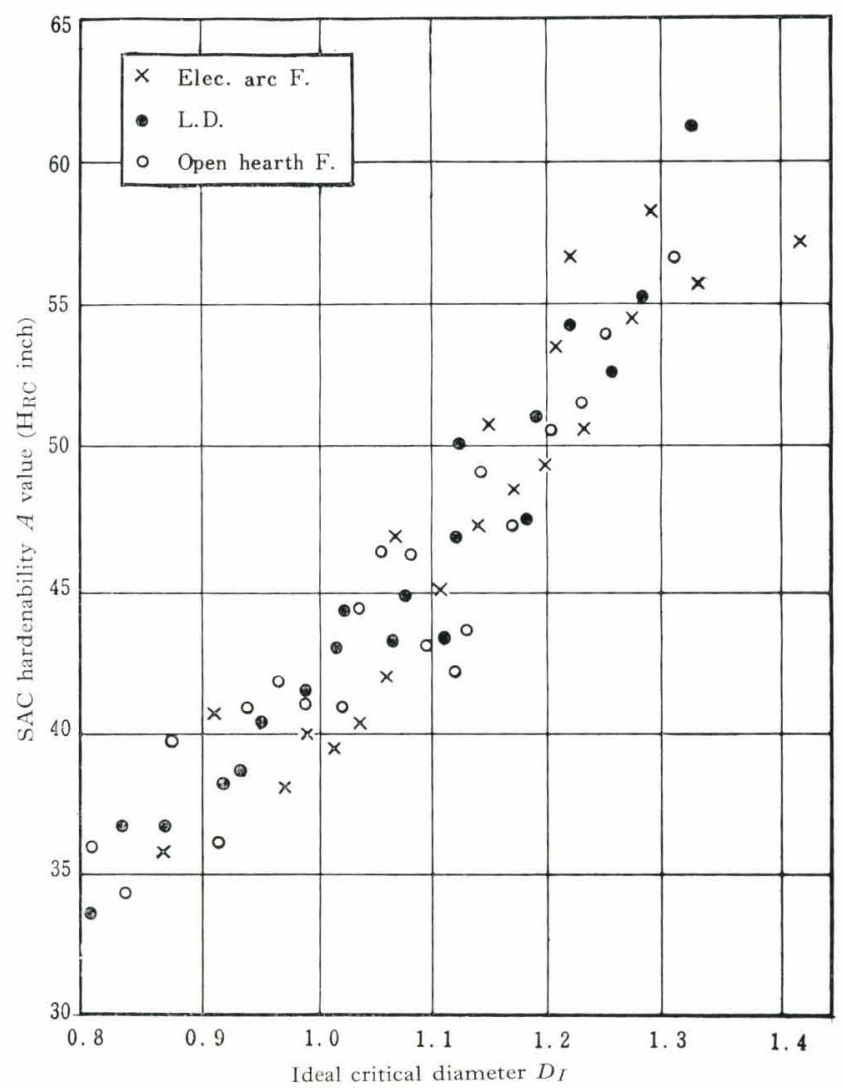

Fig. 6. Comparison of SAC hardenability in L.D., O.H.F and E. arc F. steel

Table 4. Mechanical properties of steel by each process

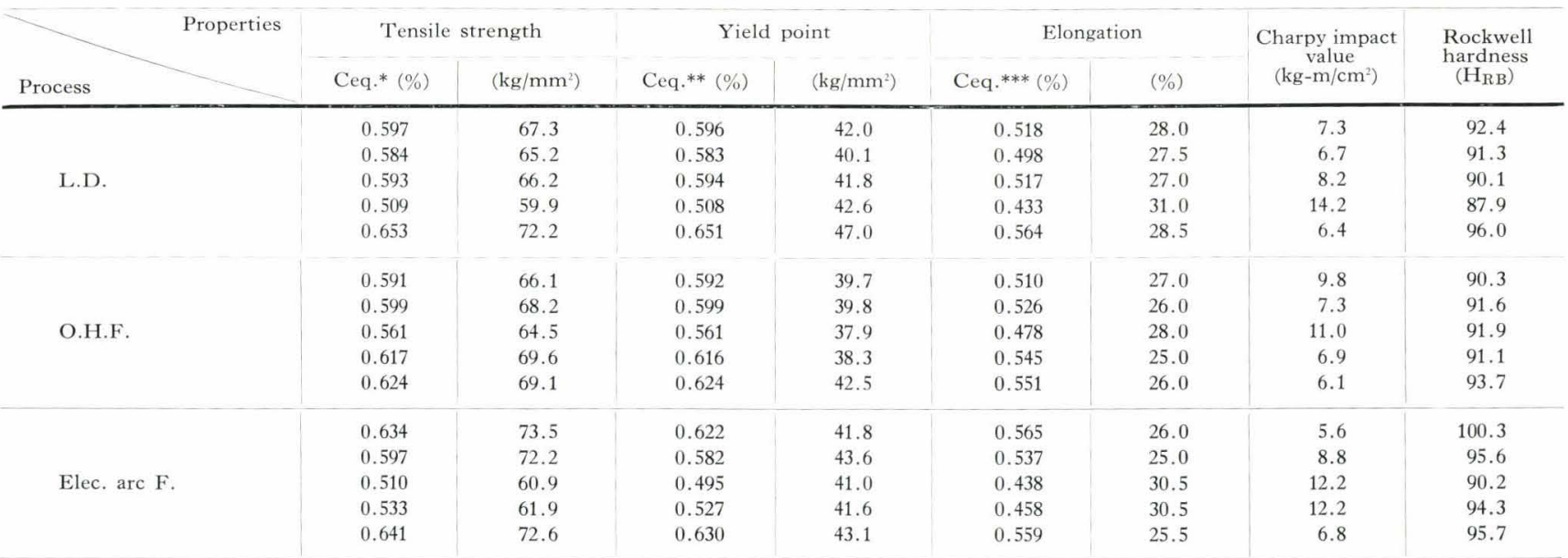

* Ceq. (T.S. $)=\mathrm{C}+0.1525 \mathrm{Si}+0.1880 \mathrm{Mn}+0.6633 \mathrm{P}-0.3583 \mathrm{~S}+0.1334 \mathrm{Cu}+0.1169 \mathrm{Cr}$

** Ceq. (Y.P. $=\mathrm{C}+0.1209 \mathrm{Si}+0.1881 \mathrm{Mn}+0.6756 \mathrm{P}+0.1689 \mathrm{Cu}$

*** Ceq. $(\mathrm{El})=.\mathrm{C}+0.0784 \mathrm{Si}+0.1176 \mathrm{Mn}+0.0980 \mathrm{Cu}+0.2353 \mathrm{Cr}$ 
be able to melt by the single slag method high carbon steel containing up to $0.55 \% \mathrm{C}$ and less than $0.030 \%$ $\mathrm{P}$, if $\mathrm{P}$ in the hot metal was less than $0.200 \%$. We have also found that the quality of the steel melted by the oxygen converter was as good as that of open hearth furnace steel and electric furnace steel.

\section{ON MELTING OF HIGH CARBON STEEL BY OXYGEN GONVERTER PROCESS}

\section{By Hideo Sugizawa, Osamu Saeki, Shōzō Mitsu- shima, Kiichi Narita and Akitsu Tomita \\ (Kobe Steel Works, Ltd.)}

\section{Introduction}

Since the 60-ton oxygen converter plant was built at the Nadahama Works of Kobe Steel Works, Ltd. in 1961, we have been operating it without any trouble, having made efforts to widen species of steel which can be produced by that plant and we are now producing over ten species of steel. At the beginning of the operation we were chiefly melting low carbon steel and since then we have gradually improved the technique of melting high carbon steel, as the operating condition becomes stable. Now we are producing medium carbon steel and high carbon steel, the qualities of which are comparable to steels melted by open hearth furnaces and electric furnaces.

In this lecture, the progress of operating practices and some results of examinations made on the melting of high carbon steel by the oxygen converter, are discussed.

\section{On the Melting Practices of High Carbon Steel}

As melting practices of high carbon steel by the oxygen converter, the combination of four methods is generally considered. Which method should be adopted, the single slag method or the double slag method, is decided by the relation between the phosphorus content in hot metal as a main raw material and the phosphorus content in steel demanded as products. As to the method of controlling carbon contents in steel, we adopted either the "catch-carbon method" or the "carbon addition method". We began to examine the double slag catch-carbon method at first, but finally we chose to adopt the single slag catch-carbon method because this method was more economical and easier to operate than the others.

\section{On the Melting Practices by Double Slag Catch-Carbon Method}

The double slag method is effective when the phosphorus content in the hot metal is high, but has some weak points, that is to say, the refining time becomes long, the operating practice is complex and the metallic yield becomes low because deslagging must be done during the blowing. Especially in this system it is necessary to consider the degree of achievement of dephosphorization at the end of blowing and the time and method of deslagging, which are pertinent to the bath temperature. So we examined in order to decide when deslagging should be done under the stipulated conditions where the main and sub raw materials and the blowing are fixed, as shown in Table 1 .

Table 1. Operating conditions

\begin{tabular}{|c|c|}
\hline \multicolumn{2}{|l|}{ 1st blow } \\
\hline Hot metal & $69 \mathrm{t} / \mathrm{ch}$ \\
\hline \multicolumn{2}{|l|}{ Raw materials } \\
\hline (Burnt lime & $\left(\mathrm{CaO} / \mathrm{SiO}_{2}: 3.0\right)$ \\
\hline Iron ore & $1,500 \mathrm{~kg} / \mathrm{ch}$ \\
\hline Mill scale & $1,500 \mathrm{~kg} / \mathrm{ch}$ \\
\hline Fluorspar & $200 \mathrm{~kg} / \mathrm{ch}$ \\
\hline $\mathrm{O}_{2}$ pressure & $5 \sim 7 \mathrm{~kg} / \mathrm{cm}^{2}$ \\
\hline Lance height & $1.4 \sim 1.5 \mathrm{~m}$ \\
\hline \multicolumn{2}{|l|}{ 2nd blow } \\
\hline \multicolumn{2}{|l|}{ Raw materials } \\
\hline (Burnt lime & $\left(\mathrm{CaO} / \mathrm{SiO}_{2}: 4.0\right)$ \\
\hline Iron ore & $500 \mathrm{~kg} / \mathrm{ch}$ \\
\hline Mill scale & $700 \mathrm{~kg} / \mathrm{ch}$ \\
\hline Acid O.H.F. slag & $800 \mathrm{~kg} / \mathrm{ch}$ \\
\hline Fluorspar & $300 \mathrm{~kg} / \mathrm{ch}$ \\
\hline $\mathrm{O}_{2}$ pressure & $3.5 \sim 6.0 \mathrm{~kg} / \mathrm{cm}^{2}$ \\
\hline Lance height & $1.4 \sim 1.5 \mathrm{~m}$ \\
\hline
\end{tabular}

\section{Investigation on the First Blowing}

In the test melting we are chiefly concerned with the promotion of dephosphorization by promoting slag-formation, the investigation on the deslagging method and the problem of how to obtain a proper bath temperature. As it is thought that much dephosphorization performed during the blowing considerably affects the phosphorus content in the bath, the proper decision of the end point of the first blowing is important to promote the dephosphorization as much as possible in this period and to secure a tap temperature. As is shown in Fig. 1, the less the decarburization in the first blowing, the lower the bath temperature is and the more the dephosphorization progresses.

A slight quantity of decarburization in the first blowing means that the blowing time is so short that slag-formation is apt to be imperfect and therefore dephosphorization is not done sufficiently. The relation between the rise of the bath temperature in the secondary blowing and carbon content of the bath at the end of the first blowing was that the higher the carbon content of the bath at the end of the first blowing, the higher the temperature was raised in the secondary blowing, as shown in Fig. 2. 
Considering the time necessary for proper slag-formationin the secondary blowing, we presume that it is suitable for the end point of the first blowing when the amount of decarburization in the first blowing is 0.70 to $0.90 \%$ and the bath temperature is $1,350^{\circ}$ to $1,390^{\circ} \mathrm{C}$. Fig. 3 shows the influence of the oxygen blowing rate in the first blowing. It follows that the smaller the blowing rate is, the more favorable the dephosphorization.

So the lower oxygen pressure in the first blowing is more effective.

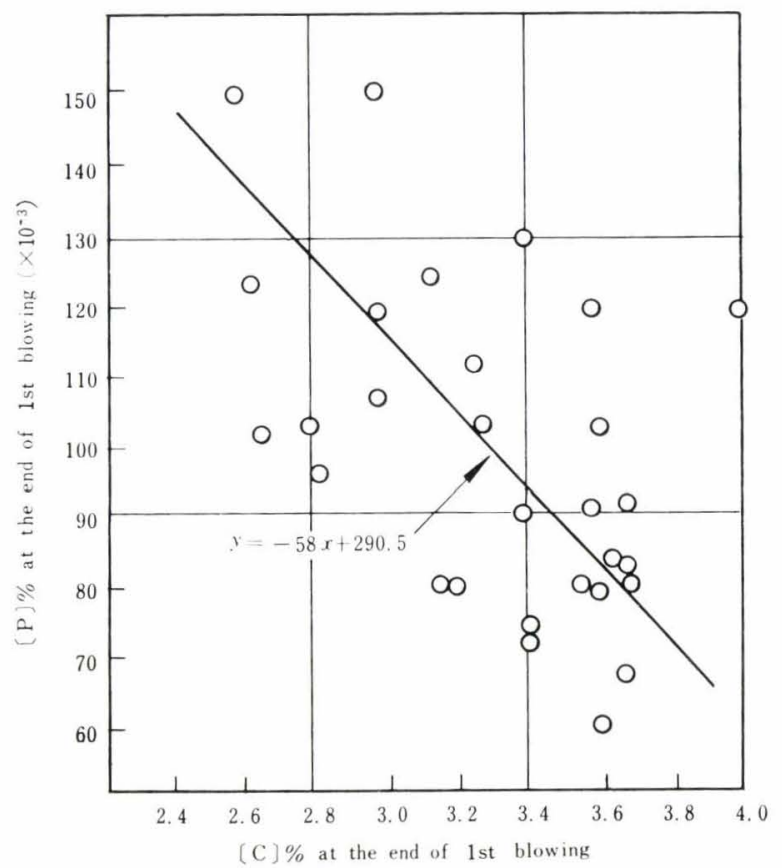

Fig. 1 (a)

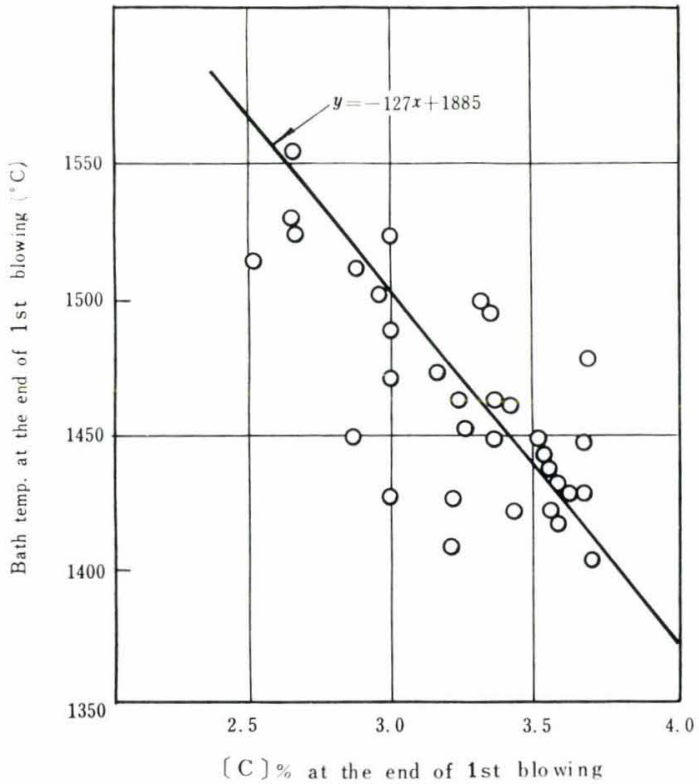

Fig. 1 (b)

\section{Investigation on the Secondary Blowing}

In the secondary blowing, we were chiefly concerned with the early achievement of the secondary slagformation, the catch of the objective carbon content and the security of the tap temperature. As the result of actual melting, we were able to catch carbon comparatively easily according to the blowing time, oxygen consumption and observation of the flame condition. But the bath temperature is difficult to secure because of the first slag discharge and the addition of the materials for the secondary slag-formation, so the addition of ferro-silicon is necessary for the heat source. Table 2 is the operating data that we decided with reference to the result of the above investigation.

\section{On the Melting Practice by Single Slag Catch- Carbon Method}

We investigated the test melting of high carbon steel by the single slag method on the basis of our experience in the double slag method, and found that it was also possible to melt high carbon steel by soft blowing, by enforcing the achievement of early slag-formation by using a large quantity of scale and fluorspar, etc., and also by an adjustment of slag basicity and security of slag quantity by the injection of the acid open hearth furnace slag,

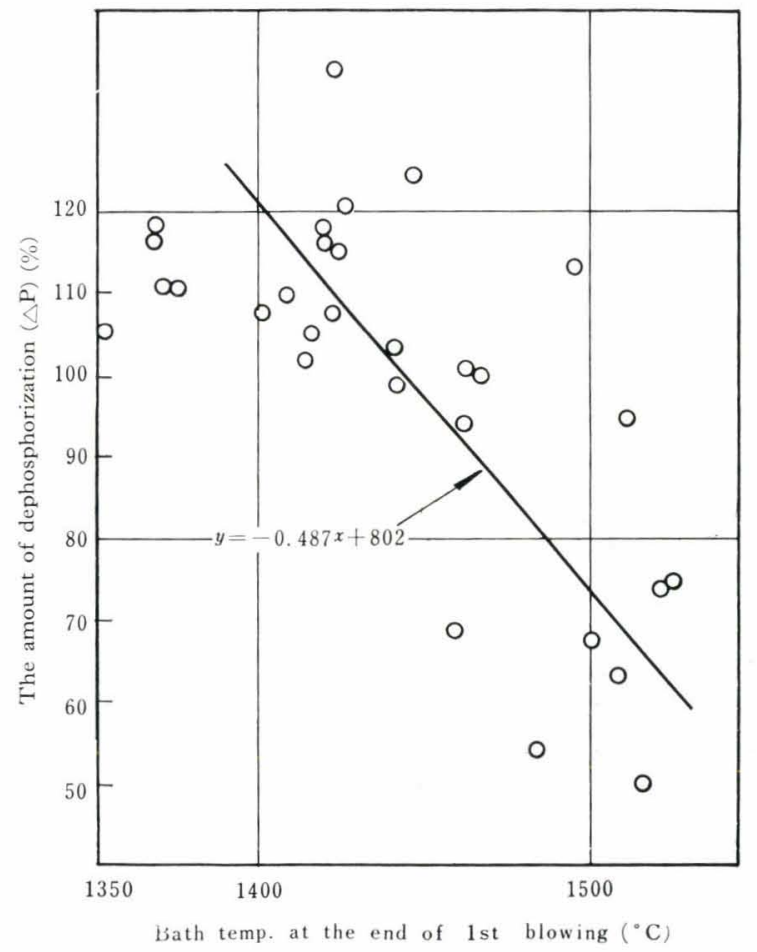

Fig. 1 (c)

Fig. 1 (a) Relation between $[\mathrm{C}] \%$ and $[\mathrm{P}] \%$ at the end of 1 st blowing

(b) Relation between $[\mathrm{C}] \%$ and bath temp. at the end of 1 st blowing

(c) Relation between bath temp. and the amount of dephosphorization at the end of 1 st blowing 
etc. So we performed test melting several times by deciding the working conditions with the basis of the result of the above investigation, as is shown in Table 3.

As in the single slag method there is of no use

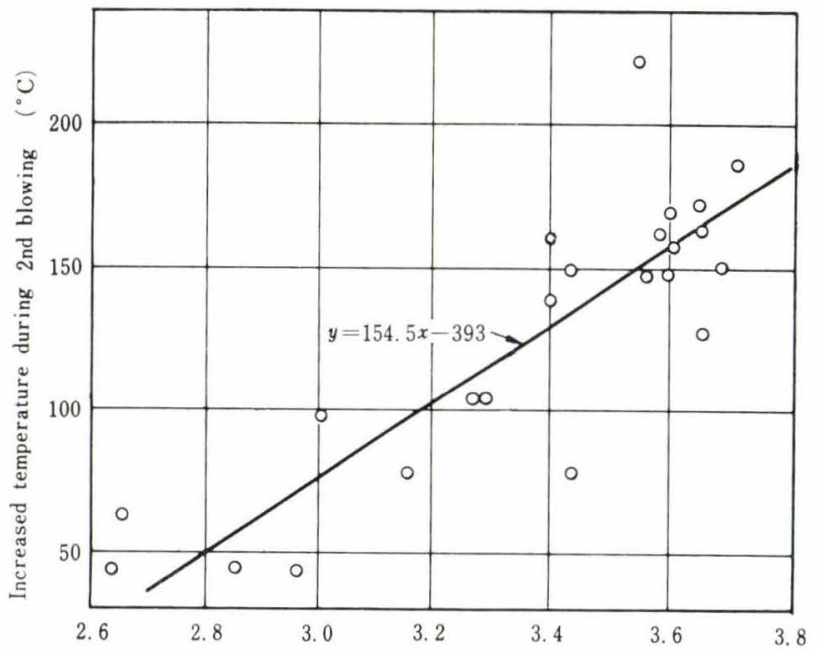

[C] $\%$ at the end of 1 st blowing

Fig. 2. Relation between $[\mathrm{C}] \%$ at the end of 1 st blowing and increased temperature during the 2 nd blowing period deslagging during the blowing and injecting material for the secondary slag-formation, we could secure a proper tap temperature by the adjustment of cold

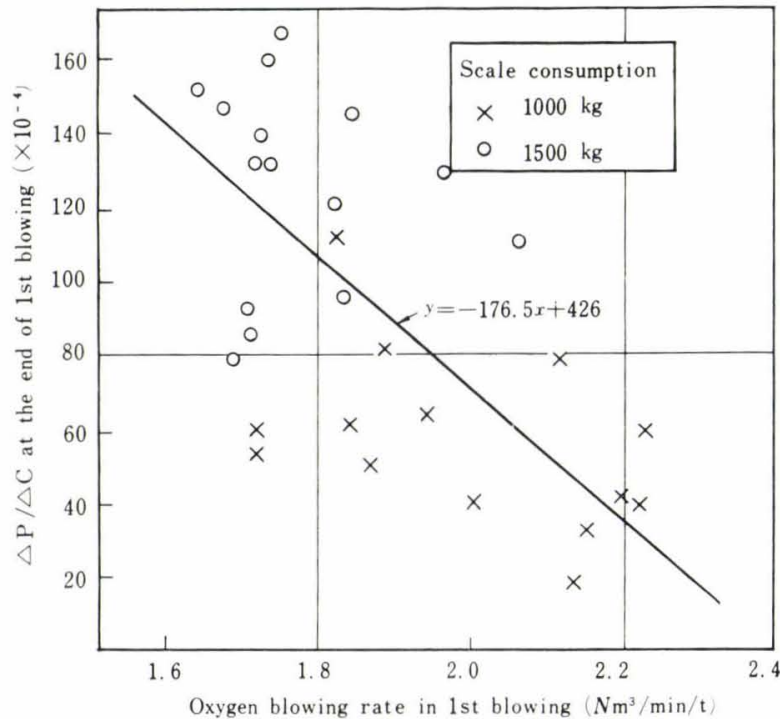

Fig. 3. Relation between $\Delta \mathrm{P} / \Delta \mathrm{C}$ and oxygen blowing rate at 1 st blowing

Table 2. Operating data for double slag process

Hot metal: $76 \mathrm{t} / \mathrm{ch}(\mathrm{C}: 4.46, \quad$ Si: $0.69, \quad \mathrm{Mn}: 0.71, \quad$ P: $0.162, \quad$ S: 0.034$)$ 1st blowing

Raw materials $\left\{\begin{array}{lr}\text { Burnt lime } & 3,500 \sim 4,000 \mathrm{~kg} / \mathrm{ch} \\ \text { Iron ore } & 1,000 \mathrm{~kg} / \mathrm{ch} \\ \text { Mill scale } & 2,300 \mathrm{~kg} / \mathrm{ch} \\ \text { Fluorspar } & 200 \mathrm{~kg} / \mathrm{ch} \\ \text { Acid O.H.F. slag } & 300 \mathrm{~kg} / \mathrm{ch} \\ & 5.0 \mathrm{~kg} / \mathrm{cm}^{2}\end{array}\right.$

2nd blowing

Raw materials \begin{tabular}{lr} 
Fe-Si & \multicolumn{1}{c}{ Some } \\
Burnt lime & $2,500 \sim 3,800 \mathrm{~kg} / \mathrm{ch}$ \\
Mill scale & $1,600 \mathrm{~kg} / \mathrm{ch}$ \\
Fluorspar & $200 \mathrm{~kg} / \mathrm{ch}$ and $\mathrm{more}$ \\
Acid O.H.F. slag & $500 \sim 800 \mathrm{~kg} / \mathrm{ch}$ \\
& $3,5 \sim 5.0 \mathrm{~kg} / \mathrm{cm}$
\end{tabular}

Chemical compositions

\begin{tabular}{|c|c|c|c|c|c|c|c|c|c|c|c|c|c|c|c|c|}
\hline & \multicolumn{8}{|c|}{ Metal } & \multicolumn{8}{|c|}{ Slag } \\
\hline & C & $\mathrm{Si}$ & Mn & $\mathrm{P}$ & $\mathrm{s}$ & $\mathrm{Cu}$ & $\mathrm{Ni}$ & $\mathrm{Cr}$ & T. Fe & $\mathrm{FeO}$ & $\mathrm{Fe}_{2} \mathrm{O}_{3}$ & $\mathrm{SiO}_{2}$ & $\mathrm{CaO}$ & $\mathrm{MnO}$ & $\mathrm{P}_{2} \mathrm{O}_{5}$ & $\mathrm{MgO}$ \\
\hline Stop point of 1st blow & 3.83 & $\operatorname{tr}$ & 0.22 & 0.084 & 0.035 & - & - & - & 14.23 & 13.15 & 4.78 & 24.31 & 35.33 & 12.56 & 2.90 & 1.21 \\
\hline End point & 0.45 & $\operatorname{tr}$ & 0.29 & 0.014 & 0.020 & - & - & - & 10.99 & 8.52 & 2.24 & 15.78 & 57.48 & 4.98 & 2.16 & 2.32 \\
\hline Ladle & 0.45 & 0.26 & 0.71 & 0.018 & 0.022 & 0.07 & 0.03 & 0.06 & - & - & - & - & - & - & - & - \\
\hline
\end{tabular}

Table 3. Operating data for single slag process

Total charge: $82 \mathrm{t}$ (hot metal $74 \mathrm{t}, \operatorname{scrap} 8 \mathrm{t}$ ) Raw materials

$\begin{array}{lclr}\text { Burnt lime } & 5,000 \sim 5,500 \mathrm{~kg} / \mathrm{ch} & \text { Fluorspar } & 800 \mathrm{~kg} / \mathrm{ch} \\ \text { Mill scale } & 1,200 \sim 1,300 \mathrm{~kg} / \mathrm{ch} & \text { Acid O.H.F. slag } & 600 \mathrm{~kg} / \mathrm{ch} \\ \text { Iron ore } & 500 \sim 800 \mathrm{~kg} / \mathrm{ch} & & \end{array}$

$\mathrm{O}_{2}$ pressure $\quad 3.5 \sim 6.0 \mathrm{~kg} / \mathrm{cm}^{2}$

Chemical compositions

\begin{tabular}{|c|c|c|c|c|c|c|c|c|c|c|c|c|c|c|c|c|}
\hline & \multicolumn{8}{|c|}{ Metal } & \multicolumn{8}{|c|}{ Slag } \\
\hline & $\mathrm{C}$ & $\mathrm{Si}$ & $\mathrm{Mn}$ & $\mathrm{P}$ & $\mathrm{S}$ & $\mathrm{Cu}$ & $\mathrm{Ni}$ & $\mathrm{Cr}$ & T. $\mathrm{Fe}$ & $\mathrm{FeO}$ & $\mathrm{Fe}_{2} \mathrm{O}_{3}$ & $\mathrm{SiO}_{2}$ & $\mathrm{CaO}$ & $\mathrm{MnO}$ & $\mathrm{P}_{2} \mathrm{O}_{5}$ & $\mathrm{MgO}$ \\
\hline Charge & 3.91 & 0.43 & 0.55 & 0.193 & 0.040 & - & - & - & - & - & - & - & - & - & - & - \\
\hline End point & 0.42 & $\operatorname{tr}$ & 0.23 & 0.015 & 0.022 & - & - & - & 10.04 & 9.43 & 3.83 & 10.83 & 61.52 & 4.19 & 3.06 & 2.21 \\
\hline Ladle & 0.45 & 0.27 & 0.75 & 0.020 & 0.024 & 0.07 & 0.04 & 007 & - & - & - & - & - & - & - & - \\
\hline
\end{tabular}

Tap to tap: $45 \mathrm{~min}$; blowing time: $26 \mathrm{~min}$; metal temp. at the end point: $1,618^{\circ} \mathrm{C}$. 
charge, which was difficult in the double slag method.

But for dephosphorization the double slag method is more effective.

Next we mention dephosphorization from the theoretical point of view according to the operating data, as is shown in Table 3.

Comparing the operating data with the J. Chipman's equilibrium equation, the dephosphorization reaction seems to be in an equilibrium state, as is

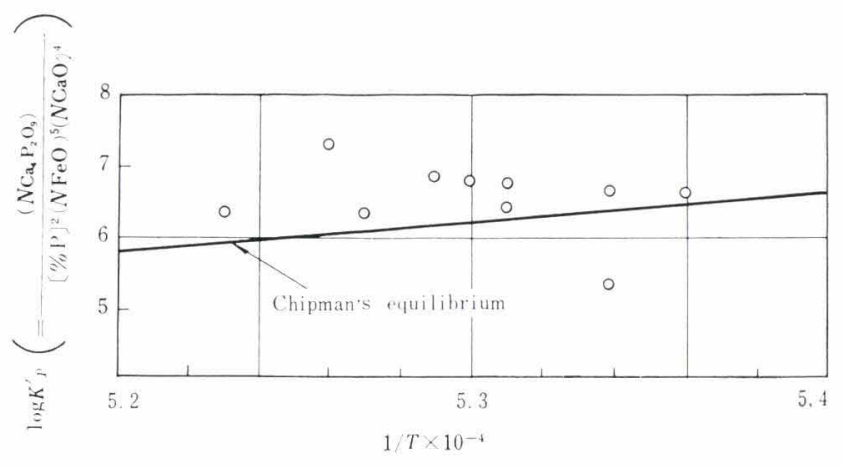

Fig. 4. Relation between bath temperature and dephosphorization equilibrium constant in the case of melting of high carbon steel by single slag method $\mathrm{NSiO}_{2}+\mathrm{NP}_{2} \mathrm{O}_{5}$

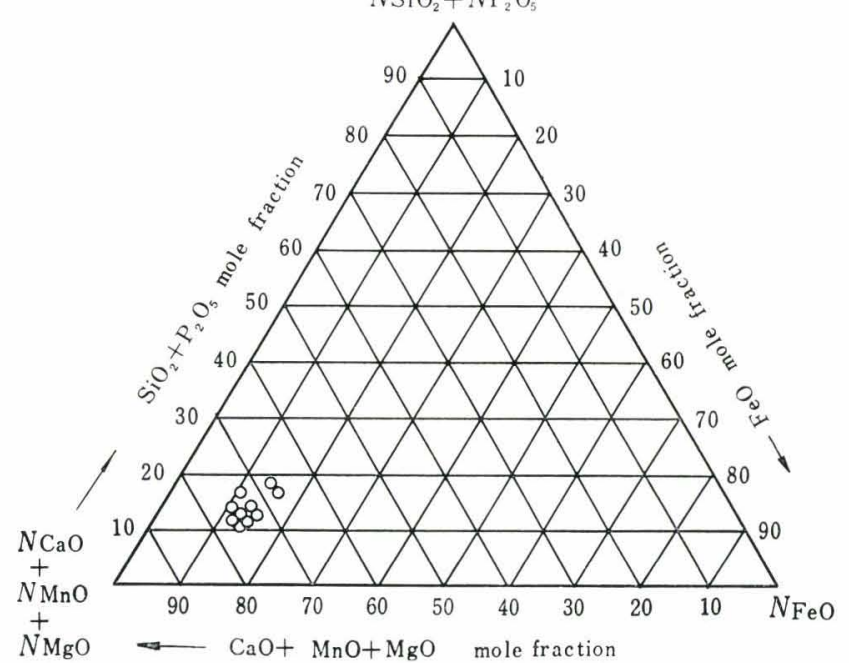

Fig. 5. Slag composition before tapping in single slag method shown in Table 4 and Fig. 4.

Speaking about slag composition before tapping used in analysis, $\left(\mathcal{N}_{\mathrm{CaO}}+\mathcal{N}_{\mathrm{MnO}}+\mathcal{N}_{\mathrm{MgO}}\right)$ was 0.68 to $0.78 \mathrm{~mol},\left(\mathcal{N}_{\mathrm{FeO}}\right)$ was 0.10 to $0.15 \mathrm{~mol},\left(\mathcal{N}_{\mathrm{SiO}_{2}}+\right.$ $\left.\mathcal{N}_{\mathrm{P}_{2} \mathrm{O}_{\tilde{5}}}\right)$ was 0.10 to $0.20 \mathrm{~mol}$, which is shown in Fig. 5.

As Fig. 6 shows the influence of slag composition on the division rate of phosphorus, it seems that the

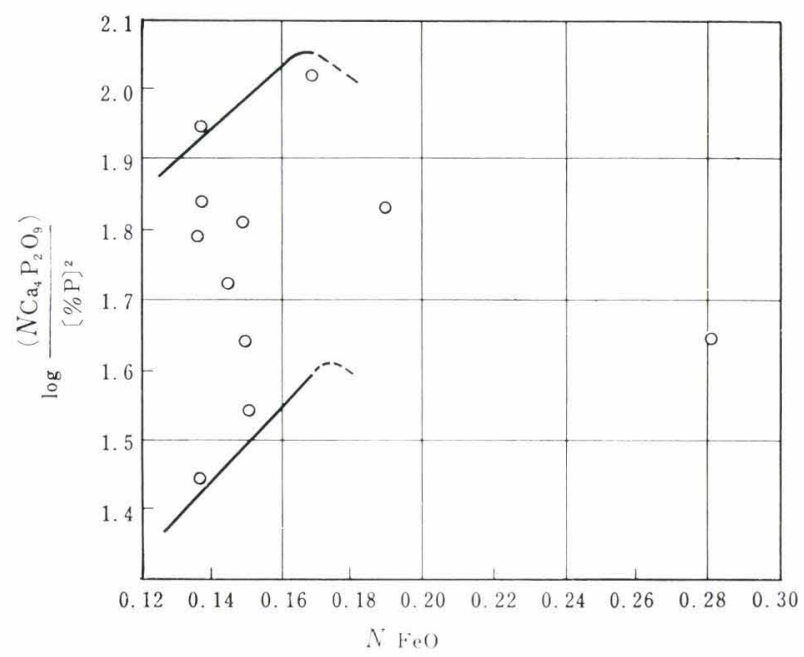

(a)

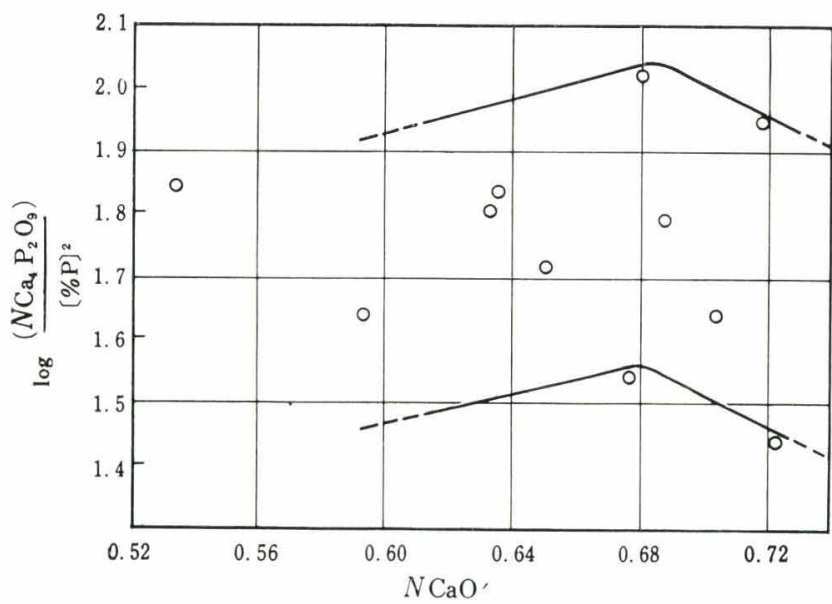

(b)

Fig. 6 (a) Relation between $N_{\mathrm{Feo}}$ and [P] division rate (b) Relation between $N_{\mathrm{CaO}^{\prime}}$ and [P] division rate

Table 4. Dephosphorization equilibrium value bofore tapping in case of melting of high carbon steel by single slag method

\begin{tabular}{|c|c|c|c|c|c|c|c|c|c|c|c|c|c|}
\hline \multicolumn{7}{|c|}{ Slag composition before tapping } & \multirow{2}{*}{$\begin{array}{l}\text { End } \\
\text { point } \\
{[\mathrm{P}]}\end{array}$} & \multirow{2}{*}{$N_{\mathrm{CaO}}{ }^{\prime}$} & \multirow{2}{*}{$\mathrm{N}_{\mathrm{Ca}_{4} \mathrm{P}_{2} \mathrm{O}_{9}}$} & \multirow{2}{*}{$N_{\text {FeO }}$} & \multirow{2}{*}{$\begin{array}{c}\text { Observed } \\
\log K^{\prime} p= \\
N_{\mathrm{Ca}_{4} \mathrm{P}_{2} \mathrm{O}_{9} /[\% \mathrm{P}]^{2}} \\
\left(N_{\mathrm{FeO}}\right)^{5}\left(N_{\mathrm{CaO}}\right)^{4}\end{array}$} & \multirow{2}{*}{$1 / T$} & \multirow{2}{*}{$\begin{array}{c}\text { Calculated } \\
\text { value } \\
\log K p= \\
40,007 / T 1,506\end{array}$} \\
\hline $\mathrm{FeO}$ & $\mathrm{Fe}_{2} \mathrm{O}_{3}$ & $\mathrm{SiO}_{2}$ & $\mathrm{CaO}$ & $\mathrm{MnO}$ & $\mathrm{P}_{2} \mathrm{O}_{5}$ & $\mathrm{MgO}$ & & & & & & & \\
\hline 0.167 & 0.027 & 0.218 & 0.980 & 0.044 & 0.024 & 0.044 & 0.020 & 0.636 & 0.027 & 0.190 & 6.22 & 5.27 & 6.06 \\
\hline 0.136 & 0.030 & 0.173 & 1.058 & 0.054 & 0.022 & 0.055 & 0.016 & 0.718 & 0.023 & 0.139 & 6.81 & 5.29 & 6.14 \\
\hline 0.149 & 0.013 & 0.189 & 0.940 & 0.059 & 0.024 & 0.092 & 0.016 & 0.687 & 0.027 & 0.169 & 6.55 & 5.36 & 6.41 \\
\hline 0.136 & 0.034 & 0.198 & 1.000 & 0.062 & 0022 & 0.062 & 0.027 & 0.676 & 0.025 & 0.152 & 6.31 & 5.31 & 6.22 \\
\hline 0.202 & 0.040 & 0.242 & 0.911 & 0.066 & 0.028 & 0.084 & 0.030 & 0.594 & 0.039 & 0.282 & 5.29 & 5.34 & 6.33 \\
\hline 0.126 & 0.037 & 0.230 & 1.028 & 0.066 & 0.024 & 0.059 & 0.023 & 0.650 & 0.028 & 0.146 & 6.65 & 5.34 & 6.33 \\
\hline 0.094 & 0.075 & 0.250 & 0.907 & 0.065 & 0.025 & 0.067 & 0.023 & 0.533 & 0.037 & 0.138 & 7.24 & 5.26 & 6.03 \\
\hline 0.149 & 0.027 & 0.191 & 1.066 & 0.063 & 0.021 & 0.062 & 0.022 & 0.704 & 0.021 & 0.151 & 6.35 & 5.23 & 5.88 \\
\hline
\end{tabular}


division rate increases to a definite limit with the mole fraction of $(\mathrm{FeO})$ and the free lime in the slag and then decreases inversely.

So it was found in our operating condition that the dephosphorization reaction was performed most effectively in the case where the slag basicity was 4.6 and the total $\mathrm{Fe}$ in the slag was $13 \%$.

\section{Conclusions}

In short, we investigated on the melting of high carbon steel by the oxygen converter, and obtained the results as follows:

(1) Melting of high carbon steel by the double slag catch-carbon method is possible with the enforcement of a proper end point in the first blowing and with

\section{ON MELTING OF HIGH CARBON STEEL BY OXYGEN CONVERTER PROCESS}

By Yoshimasa Aoyama, Hiroharu Usui, Akira Matsunaga and Seiji Kobayashi (Amagasaki Iron \& Steel Mfg. Co., Ltd.)

\section{Introduction}

Recently the oxygen converter process which progressed mainly as a low carbon steelmaking process, has taken a step into the field of high carbon steel making. But in this process, dephosphorization is apt to be imperfect by ordinary blowing methods, so various methods such as "carbon addition", "soft blowing" and "intermediate deslagging", are considered individually or in combination to improve the dephosphorization efficiency. $\left.{ }^{1)} \sim 5\right) \quad$ As rather high carbon steel is being melted in our works, we have made efforts to study these methods. Now we are adopting a method such as adjusting lance height in high carbon steel melting, because by this method the objective composition can be easily obtained, the furnace operation is easy and a high productivity is expected.

\section{Discussion on Oxygen Jet}

The higher the basicity and oxidizing power of slag, the better the dephosphorization efficiency, and in the oxygen converter the oxidizing power of the slag is decided mainly by the impact area of the oxygen jet to the bath, impact pressure and its distribution. So to obtain a high oxidizing power of the slag, such blowing conditions as a large area of jet impact and loose distribution of impact pressure are necessary. Fig. 1 shows an example of pressure distribution of the oxygen jet in our works. According to the results, the larger the diameter of nozzle, the more loose the pressure distribution of jet, in case of the lance height and the oxygen flow rate being constant.

Fig. 2 shows a device for measuring the jet pressure the injection of heat source materials and by soft blowing for the security of the tap temperature in the second blowing.

(2) The single slag method is more efficient and workable than the double slag method, and by enforcing the proper quantity of main and sub raw materials, security of slag volume and soft blowing, the melting of high carbon steel by the single slag catch-carbon method is possible.

(3) Compared with the double slag method, the single slag method is able to improve steelmaking efficiency and facility of work to a far greater extent.

(4) The quality of high carbon steel produced by the LD converter is comparable to that produced by the open hearth furnace or the electric arc furnace.

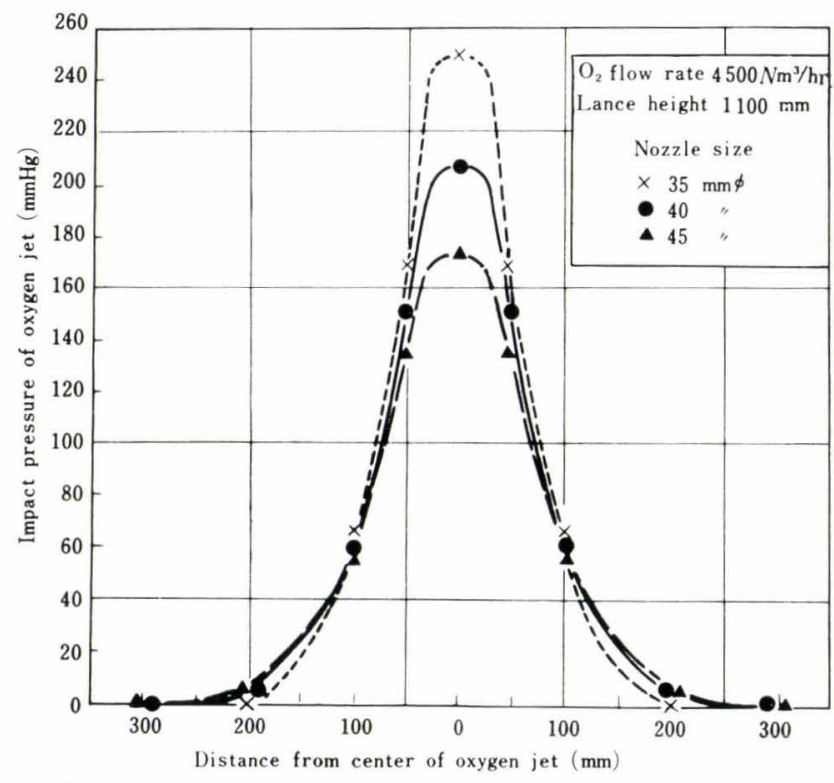

Fig. 1. Relation between diameter of lance nozzle and distribution of collision pressure
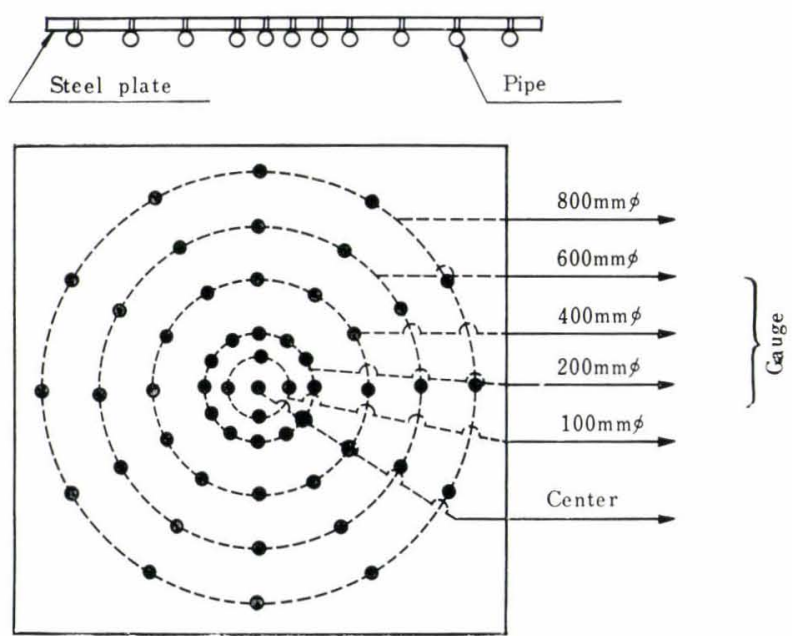

Fig. 2. A device for measuring pressure distribution 
and its distribution. This is composed of a steel plate with small holes along several circles with the same center and a guage connected to the holes by pipes. We measured the average pressure (total pressure) of each point by blowing actual oxygen jet to the plate.

The nozzle of lance used in this test was a diffusion type, having the characteristic of a low impact pressure and its diversion angle about $8^{\circ}$ by one side of the jet. At the beginning of the operation, the diameter of the nozzle was $35 \mathrm{~mm}$ and dephosphorization efficiency was not good particularly in case the tap temperature was required to be high because the desired end point $\mathrm{C} \%$ was high. We, therefore, considered that in the case of the $35 \mathrm{~mm}$ dia. the pressure was too high, and we changed the diameter from 35 to $40 \mathrm{~mm}$ in order to lower the blowing pressure at the same oxygen flow rate.

Fig. 3 shows the influence of the diameter of the nozzle on dephosphorization. Its efficiency is evidently improved by magnifying the diameter of the nozzle to $40 \mathrm{~mm}$ dia. and by lowering the blowing pressure.

Fig. 4 shows the relation between the diameter of the nozzle and the pressure behind the adjustment valve of the main oxygen pipe.

We adopted the $45 \mathrm{~mm}$ nozzle afterwards and increased the oxygen flow rate from 4,500 to 5,000 $\mathrm{Nm}^{3} / \mathrm{hr}$ for shortening the blowing time, and we were able to melt without any difficulty medium carbon

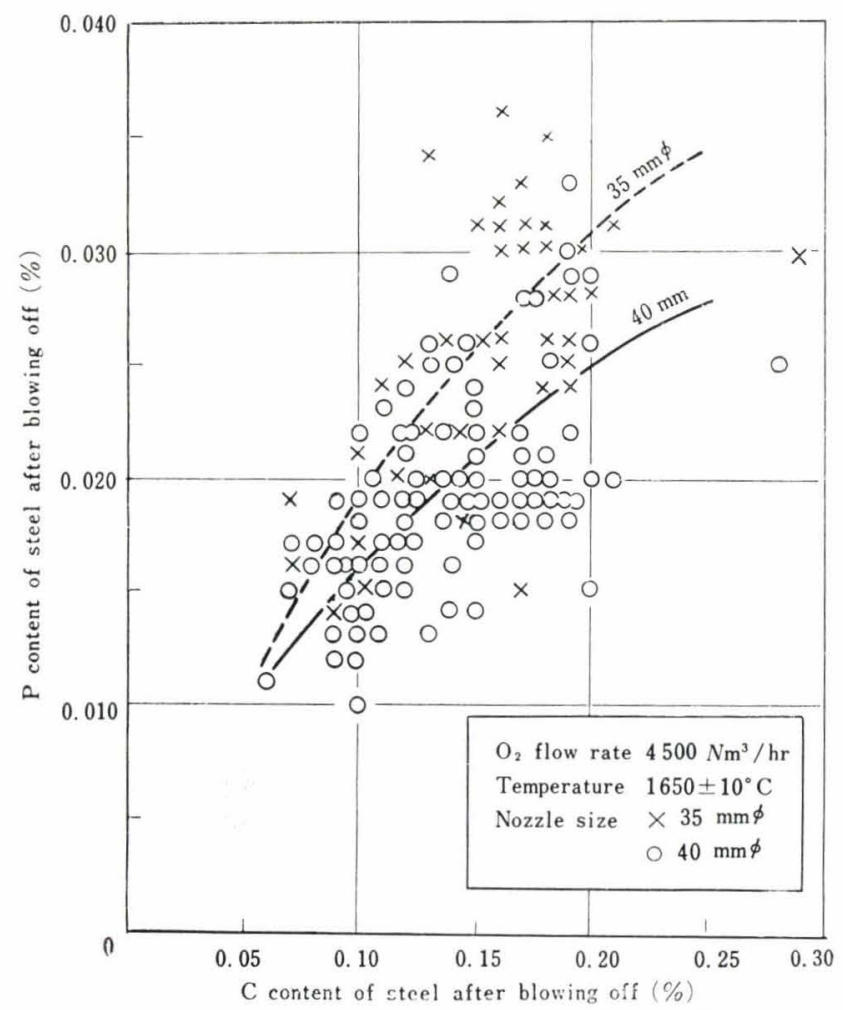

Fig. 3. The influence of nozzle diameter on dephosphorization steel (C: $0.15 \sim 0.30 \%$ ), which required a high tap temperature of $1,650^{\circ} \mathrm{C}$, because of a small ingot.

As Fig. 5 shows a distribution of phosphor in " deformed bar of high tensile strength steel", the objective compositions of which are C: $0.20 \%, \mathrm{Mn}$ : $1.25 \%$, the distribution of phosphor in the product is kept perfectly under the limit of the standard.

\section{The Melting Practice of High Carbon Steel}

In the case of melting high carbon steel over $0.40 \%$

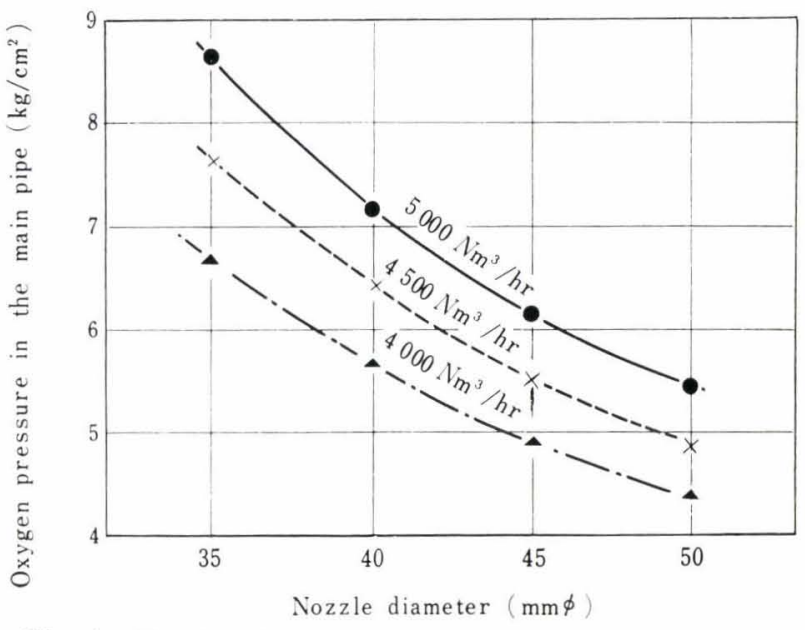

Fig. 4. Relation between nozzle diameter and oxygen pressure in the main pipe

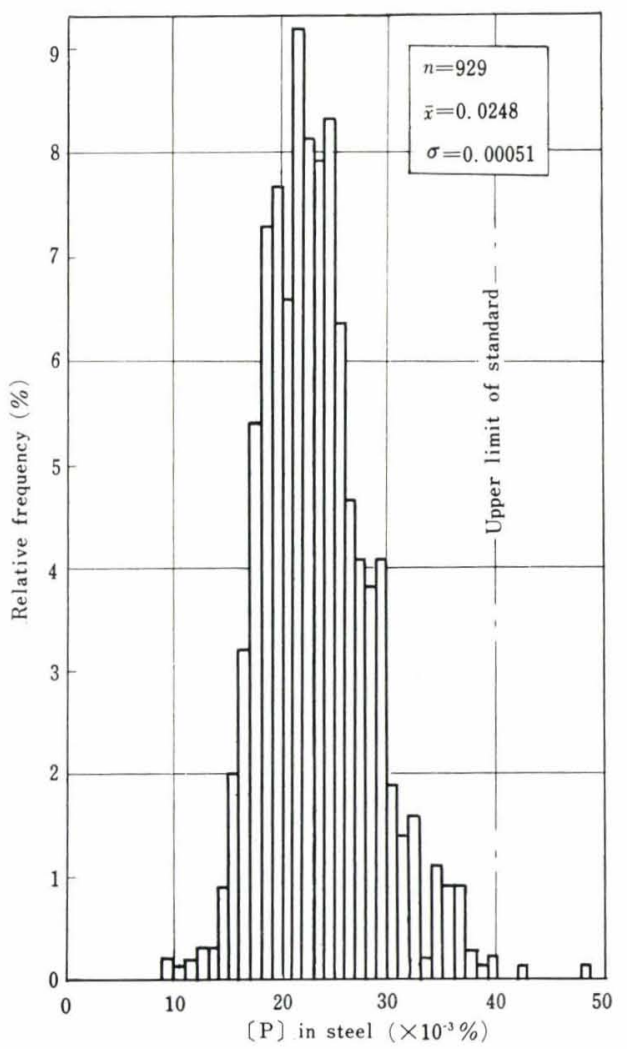

Fig. 5. The distribution of phosphor in "DACON" 
C, dephosphorization is apt to be imperfect, so the double slag method is generally adopted to improve the efficiency, but according to our experience, there are many difficulties in the double slag method, for example, while the bath temperature is low, which is favorable to dephosphorization, it is difficult to eliminate the slag perfectly even if dephosphorization of the molten steel is sufficiently performed by promoting slag-formation in the early stage, and it is not easy to obtain an objective composition by the catchcarbon method after re-blowing. We then tested a method for eliminating intermediate deslagging and blowing with a lower oxygen pressure at the second half of the blowing, but the result was not satisfactory because foaming of the slag was unstable. The condition for the iron oxide in the slag to increase, which is favorable to dephosphorization, can be actually obtained by soft blowing, but the volume of oxygen supplied in unit time is decreased and the blowing time becomes long, and moreover, dephosphorization becomes unstable and rephosphorization is apt to occur after tilting the vessel.

On the other hand, in a blowing method where the lance is pulled up in the second half of the blowing, keeping the oxygen flow rate high, although the slag becomes foamier and slopping of the slag during blowing occurs more violently, dephosphorization is performed sufficiently, the influence of such conditions as end point $\mathrm{C} \%$, end point temperature and other bath conditions on the dephosphorization reaction remarkably decreases, and re-phosphorization after tilting the vessel is minimized. So this method makes operation stable.

Fig. 6 shows the relation between the end point $\mathrm{C} \%$

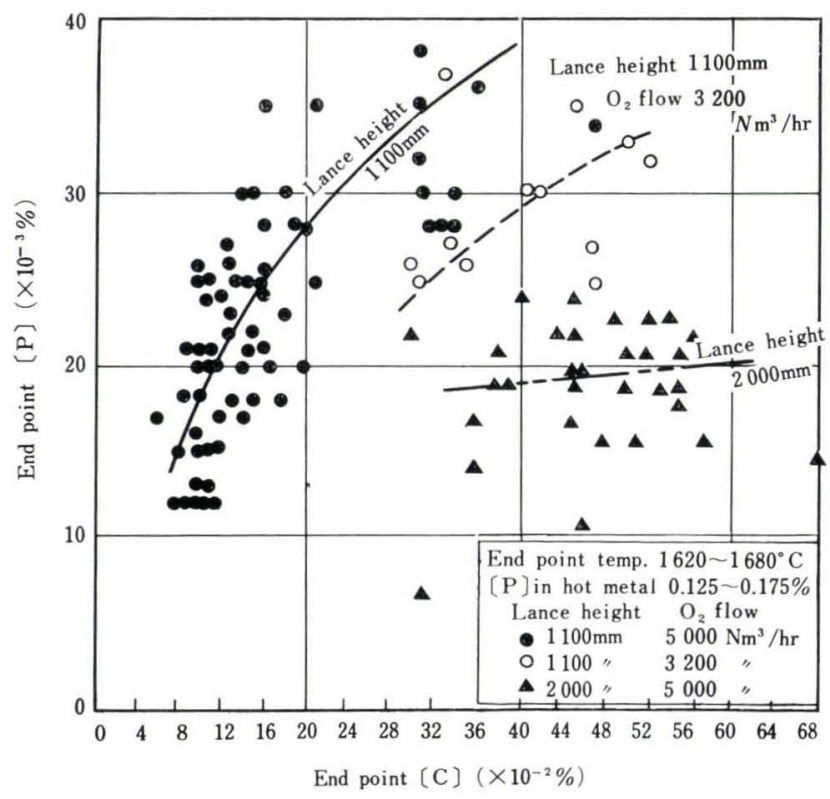

Fig. 6. Relation between $[\mathrm{C}] \%$ and $[\mathrm{P}] \%$ at the end point and the end point $\mathrm{P} \%$. In this figure, mark is an example of standard blowing of lance height $1.1 \mathrm{~m}$, oxygen flow rate $5,000 \mathrm{Nm}^{3} / \mathrm{hr}$. It is shown that the end point $\mathrm{P}$ rises abruptly, as the end point $\mathrm{C} \%$ increases. $\circ$ mark is an example of the blowing where the oxygen pressure is decreased at the second half of the blowing, and the oxygen flow rate $3,200 \mathrm{Nm}^{3} / \mathrm{hr}$. In this case the end point $\mathrm{P}$ is lower than in the above case. $\triangle$ mark is in the case where the lance is pulled up to $2.0 \mathrm{~m}$ at the second half of the blowing, keeping the oxygen flow rate $5,000 \mathrm{Nm}^{3} / \mathrm{hr}$. In this case, the end point $\mathrm{P}$ is low enough regardless of the end point $\mathrm{C} \%$.

In this method, while the bath temperature is low, which is favorable to dephosphorization, the reaction can be promoted by means of a violent agitation of the bath by the oxygen jet. When the bath temperature is elevated, the lance is pulled up, by which the impact area is enlarged and its pressure distribution becomes loose. The refining is performed mainly by metalslag interaction and the speed of decarburization is restrained because the agitating power by the jet becomes weak and the oxidizing power of slag becomes higher. The characteristic of this method is that the slag covers the metal with a considerable thickness and becomes foamy after the lance is pulled up till the blowing off, such conditions being easily obtained.

Fig. 7 shows the relation between the end point $\mathrm{P}$ and the end point temperature in the case where the end point $\mathrm{G}$ is $0.40 \sim 0.60 \%$. As the end point temperature is increased, the end point $\mathrm{P}$ is apt to increase abruptly

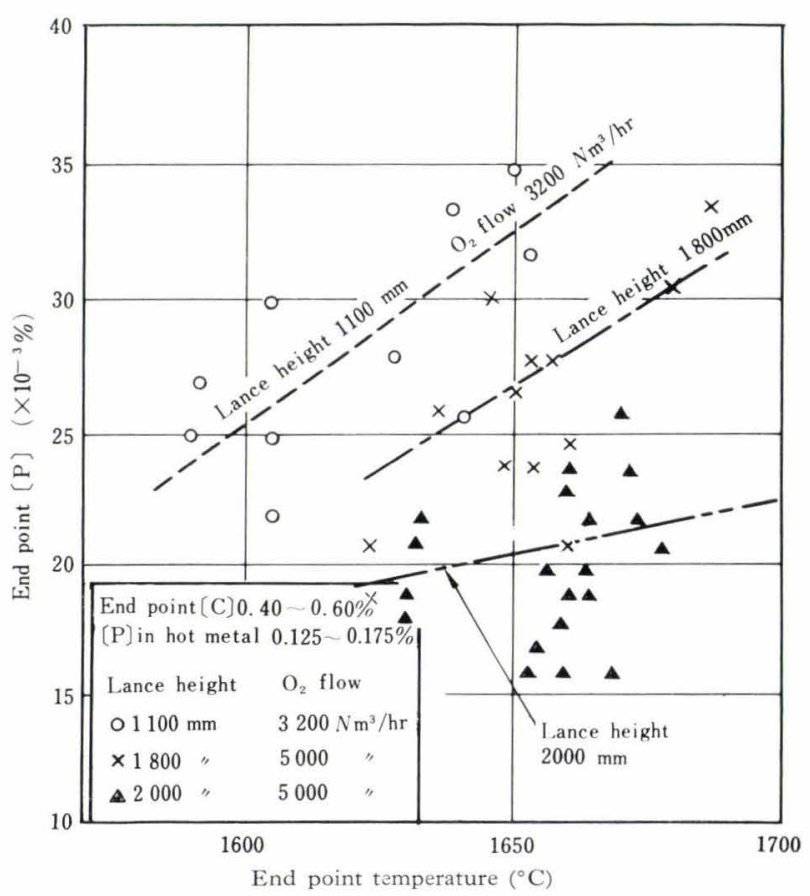

Fig. 7. The influence of the end point temperature on the end point $[\mathrm{P}]$ 
owing to re-phosphorization, but the tendency is relaxed by pulling the lance up, that means "soft blow".

Fig. 8 shows the relation between the end poinc $\mathrm{C}$ and the total $\mathrm{Fe}$ in the slag. mark in this figure is an example of standard blowing of lance height $1.1 \mathrm{~m}$, where the total Fe is a little higher than in other works, because our works produces mainly medium carbon steel. The higher the lance position, the higher the total $\mathrm{Fe}$ in the slag, and the high oxidizing power in the slag is maintained even in a high carbon range independently regardless of the $\mathrm{C}$ in molten steel.

Fig. 9 shows the relation between $\mathrm{P}$ in hot metal and the end point $\mathrm{P}$ in the case of the end point $\mathrm{C} 0.40$ $\sim 0.60 \%$, the end point temperature $1,650^{\circ} \pm 30^{\circ} \mathrm{C}$. In the ordinary blowing method, the dephosphorization rate is so low that the influence of $\mathrm{P}$ in hot metal is prominent, but this method has a good point in that $\mathrm{P}$ in hot metal scarcely influences the end point $\mathrm{P}$. Furthermore the slag at the end point is so foamy that it can be taken off only by tilting the vessel and rephosphorization owing to time for analysis is slight.

Basicity of slag, dealt with from Figs. 6 9, is shown in Table 1. Burnt lime, scale and fluorspar are used for slagging more than usual, so the basicity is about
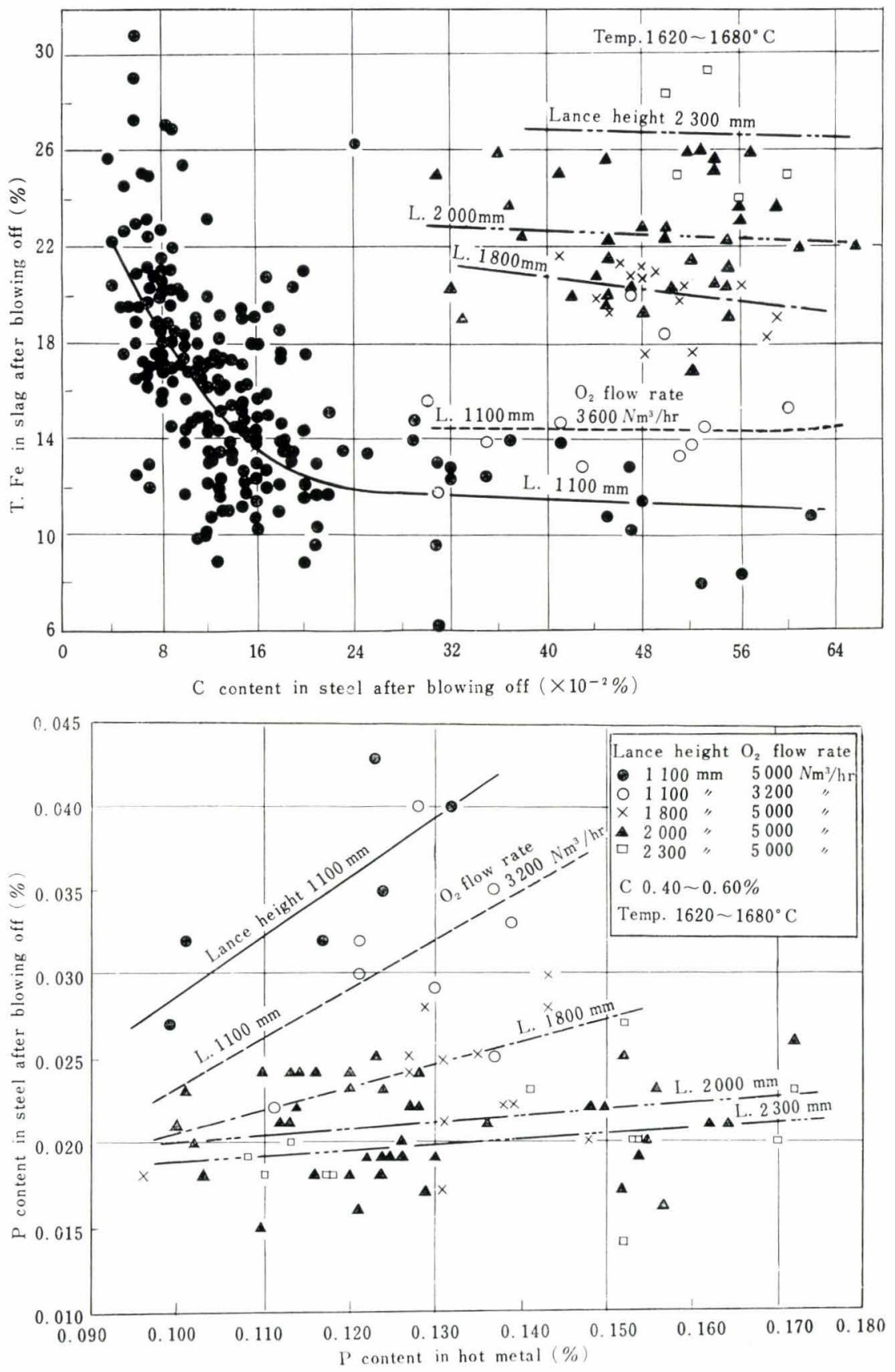

Fig. 8.

Relation between lance height and (T. Fe) in the slag
Fig. 9.

The influence of lance height on dephosphorization 
5.5, which is rather high. Fig. 10 shows the relation between $\mathrm{S}$ in hot metal and the end point $\mathrm{S}$. Better results could be obtained in the case of melting high carbon steel than in the case of the ordinary method for melting medium carbon steel. It may be due to the high basicity of the slag and the high consumption of fluorspar in the case of high carbon steel.

Fig. 11 is an example showing the relation between the pressure distribution of the oxygen jet and lance height. It is shown that the higher the position of

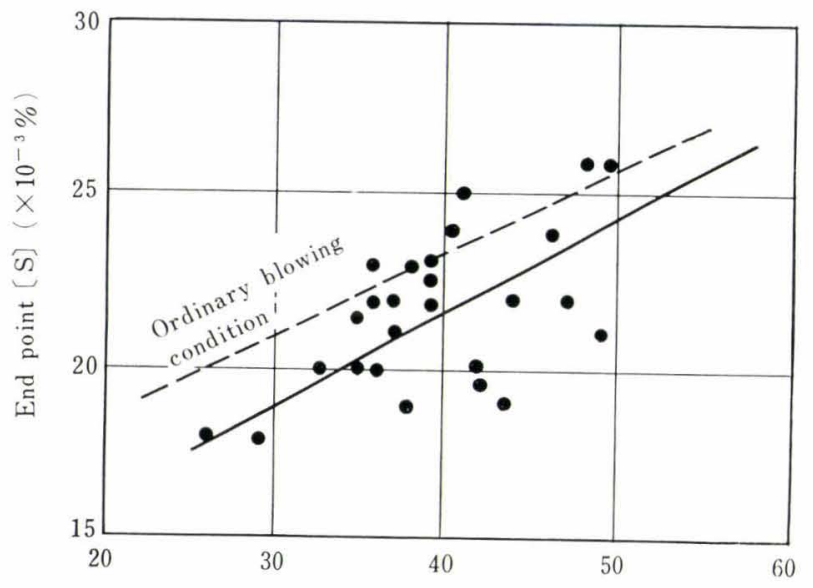

[S] in hot metal $\left(\times 10^{-3} \%\right)$

Fig. 10. Relation between [S] in hot metal and [S] at the end point. ( $\mathrm{C}$ in steel : $0.45 \sim 0.60 \%$ )

Table 1. Average basicity under various blowing conditions

\begin{tabular}{l|c|c|c|c|c|c}
\hline & $\begin{array}{c}\mathrm{O}_{2} \text { flow } \\
(\mathrm{Nm} / \mathrm{hr})\end{array}$ & 5,000 & $\begin{array}{c}5,000 \\
\sim 3,200\end{array}$ & 5,000 & 5,000 & 5,000 \\
\hline $\begin{array}{l}\text { Blowing } \\
\text { condition }\end{array}$ & $\begin{array}{c}\text { Lance } \\
\text { height } \\
(\mathrm{mm})\end{array}$ & 1,100 & 5.98 & $\underset{1}{1,100} \sim 1,800$ & $\underset{\sim}{1,100} \sim 2,000$ & $\begin{array}{c}1,100 \\
\sim 2,300\end{array}$ \\
\hline Basicity & $\left(\mathrm{CaO} / \mathrm{SiO}_{2}\right)$ & 4.51 & 5.98 & 5.39 & 5.66 & 5.55 \\
\hline
\end{tabular}

lance is, the weaker the impact pressure of the jet and the larger the distribution of pressure. So both the dephosphorization and the de-carburization can be controlled by adjusting the combination of the oxygen flow rate and the lance height. We have adopted, therefore, the method of controlling the lance height and time of pulling up the lance according to conditions such as bath, raw materials and kinds of steel.

Table 2 is an example of the operational data of melting $0.55 \%$ carbon steel by the above-mentioned

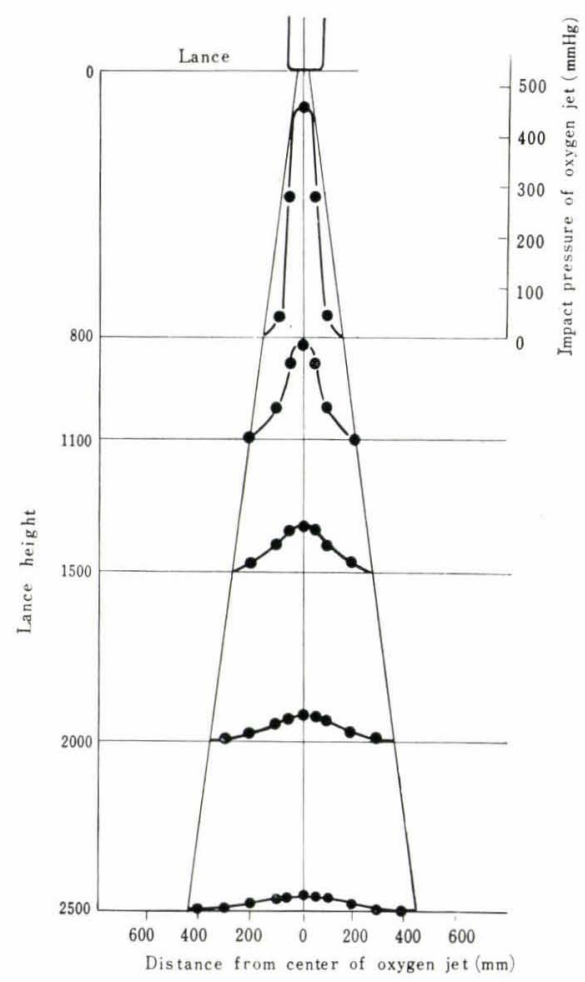

Fig. 11. Influence of lance height on pressure distribution

Table 2. Operating data of $0.55 \%$ carbon steel melting

\begin{tabular}{|c|c|c|c|c|c|c|c|c|c|c|c|c|}
\hline \multirow{2}{*}{\multicolumn{3}{|c|}{$\begin{array}{l}\text { Blowing condition: } \\
\text { Oxygen flow rate }\left(\mathrm{Nm}^{3} / \mathrm{hr}\right) \\
\text { Lance height }(\mathrm{mm})\end{array}$}} & \multirow{2}{*}{$\begin{array}{c}\text { Number of } \\
\text { heat }\end{array}$} & \multicolumn{3}{|c|}{$\operatorname{Raw}_{(\mathrm{kg} / \mathrm{ch})}$} & \multicolumn{3}{|c|}{$\begin{array}{l}\text { Flux materials } \\
\qquad \mathrm{kg} / \mathrm{ch})\end{array}$} & \multicolumn{2}{|c|}{ Time (min) } & \multirow{2}{*}{$\begin{array}{l}\text { Oxygen } \\
\text { consump- } \\
\text { tion } \\
\left(N \mathrm{~m}^{3} / \mathrm{hr}\right)\end{array}$} \\
\hline & & & & Hot metal & Scrap & Total & Burnt lime & Scale & Fluorspar & Blowing & Melting & \\
\hline a & \multirow{3}{*}{\multicolumn{2}{|c|}{$\begin{array}{c}5,000\left(\mathrm{Nm}^{3} / \mathrm{hr}\right) \\
1,100 \sim 1,800(\mathrm{~mm}) \\
5,000\left(\mathrm{Nm}^{3} / \mathrm{hr}\right) \\
1,100 \sim 2,000(\mathrm{~mm}) \\
5,000(\mathrm{Nm} / 3 \mathrm{hr}) \\
1,100 \sim 2,300(\mathrm{~mm})\end{array}$}} & 3 & 33,873 & 4,127 & 38,000 & 1,815 & 1,080 & 172 & 19.82 & 36 & 1,733 \\
\hline $\mathrm{b}$ & & & 12 & 34,383 & 3,617 & 38,000 & 1,840 & 1,105 & 168 & 20.65 & 40 & 1,820 \\
\hline \multirow[t]{2}{*}{$\mathrm{c}$} & & & 12 & 33,453 & 4,573 & 38,026 & 1,944 & 1,170 & 150 & 22.67 & 42 & 1,937 \\
\hline & & $\mathrm{C}$ & $\mathrm{Mn}$ & $\mathrm{Si}$ & $\mathrm{P}$ & $\mathrm{S}$ & $\mathrm{Cu}$ & $\mathrm{Al}$ & $\mathrm{Ti}$ & $\begin{array}{l}\text { Tap } \\
\text { temperature } \\
\left({ }^{\circ} \mathrm{C}\right)\end{array}$ & $\begin{array}{l}\text { Weight } \\
\text { of heat } \\
(\mathrm{kg} / \mathrm{ch})\end{array}$ & $\begin{array}{l}\text { Yield } \\
(\%)\end{array}$ \\
\hline \multirow{2}{*}{ a } & End point & 0.49 & 0.31 & $\operatorname{tr}$ & 0.023 & 0.021 & - & - & - & \multirow[t]{2}{*}{1,650} & \multirow[b]{2}{*}{35,772} & \multirow[b]{2}{*}{94.13} \\
\hline & Ladle & 0.52 & 0.74 & 0.24 & 0.026 & 0.024 & 0.09 & 0.02 & 0.02 & & & \\
\hline \multirow{2}{*}{ b } & End point & 0.51 & 0.22 & tr. & 0.024 & 0.023 & - & - & - & \multirow[t]{2}{*}{1,662} & & \\
\hline & Ladle & 0.54 & 0.75 & 0.25 & 0.026 & 0.025 & 0.09 & 0.03 & 0.03 & & 35,300 & 92.89 \\
\hline \multirow{2}{*}{ c } & End point & 0.53 & 0.18 & $\operatorname{tr}$ & 0.019 & 0.021 & - & - & - & \multirow[t]{2}{*}{1,667} & \multirow[b]{2}{*}{34,680} & \multirow[b]{2}{*}{91.20} \\
\hline & Ladle & 0.55 & 0.74 & 0.25 & 0.023 & 0.023 & 0.10 & 0.03 & 0.03 & & & \\
\hline
\end{tabular}


method, which shows that it is possible to melt high carbon steel by the single slag method. Speaking on the same end point carbon, the higher the position of lance, the longer the blowing time and thus the consumption of oxygen increases more. In the actual operation, the blowing is stopped when the end point carbon is slightly under the target and the shortage is adjusted by the addition of coke. Comparing the end point $\mathrm{P}$ and $\mathrm{P}$ in products, it is seen that rephosphorization occurs by $0.002 \sim 0.004 \%$. Yield decreases as the oxidizing power of the slag increases, because the iron loss in the slopping slag and final slag increases. The degree of variation of iron loss increases when the lance height is $2.3 \mathrm{~m}$.

Judging from the actual data, the limit of the lance height is thought to be $2.3 \mathrm{~m}$, because further soft blowing is rather disadvantageous in the operation in spite of higher dephosphorization efficiency.

\section{Quality of Steel Produced by Oxygen Process}

Quality of steel produced by the said method is to be mentioned. Table 3 is chemical compositions of ladle analysis, which are all fit to the specification of JIS G3102 (machine structural steel).

\section{On Segregation of Chemical Composition}

$570-\mathrm{kg}$ ingots are made by bottom pouring and rolled directly into round bars of $19 \sim 50 \mathrm{~mm}$ dia. Generally speaking, tensile strength of steel directly rolled from an ingot, is higher at the top of the ingot than at the bottom of the ingot owing to segregation of the chemical composition. But the mechanical properties of the machine structural steel are affected by the condition of the heat treatment, so the chemical composition must fit the standard regardless to its variation owing to segregation. So we investigated the segregation of the chemical composition of the ingot by the samples which were picked up with reference to the sulphur print of the ingot cross section. Table 4 is an example of $0.55 \% \mathrm{C}$ steel. The segregated position of carbon and sulphur can be seen, but generally speaking, the degree of segregation is so little because of the small ingot that there is no problem in homogeneity, as far as the top position of the ingot, the shrinkage cavity, is cut off in the rolling process.

\section{On Nonmetallic Inclusion}

Investigation of nonmetallic inclusion was done on several sizes and several kinds of steels by the JIS method (G 0555). Table 5 shows cleanliness of the samples produced by the oxygen process and that of market products (machine structural steel) on comparative study. According to the results, the converter

Table 3. Chemical composition of the sample

\begin{tabular}{|c|c|c|c|c|c|c|c|c|c|}
\hline \multirow{2}{*}{ Ch. No. } & \multicolumn{8}{|c|}{ Chemical composition in the ladle $(\%)$} & \multirow{2}{*}{ Notes } \\
\hline & $\mathrm{C}$ & $\mathrm{Si}$ & $\mathrm{Mn}$ & $\mathrm{P}$ & $\mathrm{S}$ & $\mathrm{Cu}$ & $\mathrm{Cr}$ & Sol. Al & \\
\hline $\mathrm{T} 2027$ & 0.55 & 0.24 & 0.73 & 0.021 & 0.024 & 0.11 & 0.04 & 0.02 & S55C \\
\hline T2029 & 0.52 & 0.23 & 0.69 & 0.017 & 0.020 & 0.12 & 0.03 & 0.01 & $\mathrm{~S} 50 \mathrm{C}$ \\
\hline T2108 & 0.45 & 0.26 & 0.77 & 0.021 & 0.022 & 0.12 & 0.03 & 0.02 & $\mathrm{~S} 45 \mathrm{C}$ \\
\hline $\mathrm{T} 2140$ & 0.39 & 0.26 & 0.77 & 0.019 & 0.021 & 0.11 & 0.04 & 0.01 & $\mathrm{~S} 40 \mathrm{C}$ \\
\hline $\mathrm{T} 2170$ & 0.35 & 0.24 & 0.70 & 0.019 & 0.022 & 0.11 & 0.03 & 0.01 & $\mathrm{~S} 35 \mathrm{C}$ \\
\hline
\end{tabular}

Table 4. Segregation of the ingot

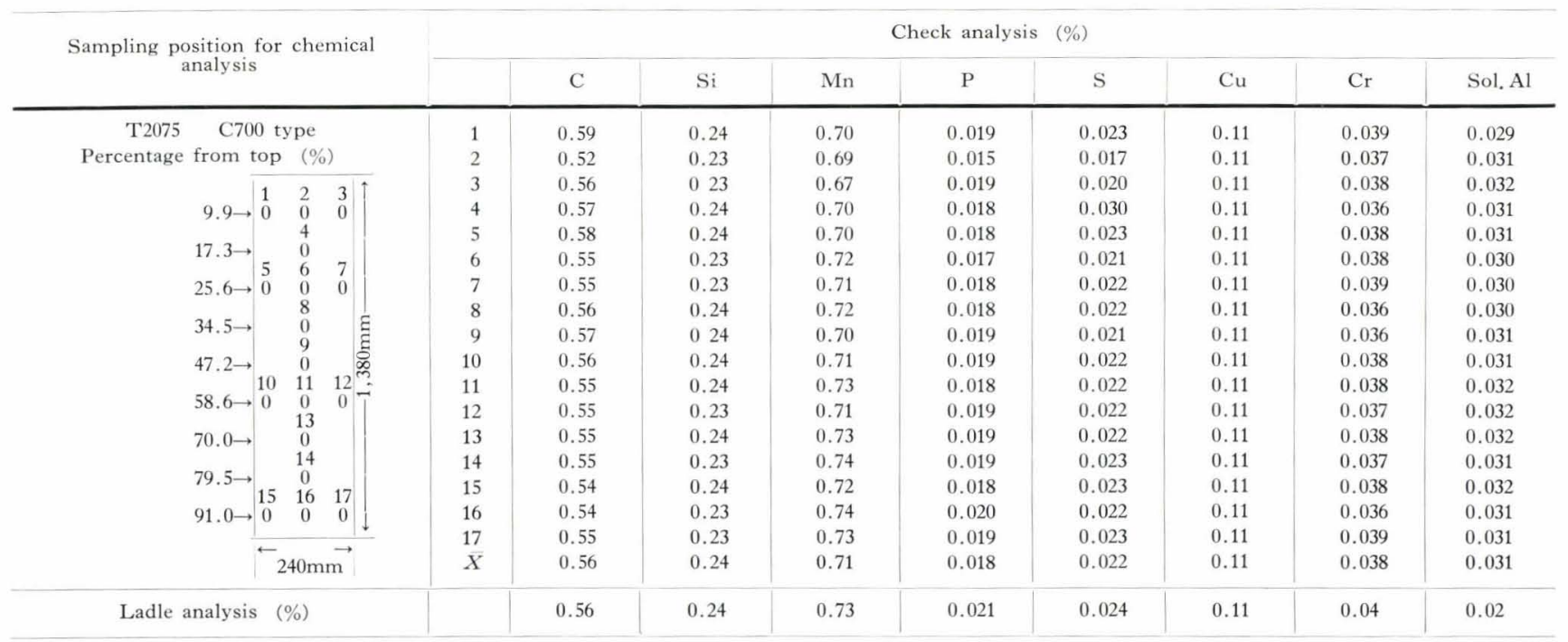


steel is much more excellent than market steel. This is one of the characteristics of the converter steel in which intervention of nonmetallic inclusion elements

Table 5. Cleanliness of steel

(Magnification $\times 400)$

\begin{tabular}{|c|c|c|c|c|c|c|}
\hline \multirow{2}{*}{$\begin{array}{l}\text { Ch. } \\
\text { No. }\end{array}$} & \multirow{2}{*}{$\underset{(\mathrm{mm} \phi)}{\text { Size }}$} & \multicolumn{4}{|c|}{ Cleanliness $(\%)$} & \multirow{2}{*}{ Notes } \\
\hline & & $\mathrm{dA}$ & $\mathrm{dB}$ & $\mathrm{dC}$ & d & \\
\hline \multirow{4}{*}{ T2075 } & 19 & 0.05 & 0.01 & 0.00 & 0.06 & \multirow{4}{*}{$\begin{array}{c}\text { Equiv. } \\
\text { to } \\
\text { S55C }\end{array}$} \\
\hline & 32 & 007 & 0.00 & 0.00 & 0.07 & \\
\hline & 38 & 0.05 & 0.00 & 0.00 & 0.05 & \\
\hline & 50 & 0.06 & 0.00 & 0.01 & 0.07 & \\
\hline \multirow{4}{*}{ T2029 } & 19 & 0.06 & 0.00 & 0.00 & 0.06 & \multirow{2}{*}{ " } \\
\hline & 32 & 0.04 & 0.02 & 0.00 & 0.06 & \\
\hline & 38 & 0.05 & 0.00 & 0.02 & 0.07 & \multirow{2}{*}{$\mathrm{S} 50 \mathrm{C}$} \\
\hline & 50 & 0.06 & 0.01 & 0.60 & 0.07 & \\
\hline \multirow{4}{*}{$\mathrm{T} 2108$} & 19 & 0.05 & 0.01 & 0.00 & 0.06 & \multirow{2}{*}{ " } \\
\hline & 32 & 0.07 & 0.00 & 0.00 & 0.07 & \\
\hline & 38 & 0.06 & 0.00 & 0.00 & 0.06 & \multirow{2}{*}{$\mathrm{S} 45 \mathrm{C}$} \\
\hline & 50 & 0.05 & 0.01 & 0.01 & 0.07 & \\
\hline \multirow{4}{*}{$\mathrm{T} 2140$} & 19 & 0.05 & 0.00 & 0.00 & 0.05 & \multirow[t]{2}{*}{$"$} \\
\hline & 32 & 0.05 & 0.00 & 0.00 & 0.05 & \\
\hline & 38 & 0.07 & 0.01 & 0.00 & 0.08 & \multirow{2}{*}{$\mathrm{S} 40 \mathrm{C}$} \\
\hline & 50 & 0.04 & 0.00 & 0.01 & 0.05 & \\
\hline \multirow{4}{*}{ T2170 } & 19 & 0.05 & 0.00 & 0.00 & 0.05 & \multirow[t]{2}{*}{ " } \\
\hline & 32 & 0.03 & 0.00 & 0.00 & 0.03 & \\
\hline & 38 & 0.05 & 0.00 & 0.00 & 0.05 & \multirow{2}{*}{$\mathrm{S} 35 \mathrm{C}$} \\
\hline & 50 & 0.05 & 0.00 & 0.01 & 0.06 & \\
\hline $\mathrm{S} 50 \mathrm{C}$ & 19 & 0.10 & 0.00 & 0.02 & 0.12 & \multirow{5}{*}{$\begin{array}{l}\text { Being } \\
\text { saled } \\
\text { for } \\
\text { market }\end{array}$} \\
\hline $\mathrm{S} 50 \mathrm{C}$ & 32 & 0.03 & 0.01 & 0.02 & 0.06 & \\
\hline $\mathrm{S} 45 \mathrm{C}$ & 19 & 0.09 & 0.00 & 0.02 & 0.11 & \\
\hline $\mathrm{S} 40 \mathrm{C}$ & 19 & 0.09 & 0.09 & 0.03 & 0.12 & \\
\hline $\mathrm{S} 35 \mathrm{C}$ & 19 & 0.08 & 0.00 & 0.01 & 0.09 & \\
\hline
\end{tabular}

is fewer.

\section{On Mechanical Properties of Steel}

Table 6 is an example of mechanical properties of steel on several sizes of round bars. The results of each size are sufficient for standard values prescribed in JIS (G3102). And it is shown that the converter steel stands sufficiently to usage as machine structural steel.

These kinds of steel are being produced by the oxygen converter process as sections and plates in our works.

\section{Conclusions}

Various methods of melting high carbon steel by the oxygen converter process were discussed in this lecture. And it was shown that high carbon steel, which required a high tap temperature of $1,640^{\circ} \sim$ $1,660^{\circ} \mathrm{C}$, could be produced by the single slag method in the oxygen converter process with a high productivity, keeping phosphor in steel within the standard limit, when producing the high dephosphorizing power of slag by adjusting the lance height. Steel produced by this method is good in cleanliness and mechanical properties, and stands enough as machine structural steel.

\section{BIBLIOGRAPHY}

1) K. Rösner: Stahl u. Eisen, 76 (1956), 1337.

2) O. Cuscoleca: J. Metals, 10 (1958), 673.

3) H. Trenkler : ibid., 12 (1960), 538.

4) S. Maehara, et ali.: Tetsu-to-Hagané, 47 (1961), 345.

5) T. Itaoka, et ali. : ibid., 48 (1962), 1366-1368.

Table 6. Mechanical properties of samples

\begin{tabular}{|c|c|c|c|c|c|c|c|}
\hline Heat treatment & Items of test & Charge No. & $\begin{array}{l}\text { T2075 } \\
\text { S55C } \\
\text { equiv. }\end{array}$ & $\begin{array}{l}\text { T2029 } \\
\text { S50C } \\
\text { equiv. }\end{array}$ & $\begin{array}{l}\text { T1208 } \\
\text { S45C } \\
\text { equiv. }\end{array}$ & $\begin{array}{l}\text { T2140 } \\
\text { S40C } \\
\text { equiv. }\end{array}$ & $\begin{array}{l}\text { T2170 } \\
\text { S35C } \\
\text { equiv. }\end{array}$ \\
\hline \multirow[t]{2}{*}{ Normalized } & Tension test & $\begin{array}{lr}\text { Yield point } & \left(\mathrm{kg} / \mathrm{cm}^{2}\right) \\
\text { Tensile strengh } & \left(\mathrm{kg} / \mathrm{mm}^{2}\right) \\
\text { Elongation } & (\%) \\
\text { Reduction } & (\%)\end{array}$ & $\begin{array}{l}42.6 \\
76.8 \\
26.0 \\
44.0\end{array}$ & $\begin{array}{l}44.0 \\
76.2 \\
24.5 \\
42.8\end{array}$ & $\begin{array}{l}45.5 \\
70.2 \\
30.0 \\
50.5\end{array}$ & $\begin{array}{l}42.3 \\
64.8 \\
32.0 \\
53.5\end{array}$ & $\begin{array}{l}42.7 \\
61.6 \\
34.0 \\
54.6\end{array}$ \\
\hline & Hardness test & Hardness $\left(\mathrm{H}_{\mathrm{B}}\right)$ & 219 & 216 & 194 & 186 & 175 \\
\hline As rolled & Bending test & $\begin{array}{ll}\text { Test condition } & r=3 d \\
& r=2 d \\
& r=1 d \\
& r=0\end{array}$ & $\begin{array}{c}\text { Good } \\
" \\
" \\
"\end{array}$ & $\begin{array}{l}\text { Good } \\
" \prime \\
" \\
"\end{array}$ & $\begin{array}{c}\text { Good } \\
" \\
" \\
"\end{array}$ & $\begin{array}{c}\text { Good } \\
" \prime \\
" \\
"\end{array}$ & $\begin{array}{c}\text { Good } \\
" \prime \\
" \\
"\end{array}$ \\
\hline \multirow{2}{*}{$\begin{array}{l}\text { Quenched } \\
\text { and } \\
\text { tempered }\end{array}$} & Tension test & $\begin{array}{lr}\text { Yield point } & \left(\mathrm{kg} / \mathrm{mm}^{2}\right) \\
\text { Tensile strength } & \left(\mathrm{kg} / \mathrm{mm}^{2}\right) \\
\text { Elongation } & (\%) \\
\text { Reduction } & (\%)\end{array}$ & $\begin{array}{l}69.2 \\
91.8 \\
21.0 \\
53.3\end{array}$ & $\begin{array}{l}69.6 \\
86.6 \\
20.8 \\
51.7\end{array}$ & $\begin{array}{l}67.2 \\
84.7 \\
25.0 \\
58.1\end{array}$ & $\begin{array}{l}60.5 \\
79.8 \\
22.8 \\
56.5\end{array}$ & $\begin{array}{l}52.0 \\
74.0 \\
26.3 \\
63.2\end{array}$ \\
\hline & $\begin{array}{c}\text { Charpy test } \\
\left(\text { Charpy value } \mathrm{kg} \cdot \mathrm{m} / \mathrm{cm}^{2}\right)\end{array}$ & $\begin{array}{c}\text { Test temperature } \\
-20^{\circ} \mathrm{C} \\
0^{\circ} \mathrm{C} \\
\text { Room temp. }\end{array}$ & $\begin{array}{l}6.93 \\
8.42 \\
7.04\end{array}$ & $\begin{array}{r}6.20 \\
7.05 \\
11.83\end{array}$ & $\begin{array}{l}10.39 \\
10.27 \\
15.58\end{array}$ & $\begin{array}{l}11.49 \\
20.71 \\
22.13\end{array}$ & $\begin{array}{l}15.44 \\
18.60 \\
22.25\end{array}$ \\
\hline
\end{tabular}

Tension test: JIS No. 4 Probe. Figures are average values at top and bottom.

Charpy test: JIS No. 3 Probe. Figures are average values of three tests.

Normalizing: $850^{\circ} \mathrm{C} \times 1 \mathrm{hr}, \rightarrow$ air cool.

Quenching and normalizing: $850^{\circ} \mathrm{C} \times 1 \mathrm{hr} \rightarrow$ water cool $\rightarrow 600^{\circ} \mathrm{C} \times 2 \mathrm{hr} \rightarrow$ rapid cool. 


\section{ON MELTING OF HIGH GARBON STEEL BY OXYGEN CONVERTER PROGESS SOME PROBLEMS ON DEPHOSPHORIZA- THON)}

\section{By Jō Doi, Takashi Itaoka and Tsuyoshi Saitō (Nippon Kokan Kabushiki Kaisha)}

\section{Introduction}

It is well-known that the proportion of LD converter steel production to the amount of total crude steel production in Japan is increasing year by year and will continue to increase in the future. Species of LD converter steel, therefore, may be spread not only in soft steel but also in high carbon steel.

So it is very important that we make an effort to acquire technique of melting high carbon steel with good quality by the LD converter economically. We, working at the converter shop in Kawasaki Works of Nippon Kokan Kabushiki Kaisha, already reported on melting practice, rolling results and properties of high carbon steel at the 64th Grand Lecture Meeting of The Iron and Steel Institute of Japan. Excellency of quality of LD converter steel could be well proved in that report. There has been no essential change on melting practice, especially on blowing method, from those days, but since then, we have tried to make some improvement through various operational experiments. In this lecture, we are reporting on the melting practice adopted in melting high carbon steel, especially on dephosphorization, and how we have come to adopt such a method.

\section{The Influence of Melting Practice on Phosphor in Steel}

When high carbon steel is melted by the LD converter, the problem of how to improve dephosphorization and produce steel with low phosphor content, would be a matter of importance to be discussed. If we adopt a blowing method in high carbon steel just as we do in low carbon steel, dephosphorization naturally becomes imperfect and $\mathrm{P}$ content in steel increases. But $\mathrm{P}$ content in steel is influenced not only by blowing practice but also by various conditions peculiar to each works, for instance, tap temperature and $\mathrm{P}$ content in hot metal etc., as seen in other steelmaking processes. ${ }^{1), 2)}$ For general discussion, main working conditions, affecting $\mathrm{P}$ content in LD converter steel, are shown in Fig. 1. First of all, we think about $\mathrm{P}$ content in hot metal and the end point temperature.

The relations between the end point $\mathrm{P}$ and $\mathrm{P}$ in hot metal, and the end point $\mathrm{P}$ and the end point temperature, which were obtained during 1960 to 61, are shown in Figs. 2 and 3, respectively. When $\mathrm{P}$ in hot metal decreases, $\mathrm{P}$ in steel naturally decreases, and the relation is expected to be parabolic ${ }^{3)}$, calculating from the equilibrium equation, but the results, obtained from operational data, show a linear relation even if with a little variation. And a clear positive relation between the end point temperature and the end point $\mathrm{P}$ can be seen, which is natural when considered from the point of view of equilibrium.

Generally speaking, these conditions may be peculiar to each works, and the conditions in our works are such that $\mathrm{P}$ in hot metal, about $0.18 \%$, the end point temperature, about $1,680^{\circ} \mathrm{C}$, and $\mathrm{C}$ in ladle analysis in high carbon steel, about $0.45 \%$. The reasons why the end point temperature is high in our works, are that ingot is made by bottom pouring with the high temperature and that, we consider, the temperature drops owing to time delay in analyzing the bath at the end point. The high temperature level of the bath is not only disadvantageous to dephosphorization, but also apt to cause re-phosphorization ${ }^{4)}$, i.e., the phenomena that $\mathrm{P}$ in the ladle increases more than at the end point. So we keep the more exact control

\begin{tabular}{|c|c|c|c|}
\hline 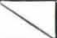 & \multicolumn{3}{|c|}{ Factors } \\
\hline \multirow{3}{*}{ 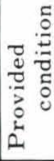 } & {$[\mathrm{P}] \%$ in hot metal $\longrightarrow$} & \multicolumn{2}{|c|}{ c. $0.180 \%$} \\
\hline & Specified ladle $[\mathrm{C}] \% \rightarrow$ & \multicolumn{2}{|c|}{ c. $0.45 \%$} \\
\hline & End point temp. $\longrightarrow$ & \multicolumn{2}{|c|}{ c. $1680^{\circ} \mathrm{C}$} \\
\hline \multirow{5}{*}{$\begin{array}{l} \\
\end{array}$} & \multirow{5}{*}{$\begin{array}{l}\mathrm{O}_{2} \text { blowing pressure } \longrightarrow \\
\text { Basicity and volume } \\
\text { of slag } \\
\text { End point (C)\% } \\
\text { Method of heating up } \longrightarrow \\
\text { With or without } \\
\text { slag off }\end{array}$} & $\begin{array}{l}\mathrm{High} \\
\left(8 \mathrm{~kg} / \mathrm{cm}^{2}\right)\end{array}$ & $\begin{array}{l}\text { Low } \\
\left(4 \mathrm{~kg} / \mathrm{cm}^{2}\right)\end{array}$ \\
\hline & & $\mathrm{CaO} / \mathrm{SiO}_{2}=3.0 \sim 3.5$ & 4. $0 \sim 4$. \\
\hline & & $\begin{array}{l}\text { Catch } \\
\text { carbon }\end{array}$ & $\begin{array}{c}\text { Coke } \\
\text { addition }\end{array}$ \\
\hline & & $\begin{array}{l}\text { Non-Fe-Si heating } \\
\text { up method }\left(\begin{array}{l}\text { ordinary } \\
\text { method }\end{array}\right)\end{array}$ & $\begin{array}{l}\mathrm{Fe}-\mathrm{Si} \text { heating } \\
\text { up method }\end{array}$ \\
\hline & & Single slag & Double slag \\
\hline & & $\begin{array}{l}\text { High carbon } \\
\text { steel }\end{array}$ & $\begin{array}{l}\text { Low carbon } \\
\text { steel }\end{array}$ \\
\hline
\end{tabular}

Fig. 1.

Various factors affecting phosphor content of steel in the steelmaking process 
on dephosphorization at high temperature level. When these preconditions are limited in order to control $\mathrm{P}$ in steel, it is necessary to adopt proper blowing method according to these conditions, as seen in Fig. 3. The refining reaction in the converter is influenced by the pressure level of blowing oxygen, the quality of slag, the level of end point $\mathrm{C}$, temperature change and the blowing method-single slag or double slag method. So we must adopt a proper blowing method according to the species of steel to be produced. For example, when ordinary low carbon rimmed steel is to be melted, it is sufficient merely to adopt blowing conditions to enable the oxygen pressure to be raised, the basicity of slag to be about from 3.0 to 5.5 , and the single slag ctach-carbon method without heating-up. On the other hand, to melt high carbon steel we must adopt the soft blow and high basicity operation as the standard, with a combination of the carbon addition, heating-up or the double slag method.

\section{On Oxygen Blowing Pressure}

The term "oxygen blowing pressure" means here

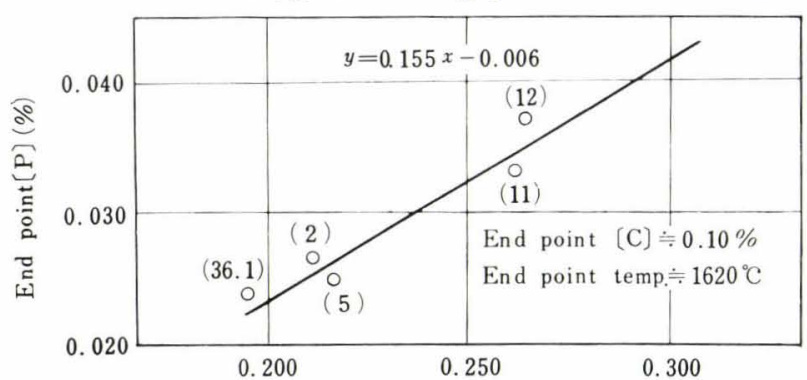

$[\mathrm{P}] \%$ in hot metal

Fig. 2. Relation between $[\mathrm{P}]$ at the end point and $[\mathrm{P}]$ in hot metal

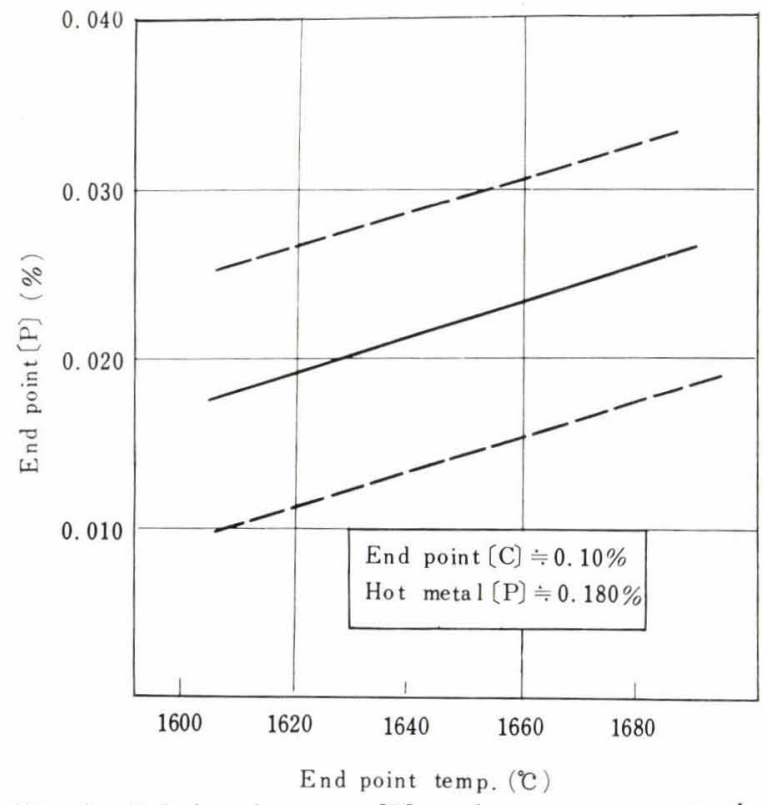

Fig. 3. Relation between $[\mathrm{P}]$ and temperature at the end point the oxygen pressure in the pipe at a point close to the lance. And according to the pressure, we call it "hard blow" or "soft blow", respectively. But in a real sense it is the impact pressure of oxygen at the surface of the bath. Fig. 4 shows the relations between the impact pressure of oxygen at the center of the oxygen jet, the oxygen blowing pressure $\left(\mathrm{kg} / \mathrm{cm}^{2}\right)$ and the lance height (the distance between the surface of the bath and the lance nozzle) in our works. Of course these relations vary according to the diameter of the nozzle, and Fig. 4 shows a case of $40 \mathrm{~mm}$ dia., which is used ordinarily in our works. It is seen that the impact pressure decreases in proportion to the decrease of the oxygen pressure at the main pipe, or to the increase of the lance height at a constant oxygen pressure. For example, the impact pressure at the surface of the bath is same between the following two cases: the lance height, 1,200 m, the oxygen pressure, $4 \mathrm{~kg} / \mathrm{cm}^{2}$, and the lance height, $2,000 \mathrm{~mm}$, the oxygen pressure, $8 \mathrm{~kg} / \mathrm{cm}^{2}$. Accordingly the condition of soft blow can be obtained either by increasing the lance height or by lowering the oxygen pressure, but generally speaking, we must take into account the fact that the lower oxygen pressure results in the lower quantity of oxygen volume injected in a unit time.

Figs. 5 and 6 show the influence of the soft blow on the blowing operation, especially on dephosphorization. Fig. 5 shows the influence of the oxygen blowing pressure and lance height on the total $\mathrm{Fe}$ in the slag at the end point. It is seen that total $\mathrm{Fe}$ in the slag can be increased either by decreasing the oxygen pressure or by increasing the lance height. Fig. 6 shows the influence of the oxygen pressure on the relation between the end point $\mathrm{C}$ and the end point $\mathrm{P}$. In this

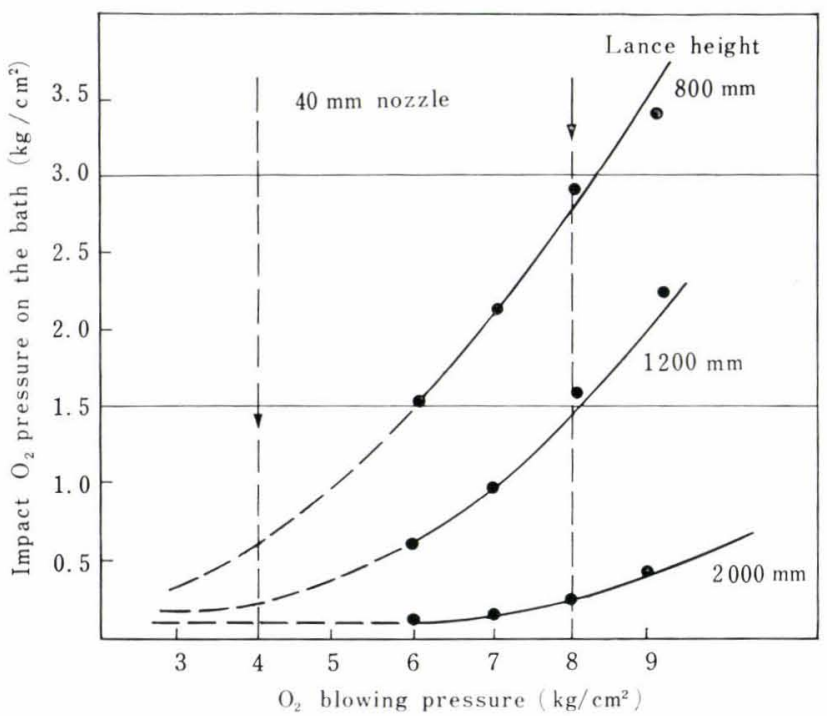

Fig. 4. Relation between impact $\mathrm{O}_{2}$ pressure on the bath and $\mathrm{O}_{2}$ blowing pressure 
figure, there is considerable discrepancy in the end point $\mathrm{P}$ corresponding to the same end point $\mathrm{C}$ between the following two cases that the oxygen pressure is kept constant at $8 \mathrm{~kg} / \mathrm{cm}^{2}$ and that the oxygen pressure is changed, $8 \rightarrow 6 \rightarrow 4 \mathrm{~kg} / \mathrm{cm}^{2}$, for instance, during the blowing. And the discrepancy increases as the end point $\mathrm{C}$ is raised, so that the influence of "soft blow" on dephosphorization is more effective in high carbon range than that in low carbon range. Fig. 7 shows how to apply soft blow as operational standard. When low carbon steel is melted, the oxygen pressure is kept constant at $8 \mathrm{~kg} / \mathrm{cm}^{2}$, and the lance height is $1.2 \mathrm{~m}$ throughout the blowing, while high carbon steel being melted by the single slag and catch-carbon method, the oxygen pressure is high at the first half of blowing and lowered at the second half so that dephosphorization may be promoted. In this case, the blowing time is prolonged because the oxygen flow rate $\left(\mathrm{m}^{3} / \mathrm{min}\right)$ is decreased owing to a lowering of oxygen pressure at the second half of the blowing.

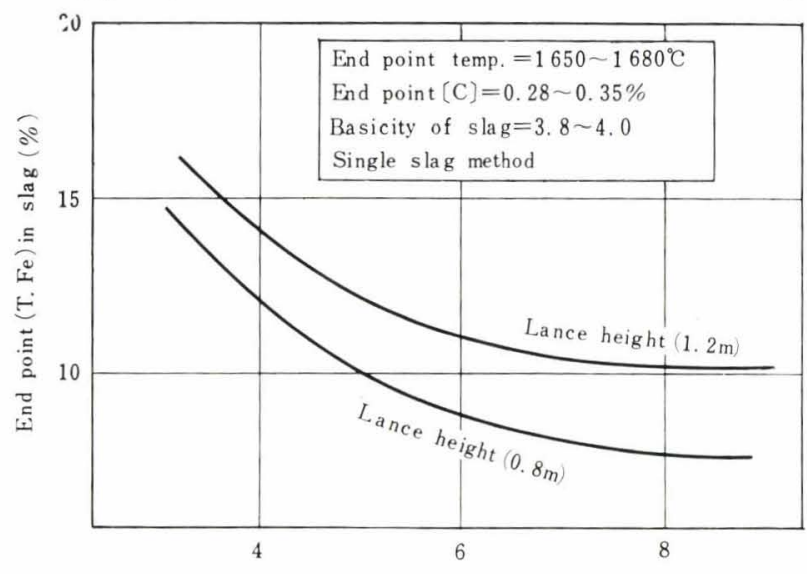

$\mathrm{O}_{2}$ blowing pressure $\left(\mathrm{kg} / \mathrm{cm}^{2}\right.$

Fig. 5. The influence of $\mathrm{O}_{2}$ blowing pressure and lance height on $(\mathrm{T} . \mathrm{Fe})$ in the slag at the end point

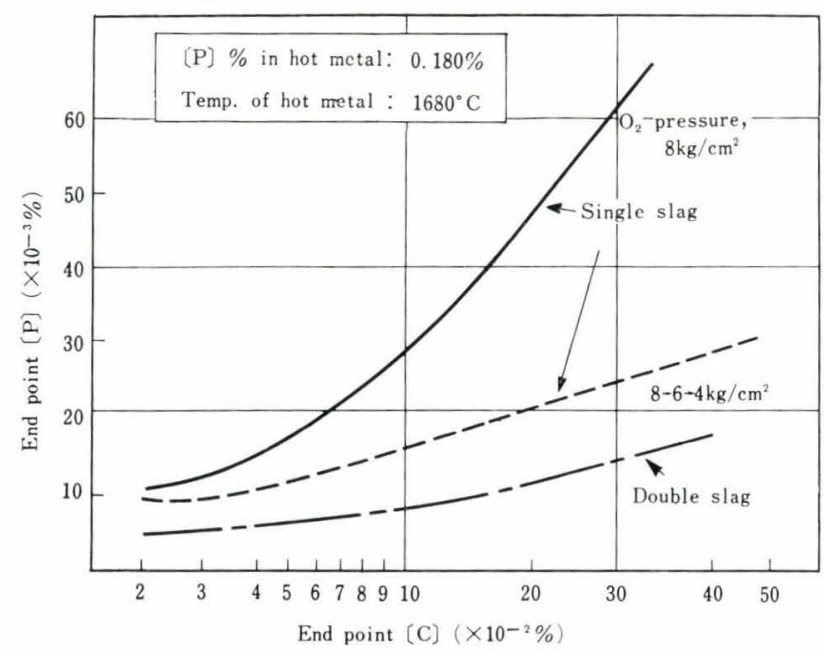

Fig. 6. The influence of the blowing method on the end point $[\mathrm{P}]$
And in the double slag method, we conduct the soft blow in such a way that oxygen pressure is kept at a high level and the lance position is pulled up to $3 \mathrm{~m}$ high, for the reasons that we expect to shorten the blowing time of the first stage of the blowing by means of promoting the decarburization rate through an increase in the oxygen flow rate and that the variation of the end point $\mathrm{C}$ of the first stage, resulted from the above-mentioned method, does not interfere with actual operation. In the second blowing, seen in Fig. 7 , we conduct the soft blow in such a way that the oxygen pressure is lowered a little to improve slagformation and then further lowered to restrain the decarburization rate in order to make the catchcarbon easier.

\section{Slag and Fluxes}

One may regard the slag and fluxes with the same general consideration as in other steelmaking processes. As seen in Fig. 7, when melting ordinary low carbon steel, burnt lime and scale are charged only once at the primary period and fluorspar is charged at different times. When melting high carbon steel by the single slag method, burnt lime is also charged at different times so that a large quantity of lime may be used effectively, and in the case of the double slag method, some quantity of slag, say about $40 \mathrm{~kg} / \mathrm{t}$, used in the previous heat is still left in

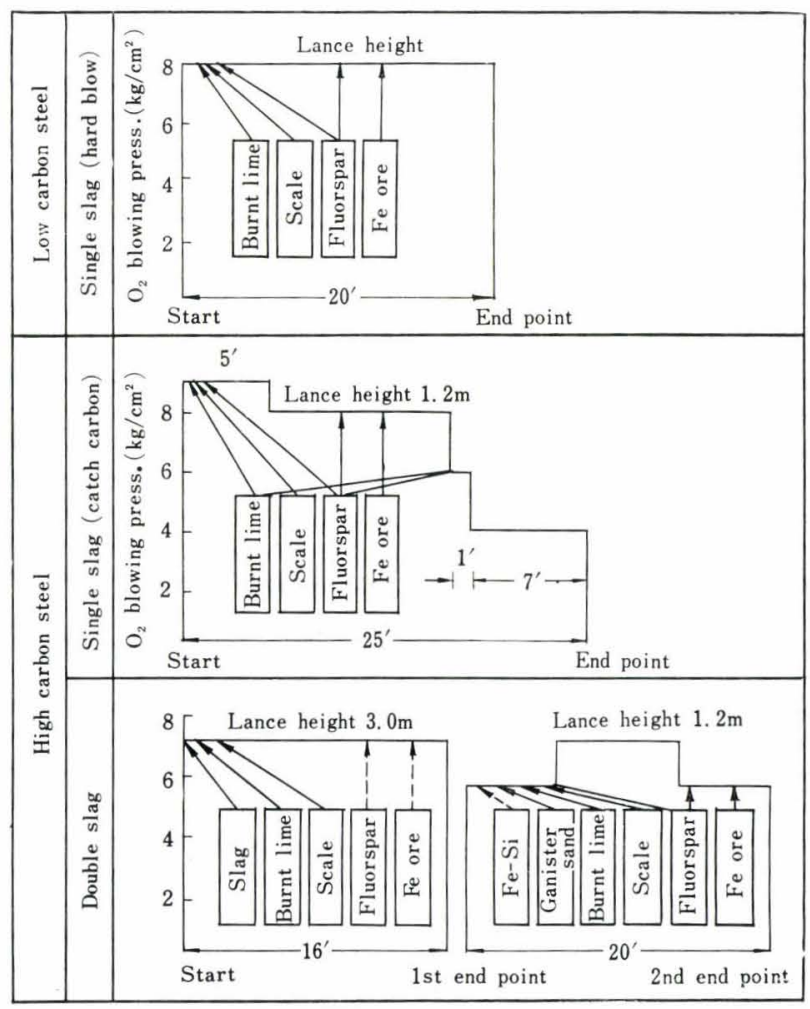

Fig. 7. $\mathrm{O}_{2}$ blowing pressure and lance height in various blowing methods 
the vessel to be used in the next heat in order to improve slag-formation effectively and to recover the $\mathrm{Fe}$ contents in slag.

Flux consumption is shown in Table 1. In the single slag method, 50 to $55 \mathrm{~kg} / \mathrm{t}$ of burnt lime is used in low carbon steel making, while, in high carbon steel, burnt lime consumption is increased from 75 to 80 $\mathrm{kg} / \mathrm{t}$ to improve dephosphorization efficiency. In the double slag method, a large quantity of lime, say 40 $\mathrm{kg} / \mathrm{t}$ in the first stage and $50 \mathrm{~kg} / \mathrm{t}$ in the second stage to the total amount of $90 \mathrm{~kg} / \mathrm{t}$, is used. Fluorspar consumption in high carbon steel increases in proportion to burnt lime, which is about twice that of low carbon steel. And the basicity of slag increases in proportion to lime consumption: ordinary low carbon steel, 3.5 to 3.7 and high carbon steel, 4.0 to 4.5 , so the quantity of slag in high carbon steel is more than that in low carbon steel by 40 to $50 \%$. It is one of the weak points of the double slag method that the metallic yield is lowered owing to large quantity of slag caused

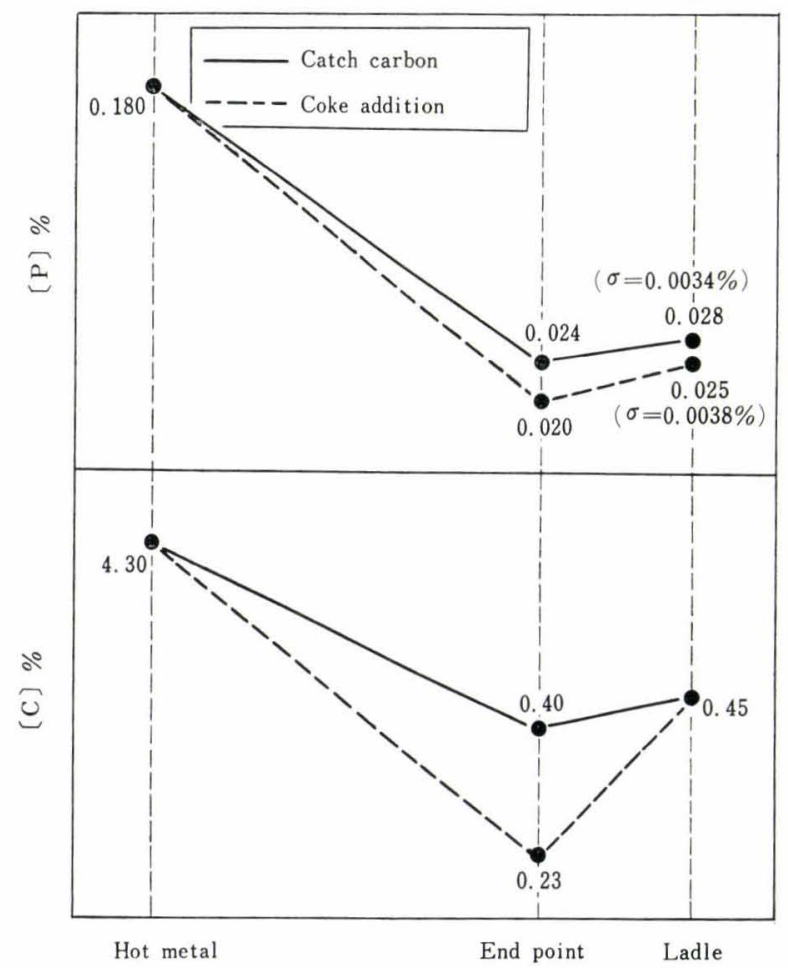

Fig. 8. Comparison between catch-carbon method and coke addition method on dephosphorization (single slag) in both the first and the second stage of the blowing.

\section{Catch-Carbon Method and Carbon Addition Method}

The catch-carbon method and the carbon addition method are considered as the methods of controlling the end point carbon in general. The carbon addition method is apt to result in increasing the amount of nitrogen in steel owing to materials for the carbon addition, and making molten steel over-oxidized, but with regard to dephosphorization, the carbon addition method may be better than the catch-carbon method. Fig. 8 is the schematic comparison of the said two methods on dephosphorization, from the results obtained in typical heats. Compared in the same ladle carbon target of $0.45 \%$, in the carbon addition method, carbon is lowered to $0.23 \%$ at the end point and then elevated to $0.45 \%$ by coke addition, while, in the catch-carbon method, the end point $\mathrm{C}$ is not lowered so much. Consequently, the end point $\mathrm{P}$ is lower in the carbon addition method than in the catch-carbon method. The difference between the end point $\mathrm{P}$ and $\mathrm{P}$ in ladle analysis, that is, the degree of re-phosphorization, is higher in the carbon addition method than in the other, but the ladle $\mathrm{P}$ is still lower in the carbon addition method.

\section{Method of Elevating Temperature of Molten Steel}

In order to obtain the objective tap temperature, two methods, which we call the Fe-Si heating-up method and the normal heating-up method, are adopted in our works for convenience' sake.

Fig. 9 shows the schematic figure of its comparison. In the normal heating-up method, the temperature is elevated to the objective temperature by the end of the blowing gradually, while in the $\mathrm{Fe}-\mathrm{Si}$ heating-up method, temperature elevation is kept under about $1,620^{\circ} \mathrm{G}$ to improve dephosphorization reaction in the first stage. Considering $\mathrm{P}$ at the first end point according to the same carbon, $0.019 \% \mathrm{P}$ in the heating-up method is lower than $0.024 \% \mathrm{P}$ in the normal method. But as seen in Fig. 9, the ladle analysis of phosphor is still lower in the heating-up method than that in the normal method, in spite of occurring re-phosphorization during elevating temperature to the objectives, say $1,680^{\circ} \mathrm{C}$. To be exact, the $\mathrm{Fe}-\mathrm{Si}$ heating-up method may fall under the category of the double slag method, because when the vessel is turned

Table 1. Flux consumption and properties of slag

\begin{tabular}{|c|c|c|c|c|c|c|c|c|c|}
\hline \multirow{2}{*}{ Grade of steel } & \multirow{2}{*}{ Blowing method } & \multicolumn{6}{|c|}{ Flux (kg/t ingot) } & \multicolumn{2}{|c|}{ Slag } \\
\hline & & Burnt lime & Scale & Fluorspar & $\mathrm{Fe}-\mathrm{Si}$ & Ganister sand & Slag & $\mathrm{CaO} / \mathrm{SiO}_{2}$ & Weight ( $t$ ) \\
\hline Low carbon steel & Single slag & $50 \sim 55$ & 20 & $3 \sim 4$ & - & - & - & $3.5 \sim 3.7$ & $5.3 \sim 5.5$ \\
\hline \multirow{2}{*}{ High carbon steel } & $\begin{array}{c}\text { Single slag } \\
\text { (catch-carbon) }\end{array}$ & $75 \sim 80$ & 24 & $8 \sim 9$ & - & - & - & $4.0 \sim 4.5$ & $7.0 \sim 7.5$ \\
\hline & Double slag & $\begin{array}{l}40 \\
50\end{array}$ & $\begin{array}{r}8 \\
10\end{array}$ & $\begin{array}{c}0 \sim 2 \\
5\end{array}$ & $\stackrel{-}{0 \sim 2}$ & $\frac{-}{8}$ & $\begin{array}{l}40 \\
-\end{array}$ & $\begin{array}{l}4.0 \sim 4.5 \\
4.0 \sim 4.5\end{array}$ & $\begin{array}{l}6.0 \sim 6.5 \\
5.0 \sim 5.5\end{array}$ \\
\hline
\end{tabular}


down to measure the bath temperature and to take a sample for analysis, a little quantity of slag flows out and burnt lime is added. But we regard it as the single slag method, considering that volume of slag flowed out, and time for slag-off are little. The reasons why $\mathrm{P}$ in steel is low in the $\mathrm{Fe}-\mathrm{Si}$ heating-up method, are not only that a little quantity of slag is taken off and burnt lime is added at the first end of the blowing, but also that the temperature of molten steel is elevated so rapidly at the last stage that the state of equilibrium on phosphor between metal and slag can not be reached. But these phenomena can not be clarified theoretically but only be obtained as operational results.

\section{Single Slag Method and Double Slag Method}

It is natural that P in steel is lower in the double slag method than in the single slag method, which is shown in Fig. 10. In the double slag method, providing that

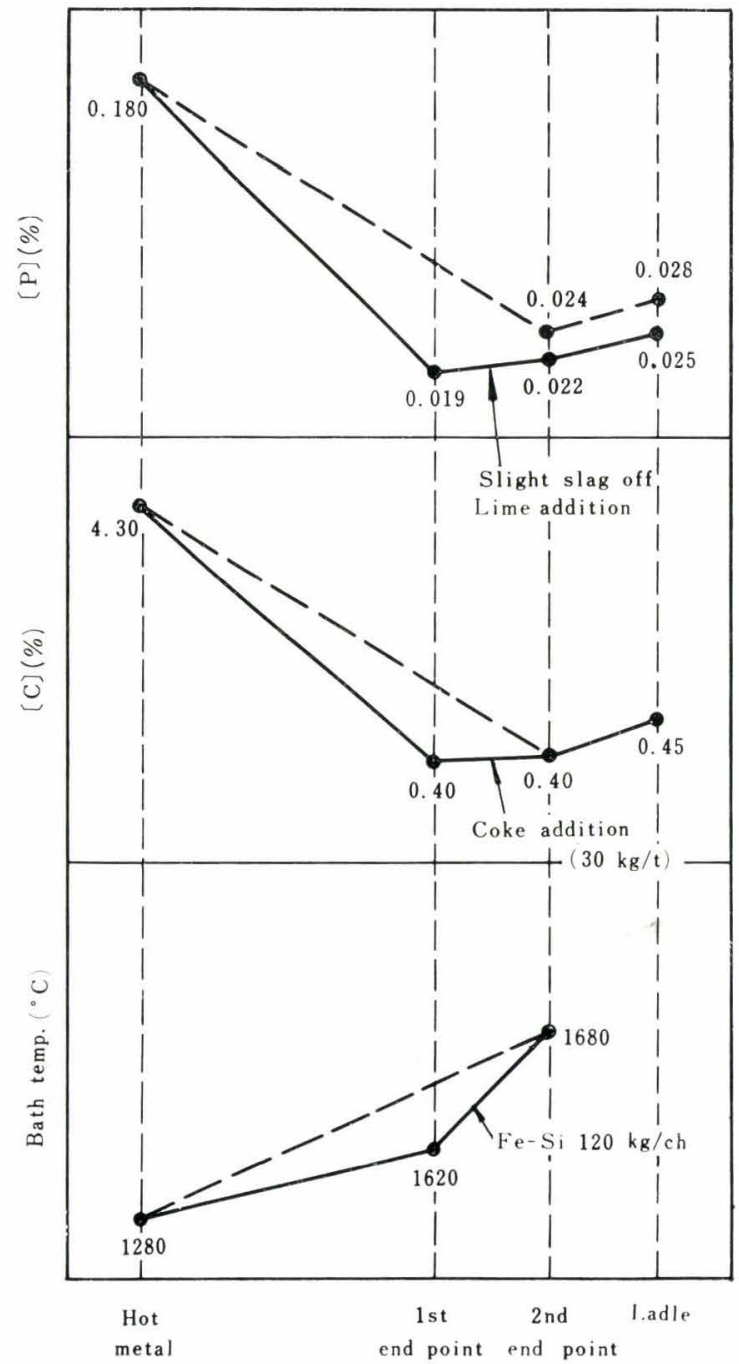

Fig. 9. Comparison between Fe-Si heating-up method and normal heating-up method on dephosphorization the blowing of the first stage is controlled so that it may come to an end when the carbon in steel 2 to $3 \%$, the bath temperature is $1,400^{\circ} \pm 30^{\circ} \mathrm{C}$ and $\mathrm{P}_{2} \mathrm{O}_{5}$ in slag is 2.3 to $2.7 \%, 90 \%$ of which is taken off in deslagging. That is to say, $70 \%$ of the phosphor in the charged materials is taken off, and $\mathrm{P}$ in steel is naturally further lowered to about $0.015 \%$ by the secondary blowing.

\section{Phosphor in Steel and Refining Time in Var- ious Blowing Methods}

Fig. 11 shows a comparison of blowing time in the said various blowing methods, which is an index of economics of the process. Under conditions in which $\mathrm{P}$ in hot metal is $0.180 \%$, the end point temperature is $1,6800^{\circ} \mathrm{C}$ and ladle carbon is $0.45 \%$, the correlation between refining time and $\mathrm{P}$ in steel is negative, as seen in Fig. 11.

\section{Blowing Practices under Various Conditions}

As the refining time is to be considered from the economic point of view in the converter process, we may well adopt the blowing practice which makes the refining time shortest. But how to produce steel with the required chemical composition should be most important. So we must select such a blowing method as not only make the refining time shortest but also produce steel with allowable $\mathrm{P}$ content.

At the present technical level of our works, we are conducting combination of the blowing standards, as seen in Table 2. That is to say, the blowing methods

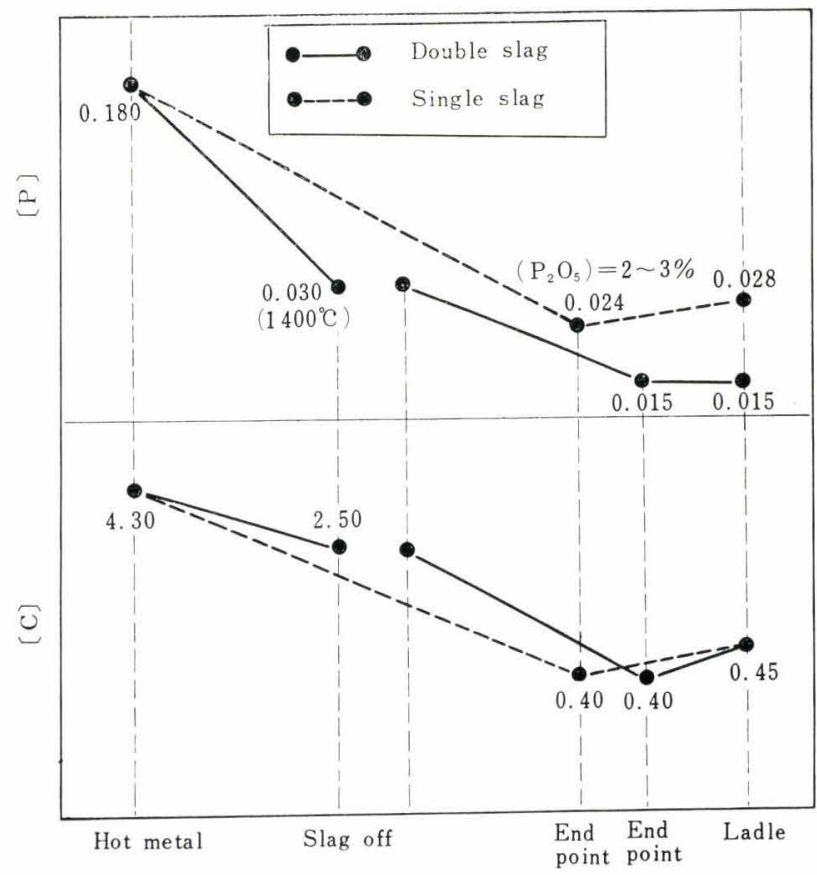

Fig. 10. Comparison between double slag method and single slag method regarding dephosphorization 
Table 2. Steelmaking methods of high carbon steel in various conditions

\begin{tabular}{|c|c|c|c|c|c|}
\hline \multirow{4}{*}{$\begin{array}{l}\text { End point } \\
\text { temp. }\left({ }^{\circ} \mathrm{C}\right)\end{array}$} & & \multicolumn{4}{|c|}{$[\mathrm{P}]$ in hot metal } \\
\hline & & \multicolumn{2}{|c|}{0.180 over } & \multicolumn{2}{|c|}{0.180 under } \\
\hline & & \multicolumn{4}{|c|}{ Ladle carbon $[\mathrm{P}] \%$} \\
\hline & method & 0.020 under & 0.020 over & 0.020 under & 0.020 over \\
\hline $1,640 \sim 1,680$ & Slag carbon heating up & Catch-carbon (normal) & $\stackrel{\mathrm{S}}{\text { Coke addition (normal) }}$ & $\stackrel{\mathrm{S}}{\text { Coke addition (normal) }}$ & $\stackrel{\mathrm{S}}{\text { Catch-carbon (normal) }}$ \\
\hline 1,680 over & Slag carbon heating up & $\begin{array}{c}\mathrm{D} \\
\text { Catch-carbon }(\mathrm{Fe}-\mathrm{Si})\end{array}$ & Coke addition $(\mathrm{Fe}-\mathrm{Si})$ & $\stackrel{\mathrm{S}}{\text { Coke addition }}(\mathrm{Fe}-\mathrm{Si})$ & $\stackrel{\mathrm{S}}{\text { Catch-carbon }}(\mathrm{Fe}-\mathrm{Si})$ \\
\hline
\end{tabular}

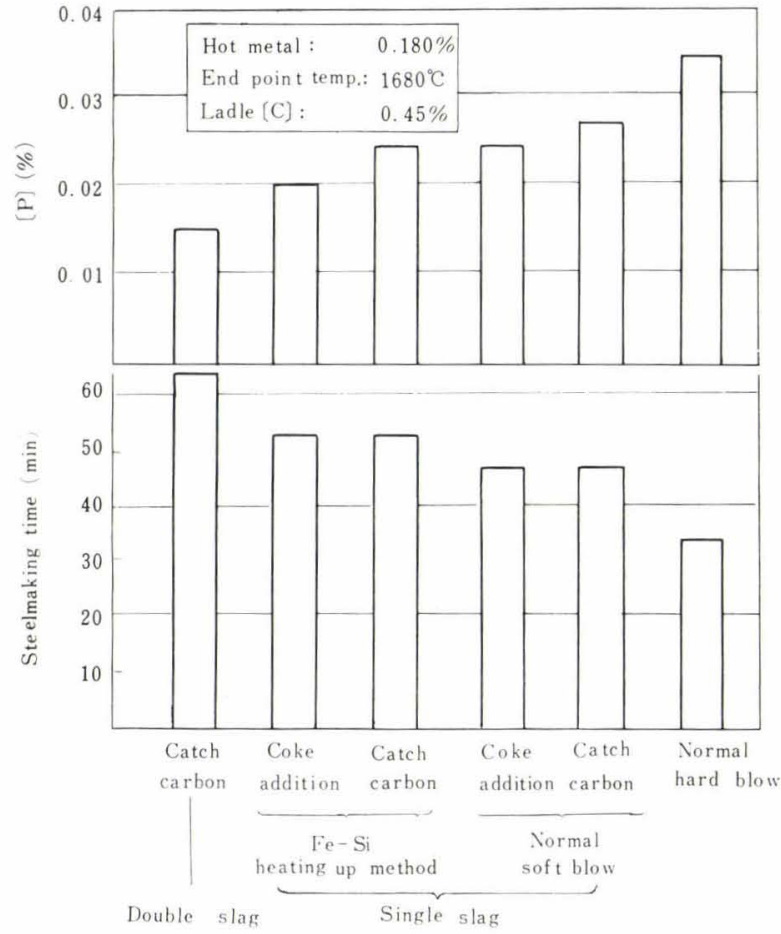

Fig. 11. Comparison of $[\mathrm{P}]$ in steel and steelmaking time about various blowing methods of high carbon steel

are differed not only according to $\mathrm{P}$ in hot metal, above or bellow $0.18 \%$, to adjust itself with the fluctuation of blast furnace operation, but also according to the quantity of ferro-alloy to be added, the mold size and the end point temperature. And further, the blowing method is decided according to the phosphor in steel required to be more or less than $0.020 \%$; for example, when $\mathrm{P}$ in hot metal is more than $0.180 \%$ and $\mathrm{P}$ in steel is required under $0.020 \%$, the double slag method is adopted regardless of the end point temperature, and when $\mathrm{P}$ in hot metal is less than $0.180 \%$ and $\mathrm{P}$ in steel about $0.020 \sim 0.030 \%$, the single slag and catch-carbon method with normal heatingup method is adopted in case of the end point temperature $1,640^{\circ} \sim 1,680^{\circ} \mathrm{C}$, and in case of the end point temperature more than $1,680^{\circ} \mathrm{C}$, single slag and catch- carbon methods with $\mathrm{Fe}-\mathrm{Si}$ heating-up method is adopted. The method in the daily operation is mainly single slag and catch-carbon method with normal heating-up method, and if necessary, carbon-addition or Fe-Si heating-up method is adopted.

\section{Conclusions}

Various blowing methods are discussed mainly from the viewpoint of dephosphorization according to the results obtained from daily operation. In short, in melting high carbon steel, we must make an effort to study ways of shortening the refining time from the economic point of view, and of producing steel of good quality. From the point of quality of steel, soft blow, which elevates total Fe in slag, is unfavorable, so in future, we must study methods of improving dephosphorization by causing violent bath agitation, without increasing total $\mathrm{Fe}$ in slag at the end point, and of adopting "LD-AC method" efficiently to melt high carbon steel using low phosphor hot metal.

It is well proved that the LD process is superior to other steelmaking processes in melting high carbon steel not only from the economic point of view, but also from the stand point of steel quality, but we must make a further effort to study ways of improving the L.D process in these fields.

\section{REFERENCES}

1) Kawasaki Iron Works, Nippon Kokan Kabushiki Kaisha: Materials for the 1st International LD Technical Conference.

2) T. Itaoka, T. Saitō, S. Tanaka and O. Muroga: Tetsu-toHagané, 48 (1962), 1366.

3) T. Itaoka, R. Fujii, S. Tanaka and K. Yano: ibid., 48 (1962), 1368.

4) K. Mizui : Nippon Kokan Technical Report, No. 15, May (1959), 17.

5) J. Perason: Iron \&̊ Coal, Tr. R., Mar. 9 (1954), 685-695.

6) T. Itaoka, T. Saitō and M. Itō: Nippon Kokan Technical Report, No. 23 June (1962).

7) T. Itaoka, T. Saitō and O. Muroga: Tetsu-to-Hagané, 49 (1963), 408. 


\section{Ghairman}

Valuable reports are just announced by four lecturers. I think that these lectures could be divided roughly into three points, as follows:

(1) On the mechanism of decarburization and dephosphorization in the LD process.

(2) On the quality of steel produced by the LD process.

(3) On various problems of the operation in melting high carbon steel by the LD process.

I hope that the questioners will discuss these points respectively from their own experiments from now on.

\section{ON THE MECHANISMS OF DEGARBURIZA- TION AND DEPHOSPHORIZATION IN THE LD PROGESS}

Yukio Matsushita Question to Mr. Mitsushima)

Mr. Mitsushima thinks of the speed in arriving at the chemical equilibrium on dephosphorization, as seen in Table 4, Figs. 4 and 6 on page 175, but I think that also decarburization should be naturally considered as its simultaneous reaction. I want to know how much the degree of deviation from the equilibrium oxygen contents with decarburization or dephosphorization is. For instance, T. Kooz et ali. reported (ref. Stahl u. Eisen, 81 (1961), 1804, 1810) from their experiments of the refining Thomas pig iron by the 2 -ton top blowing test converter that oxygen contents in steel were higher than the value corresponding to the equilibrium value with carbon content, and were considerably lower than the value corresponding to the dephosphorization equilibrium, as seen in Figs. 1, 2 and 3 (ref. Tetsu-to-Hagané, 49 (1963), 12, 1827). Now, please explain the method of sampling and how do you think of its applicability?

\section{Mitsushima (Answer)}

Sampling in the single slag method is done, when the blowing is stopped before tapping, from only one place in the vessel by the spoon; the same method is used in the open hearth furnace. So it is not clear in this investigation how the oxygen content in steel in rela-

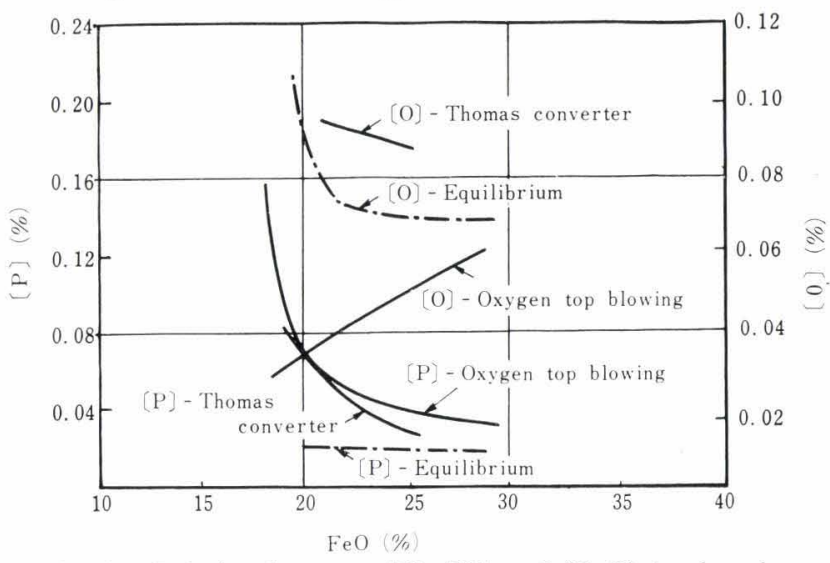

Fig. 1. Relation between $[\mathrm{P}],[\mathrm{O}]$ and $(\mathrm{FeO})$ in the slag in various oxygen steelmaking methods

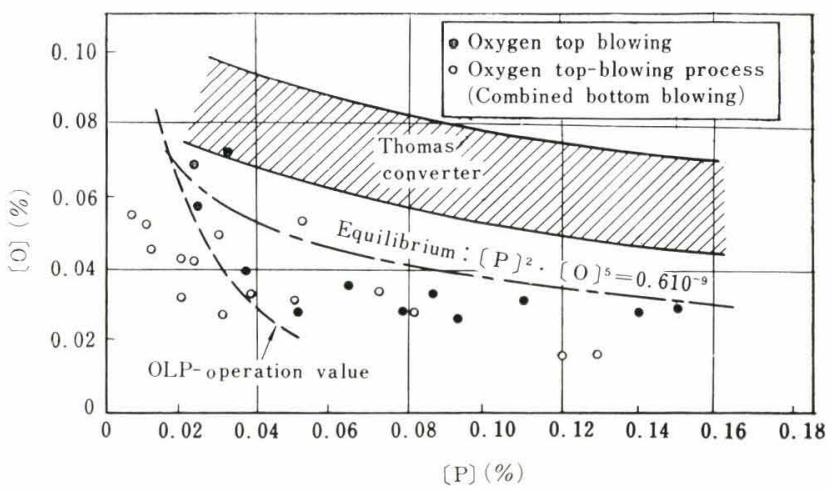

Fig. 2. Relation between $[\mathrm{P}]$ and $[\mathrm{O}]$ in the $\mathrm{LD}$ process and Thomas converter

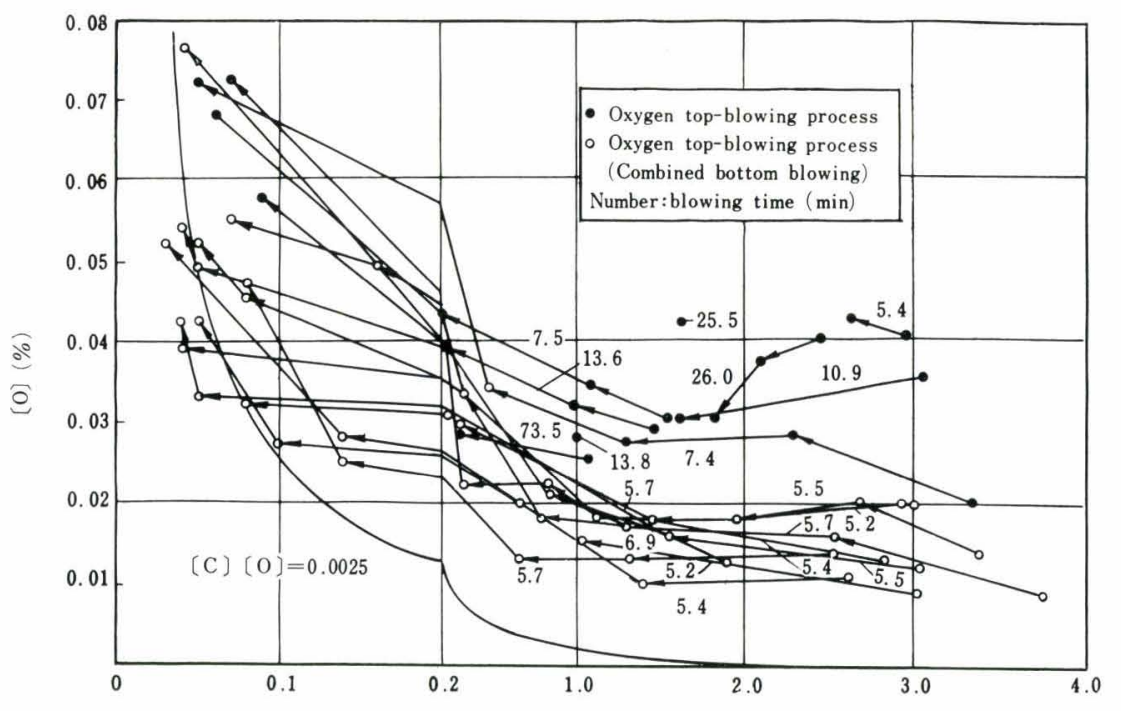

(C) $(\%)$
Fig. 3 .

Relation between $[\mathrm{O}]$ and $[\mathrm{C}]$ in oxygen top-blowing process and its combination process with bottom blowing 
tion to dephosphorization and to decarburization changes in terms of the blowing. But generally speaking, in the LD process, slag-formation is performed in such an early period that dephosphorization reaction progresses from the beginning of the blowing and approaches to the equilibrium value with the increase of the oxygen activity in the slag. It is generally considered that oxygen activity is controlled by the relation between the speed of oxidizing slag and the decarburizing speed. But in the LD process, the oxygen absorption from the surface of slag is accelerated by the stirring of slag and metal owing to oxygen jet, and moreover the oxygen absorption owing to surface reaction between gas and metal is performed by jet current. Consequently, it is considered that there is no deviation of oxygen in steel from the equilibrium value of dephosphorization and decarburization reactions. Samples are prepared by casting into a metal mold for analysis as seen in the daily operation.

As dephosphorization equilibrium is calculated in relation to $\mathrm{FeO}$ in the slag, it is considered there is no influence of sampling method on this equilibrium relation.

\section{Tasuku Fuwa Question to Mr. Itaoka)}

Not only from the equilibrium study in the laboratory but also from the operation at the steel plant, it has been disclosed that higher iron oxide, higher slag basicity and lower temperature are favorable for dephosphorization. For instance, Fig. 4 shows the effects of slag $\mathrm{FeO}$ and slag lime-silica rate on residual phosphor in steel at $1,600^{\circ} \mathrm{C}$ that was calculated from the Winkler and Chipman's data. And Fig. 5 shows the equilibrium relation between carbon, oxygen and phosphor in liquid metal, and the effect of the temperature on these relationship, obtained by Matoba and Ban-ya. The ranges of carbon and phosphor in steel at the end of the blowing in the LD and Thomas processes are shown with the marks "A" and "B" in Fig. 6, which shows the equilibrium between carbon and phosphor in liquid metal, obtained by Matoba and Ban-ya. The straight lines in the figure show roughly the directions of changes of compositions during blowing.

I was much interested to hear from you how to apply these three principles for phosphor-elimination to the LD process, in which the rate of chemical reactions was very fast and the temperature was easily apt to rise.

According to your speech, the metal bath at the end of the blowing seems to be close to the equilibrium. Therefore, if the temperature is raised, re-phosphorization will take place. In order to rise a tapping temperature rapidly, you added ferro-silicon to the bath at the end of the blowing, avoiding re-phosphorization caused by holding the metal bath at a high temperature. In the heat for high carbon steel, decarburization in the high carbon range takes place so easily that various special methods are necessary to facilitate early dephosphorization prior to the carbon drop,-by the

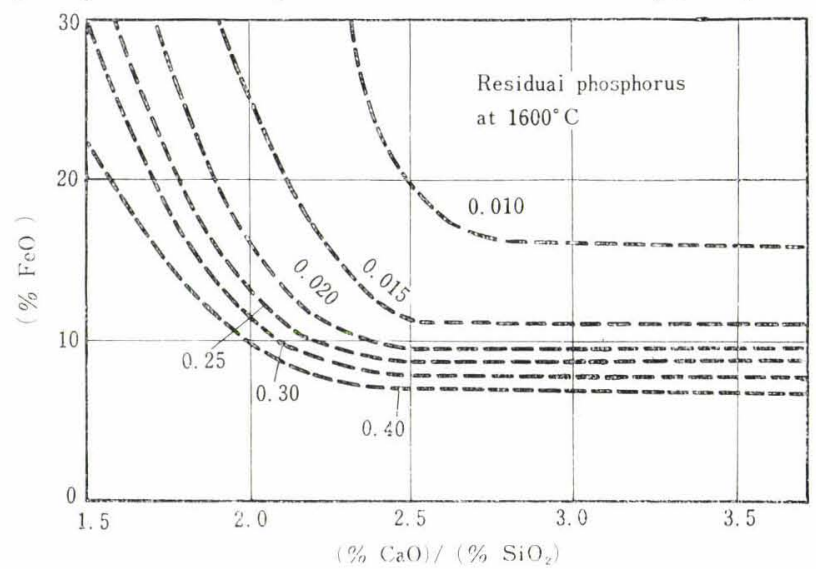

Fig. 4. Residual phosphor at $1,600^{\circ} \mathrm{C}$. (Basic open hearth steelmaking)

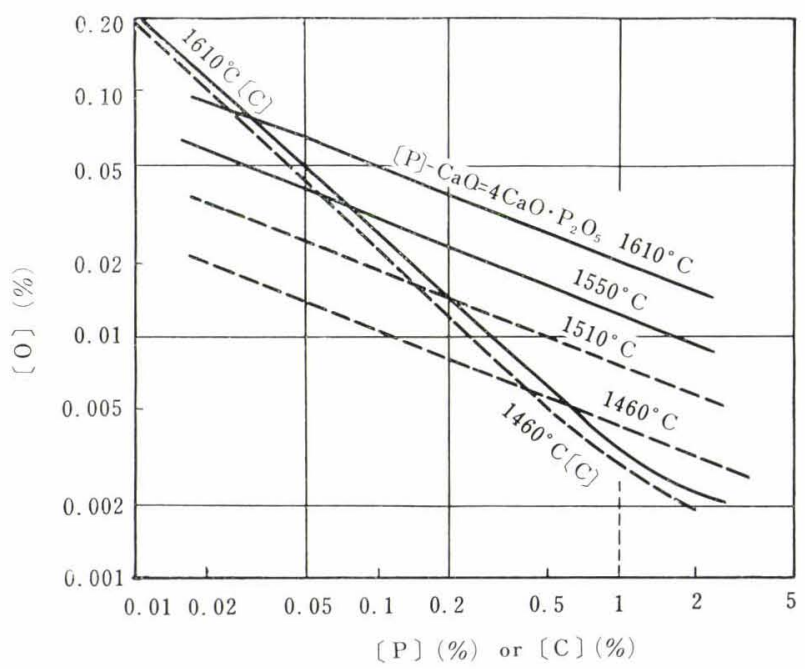

Fig. 5. Comparison of deoxidation power. (S. Ban-ya and S. Matoba)

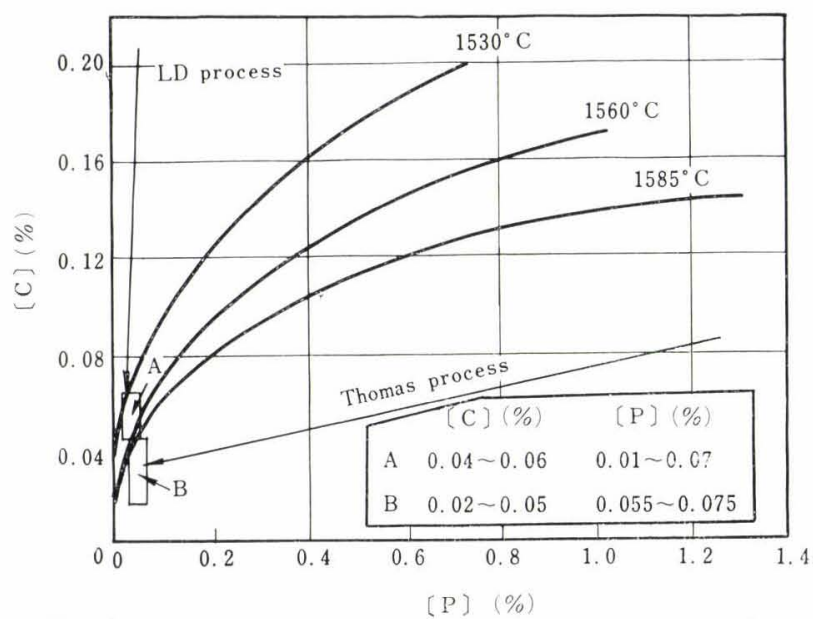

Fig. 6. Relation between $[\mathrm{C}]$ and $[\mathrm{P}]$. (S. Ban-ya and S. Matoba) 
rapid dissolution of lime, or by early formation of a reactive slag, in which the $\mathrm{FeO}$ content is raised by the soft blowing, or by using a part of slag of the second blowing period in the double slag process as the starting slag for the first part of the subsequent heat.

The mechanism of decarburization can be ascertained by the reaction in the open hearth or by Larsen's experimental work and by the Darken's calculation. Namely, in the reaction that carbon reacts with oxygen in liquid metal and $\mathrm{CO}$ is produced, the chemical reaction is not considered as the rate controlling step, but the migration of the desolved oxygen to adjacent positions on the surface where the above mentioned reaction occurs, in other words, the diffusion of oxygen is considered to control the rate of the reaction in the high carbon range. And it is considered that the strong oxidation and the violent agitation of the bath by oxygen accelerate decarburization in the LD process. In case of decarburization, the reaction product $\mathrm{CO}$ can be easily removed from the reaction system, because $\mathrm{CO}$ has no solubility in molten steel, and does not react with slag. However, dephosphorization does not occur unless $\mathrm{P}_{2} \mathrm{O}_{5}$ reacts with free-lime in the slag, even if phosphor in molten steel is oxidized to the state of $\mathrm{P}_{2} \mathrm{O}_{5}$.

I understood that single slag or double slag method was applied as the case may be in the heat for high carbon steel, as you show in Table 2. I guess that the operation has been standardized based on your understanding of the mechanism of dephosphorization. The data in connection with dephosphorization in the open hearth and also in the LD process used

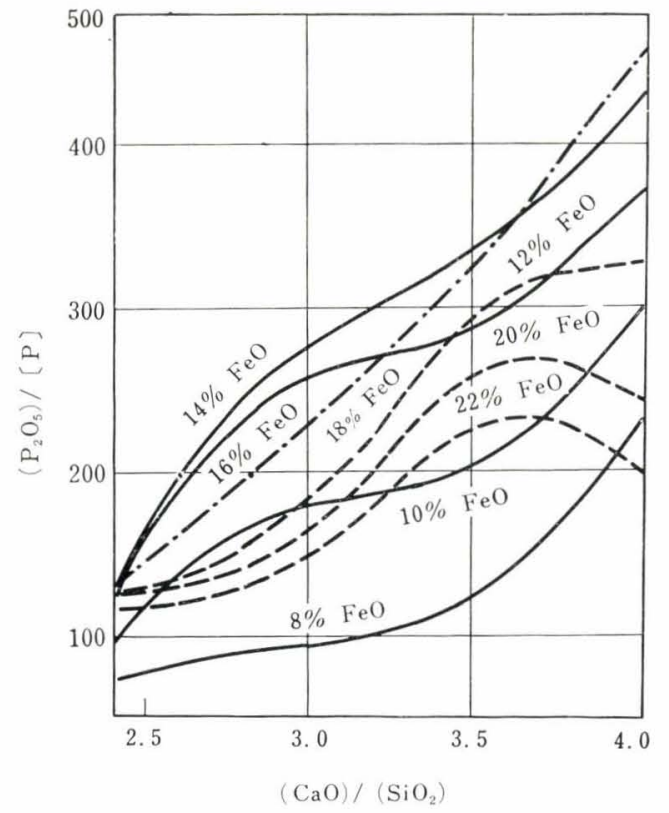

Fig. 7. Relation between $(\mathrm{CaO}) /\left(\mathrm{SiO}_{2}\right)$ and $\left(\mathrm{P}_{2} \mathrm{O}_{5}\right) /[\mathrm{P}]$. (Balajiva, Quarrell \& Vajragupta) to be plotted against lime-silica rate, or FeO content or total Fe content in the slag.

Balajiva, Quarrell and Vajragupta showed the most adequate FeO content in the slag to dephosphorization, as shown in Fig. 7.

I would like to ask your opinion why you apply the "soft blowing" at the beginning of the process? Do you think that $\mathrm{FeO}$ in the slag, raised by soft blowing, plays differently the role for dephosphorization in the LD process from that in the open hearth process? Or is "soft blowing" just to help the rapid dissolution of lime by increasing $\mathrm{FeO}$ content to form slag? Or do you take into consideration $\mathrm{FeO}$ content in slag instead of oxygen content in steel because of the difficulty to determine it?

And also I would like to ask you, related to standardization of the operation: Which of the following reactions did you think as the rate controlling step for dephosphorizing? In other words, I would like to know your opinion on the correlation between decarburization and dephosphorization.

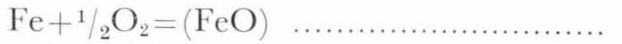

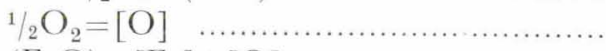

$$
\begin{aligned}
& (\mathrm{FeO})=[\mathrm{Fe}]+[\mathrm{O}] \quad \ldots \ldots \ldots \ldots \ldots \ldots \ldots . . . . . . . . . \\
& 2[\mathrm{P}]+5[\mathrm{O}]=\left(\mathrm{P}_{2} \mathrm{O}_{5}\right) \ldots \ldots \ldots \ldots \ldots \ldots \ldots \ldots \ldots \ldots \ldots \ldots \\
& 2[\mathrm{P}]+5(\mathrm{FeO})=\left(\mathrm{P}_{2} \mathrm{O}_{5}\right)+5[\mathrm{Fe}] \\
& \left(\mathrm{P}_{2} \mathrm{O}_{5}\right)+4(\mathrm{CaO})=4 \mathrm{CaO} \cdot \mathrm{P}_{2} \mathrm{O}_{5}
\end{aligned}
$$

\section{Itaoka (Answer)}

For our part, the basic research on the difference between the LD process and the open hearth furnace on dephosphorization mechanism or on the function of slag, or on how to improve the dephosphorization reaction is now left to be studied. So we cannot answer your questions definitely, but at the present, we are investigating these points experimentally or operationally. So I will speak on the influences of the blowing methods upon the speed of decarburization and dephosphorization, from the operational data. We compare the two blowing conditions in which the volume of injected oxygen is the same in the two cases and impact oxygen pressure is varied. Varying the impact oxygen pressure, while keeping the oxygen flow rate constant, is possible by changing either the nozzle diameter or the lance height. When the impact oxygen pressure is increased by varying either the nozzle diameter or the lance height, agitation of the bath naturally becomes stronger and consequently $\mathrm{CO}$ gas bubbling becomes easier and the efficiency of oxygen is increased, and the speed of decarburization is also promoted. It is said that the higher the total $\mathrm{Fe}$ in the slag and the more violent the agitation of the bath, the greater the speed of dephosphorization.

So the dephosphorization reaction is influenced by both the total Fe in the slag and the degree of agitation 
of the bath. Judging from the results obtained from the operational data, the relative speed of dephosphorization is high in soft blowing conditions, that is to say, the relative speed between decarburization and dephosphorization is important in discussing the dephosphorization reaction. The efficiency of dephosphorization can be improved when the speed of dephosphorization is promoted and the speed of decarburization is restrained. These relations are shown in Figs. 8 and 9. In Fig. 8, the relative speed between decarburization and dephosphorization is investigated by varying the oxygen pressure, extending the oxygen jet to the bath, at the second half of the blowing, and keeping the lance height constant at $1.2 \mathrm{~m}$.

It is shown in this result that when agitation of the bath is promoted by increasing the penetration of the oxygen jet (in case of $8 \mathrm{~kg} / \mathrm{cm}^{2}$ ), both dephosphorization and decarburization are promoted, the degree of each being much higher in decarburization. Fig. 9 shows the comparison between the soft blow when the lance height is raised and the oxygen supply is increased by increasing the oxygen pressure, and the hard blow when the oxygen supply is lowered. It is recognized in this figure that there is almost no difference in the speed of decarburization, while the speed of dephosphorization is improved in the soft blowing method.

Judging from the results and from the level of the present blowing techniques, it is considered effective for dephosphorization in melting high carbon steel to have the penetration of oxygen jet to the bath restrained by soft blowing and to have the removal of the supplied oxygen to slag promoted. But these results are only obtained from the daily operation, and the relative changes of the speed of dephosphorization

\begin{tabular}{c|c|c|c|c|c|c}
\hline $\begin{array}{c}\text { Blowing } \\
\text { press. } \\
\left(\mathrm{kg} / \mathrm{cm}^{2}\right)\end{array}$ & $\begin{array}{c}\text { Lance } \\
\text { height } \\
(\mathrm{m})\end{array}$ & $\begin{array}{c}\mathrm{O}_{2} \text { blowing } \\
\text { velocity } \\
\left(\mathrm{Nm}^{3} / \mathrm{min}\right)\end{array}$ & $\begin{array}{c}\text { Blowing } \\
\text { method }\end{array}$ & $\begin{array}{c}\text { Mean } \\
\text { decarburi- } \\
\text { zation } \\
\text { velocity } \\
(\% / \mathrm{min})\end{array}$ & $\begin{array}{c}\text { Mean } \\
\text { dephosphor- } \\
\text { ization } \\
\text { velocity } \\
(\% / \mathrm{min})\end{array}$ \\
\hline- & 4 & 1.2 & 58 & Soft blow & $5.7 \times 10^{-2}$ & $4.5 \times 10^{-3}$ \\
\hline$\ldots$ & 8 & 1.2 & 115 & Hard blow & $15.1 \times 10^{-2}$ & $5.7 \times 10^{-3}$ \\
\hline
\end{tabular}

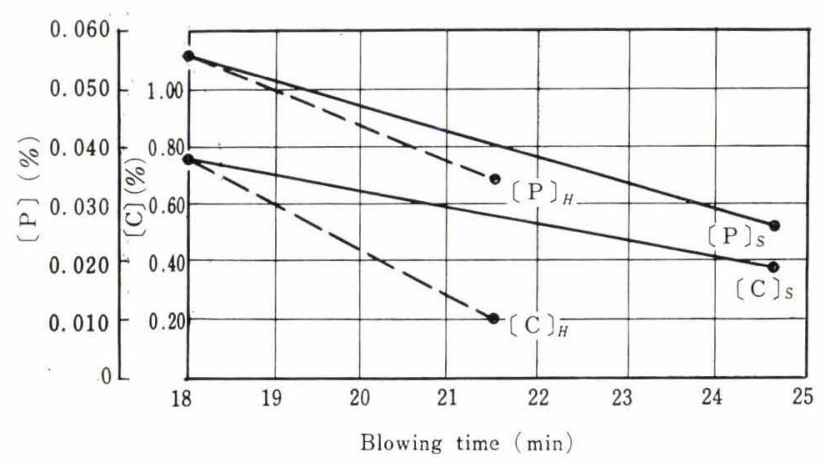

Fig. 8. Influence of blowing pressure on decarburization and dephosphorization during the blowing are not yet clarified. So we must make an effort from now on to study these points as the basic research on the blowing reaction.

\section{ON THE QUALITY OF OXYGEN CONVERTER STEEL}

\section{Kōkichi Sano (Question to Mr. Nakatani)}

It is most important in studying nonmetallic inclusions to clarify first of all the origin and structures of nonmetallic inclusions in steel and then to adopt a proper counterplan according to the results. A great many investigations on the origin and formation of sand marks have been made, but these points have not yet been clarified. Tentatively providing that a sand mark is a sort of inclusion which is detectable by the naked eye, some experimental results show that these substances can exist in a molten steel neither in the bath nor in the ladle, and this phenomena can be estimated by the Stokes' Law. It is thought, therefore, that sand marks in steel may be formed either when molten steel is poured into a mold, or when molten steel is solidifying, that is to say, one case is that refractories, slag or the oxide film which is made when molten steel contacts with the air, is poured into the mold with molten steel, the other case is that inclusions in steel are formed into sand marks owing to concentration, segregation or precipitation which occurs during the solidification of molten steel. The occurrences of the said two cases may be mainly influenced by pouring conditions. And the sand marks in steel are also influenced by rolling conditions, as far as the
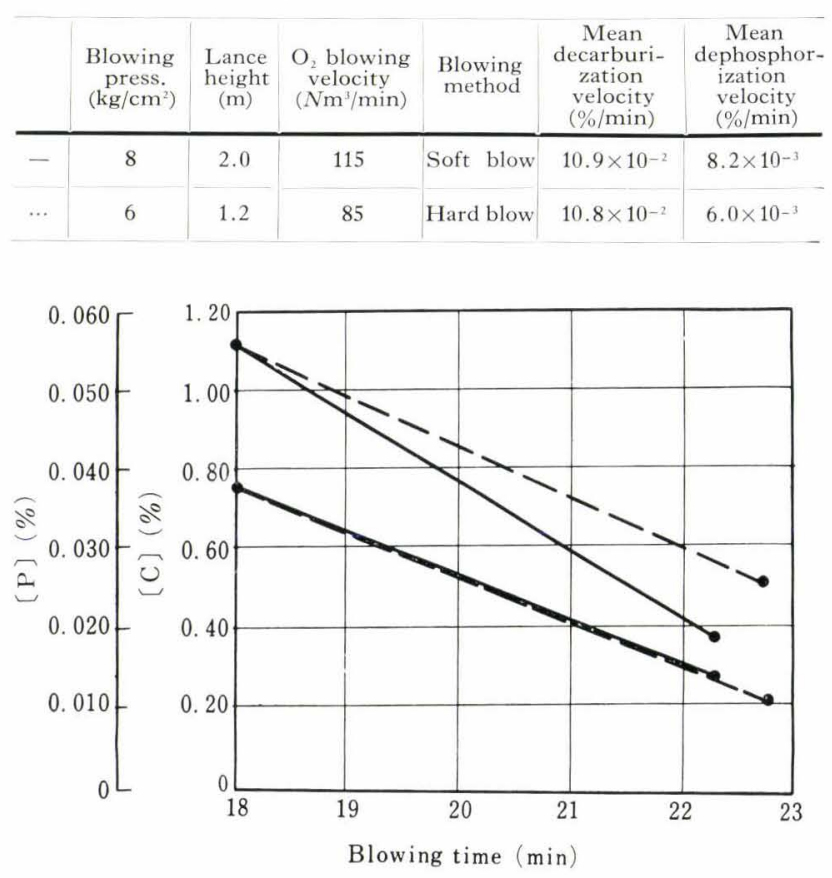

Fig. 9. Influence of lance height on decarburization and dephosphorization 
present detecting method is applied.

Mr. Nakatani reported that the sand values of converter steel were better than those of open hearth furnace steel or electric furnace steel. Providing that these values are compared on the same pouring conditions, especially on the pouring temperature, the ingot size or the reduction rate etc., what sort of different characteristics can be considered among converter steel, open hearth furnace steel and electric furnace steel?

\section{Nakatani Answer}

As Prof. Sano mentioned, the problems of sand marks should be discussed in reference to pouring conditions and reduction rate etc., and it is very difficult to investigate the origin of sand marks from the operational data. As converter steel and electric furnace steel, mentioned in my lecture, are produced in different shops, the conditions, especially the pouring conditions and refractories are not identified between these two shops. Therefore, we cannot clarify the reasons for the difference in the said two kinds of steel. But as far as our present study is concerned, the followings are considered as one of the reasons: the size of converter steel is larger than that of electric furnace steel, and the reduction rate in that is larger than in this. And as for the difference in refining conditions, we consider as follows: in the case of the converter, raw materials with good quality are generally used and the stirring of the bath during the blowing is as good as in electric furnaces, because we are adopting such blowing conditions as to enable sufficient boiling, preventing extremely low pressure blowing and the degree of oxidization of the bath or the slag at the end point of the converter process is lower than that at the end of the oxidizing refining period of the electric furnace. And furthermore, the mixing of metal and slag in the ladle while tapping is slight in the converter, because molten steel can be poured into the ladle completely divided from the slag.

The more detailed reasons are left for further investigations. But we expect to produce converter steel with as good quality as the electric furnace steel by controlling the pouring conditions.

\section{Tōru Araki Question to Mr. Nakatani)}

Considering that the proportion of impure materials from the raw materials is slight in the LD process, and the nitrogen content in steel is low, the followings are generally said in comparison with electric furnace steel of the same principal compositions, which is made from a large portion of commercial scrap:

(1) Hardenability and tempered hardness are lower in LD steel.

(2) After the same heat treatment, the strength is lower but ductility and toughness are greater.

(3) Plastic workability is a little better, but machinability is not always said so.
In your lecture, it is mentioned that the converter steel is better than the electric furnace steel in inclusions from both microscopic and macroscopic points of view, in addition to the above-mentioned characteristics. I should like to know if you consider these reasons to be the quality control of the end point temperature and the oxidizing power of metal and slag etc. It is considered that the relations between the austenite grain size and the aluminium consumption are different between oxygen converter steel and electric furnace steel, the latter usually containing more nitrogen than the former. I should like to know your opinion on this point, too.

\section{Nakatani Answer}

Many experimental investigations on the matter of inclusions have been made, but it is very difficult to study the above-mentioned reasons from the operational data. As far as our investigations are concerned, there is no difference in the tap temperature between converter steel and electric furnace steel, but in case of the converter process, carbon content in the bath is controlled so as not to be over-decarburized by the catch-carbon method, and we control FeO in the slag at the end point between 8 to $12 \%$ and oxygen content between 0.02 to $0.03 \%$ by preventing extremely soft blowing.

On the relations between the austenite grain size and aluminium consumption - in electric furnace steel, the weight of aluminium addition is lowered by adding titanium to improve brittleness because the nitrogen content is high in electric furnace steel and the method of addition of aluminium differs between the two processes: in case of the converter process, aluminium block is thrown into the ladle while tapping, whereas in case of the electric furnace process, aluminium rod is plunged into the ladle after having tapped. Therefore, owing to the difference of the titanium addition and to the method of aluminium addition, aluminium consumption of the electric furnace is lower than in that of the converter process, and the grain size of electric furnace steel is finer than that of converter steel inspite of lower content of soluble $\mathrm{Al}$, which is considered to be the effect of Ti addition. But in the same weight of $\mathrm{Ti}$ addition, we think that there is no difference between converter steel and electric furnace steel on the relations between soluble $\mathrm{Al}$ content and the grain size, so we are controlling the soluble $\mathrm{Al}$ in the same value between the two processes.

On hardenability of steel, there is little difference in quality of steel between the two processes, as far as the difference in chemical composition is counterbalanced, but the hardenability of converter steel, which contains a little amount of impurity elements such as Ni, Cr etc., is slightly lower in commercial use. But the low value of hardenability of converter 
steel can be easily compensated by applying certain methods.

\section{Yūshirō Fukao Question to Mr. Usui)}

It is shown in Mr. Usui's lecture that cleanliness of converter steel is remarkably better than any other commercial steels of the same kind. I should like to know the values of the grain size and cleanliness of converter steel, which is investigated in your works. The objective values of the electric furnace steel in our works are that the grain size, after heat treatment of $925^{\circ} \mathrm{C} \times 6 \mathrm{hr}$., is better than 7.0 to 8.0 , and the cleanliness value is 20 in the number of sand marks, 15 in total length $(\mathrm{mm}),(6)$ in the longest $(\mathrm{mm})$.

\section{Usui (Answer)}

The cleanliness of converter steel is already shown in Table 5 on page 182. The inspection of sand marks is done by the macrographic method and by the etching method with aqua regia on the samples prepared in accordance with the JIS method. Some sand marks are detected at the top of the ingots, but at the bottom of the ingot almost nothing is detected. The position, where they are detected, coincides with the position of the primary shrinkage cavity, which concerns with pouring conditions. From this point of view, it becomes necessary to study the degree of top cut of ingots.

The austenite grain size is intended to be fine in order to improve the impact value. The austenite grain size, being objected fine grain structure, is 7.6 in case of 0.55 carbon steel and 5.9 in case of 0.355 carbon steel. It is shown that the higher the carbon content, the finer the grain size.

\section{ON VARIOUS PROBLEMS OF THE OPERA- TION IN MELTING HIGH GARBON STEEL BY LD PROGESS}

\section{Kiyoshi Mizui (Question to Mr. Usui)}

In Mr. Usui's lecture, it is shown that the slope of the correlation between $\mathrm{P}$ in hot metal and $\mathrm{P}$ at the end point is gentler in the case of lance height $2,300 \mathrm{~mm}$ than in case of the lance height $2,000 \mathrm{~mm}$, and that there is little influence of $\mathrm{P}$ in hot metal on the end point $\mathrm{P}$ in the latter case. It is also said that these phenomena are the characteristic results of the method of elevating the lance height. But I think that the same results can be obtained also by the soft blow method, in which $\mathrm{FeO}$ in the slag is increased by lowering the oxygen pressure. The reason why the dephosphorization efficiency is improved by elevating the lance height is that the relation between $\mathrm{P}$ in hot metal and the end point $\mathrm{P}$ is changed by the increased slag volume, decreased $\mathrm{P}_{2} \mathrm{O}_{5}$ in the slag and the lowered level of $\mathrm{P}$ in the bath, which is caused by increased $\mathrm{FeO}$ in the slag. Fig. 9 on page 179 shows a case of $3,200 . \mathrm{Nm}^{3} / \mathrm{hr}$, and I want to know what relation can be shown in the figure in the case of the lower oxygen pressure. In relation to the above question, I should like to know the following points, when comparing the method of elevating the lance height and the method of controlling $\mathrm{FeO}$ in the slag by lowering oxygen pressure:

(1) Aren't there any disadvantages in operation, such as the metallic yield being lowered owing to occurrence of slopping, and the fluctuation of tap temperature increased, owing to an elevation of the lance height, although these differ according to the inner volume of the vessels?

(2) Show me the operational data when re-phosphorization is decreased in case of elevating the lance height, and what do you think the reasons thereof are?

\section{Usui Answer}

In the method of the soft blowing, we are adopting various processes: the oxygen pressure is lowered to $4 \mathrm{~kg} / \mathrm{cm}^{2}$ from $15 \mathrm{~min}$. after the start, and to 3.2 $\mathrm{kg} / \mathrm{cm}^{2}$ from $10 \mathrm{~min}$., and kept $4 \mathrm{~kg} / \mathrm{cm}^{2}$ throughout. It is found that $\mathrm{FeO}$ in the slag can be increased similarly by the two methods: one is to elevate the lance height and the other is to decrease the oxygen pressure. But when the oxygen pressure is lowered so as to correspond to the case of the lance height of 2.0 to $2.3 \mathrm{~m}$, the blowing time is prolonged by 30 to $40 \%$, and the agitation of the bath becomes insufficient because of the decreased gas volume caused by oxidizing reaction, and slag swells so much as to overflow from the mouth of the vessel. This causes disadvantages in operation at the present inner volume of the vessel of our works. On the other hand, the method of elevating the lance height and keeping the oxygen flow rate constant, is the most suitable to the conditions in our works from the viewpoint of operational efficiency, even if it increases the occurrence of slopping. Table 2 on page 180 shows an operational data of $0.55 \%$ carbon steel, and that the higher the oxidizing power, the lower the metallic yield, which of course includes the iron loss in the slopping slag and in the final slag.

It has been found by our experiments, as Mr. Itaoka mentioned, that the degree of re-phosphorization is influenced by the end point $\mathrm{P}$ and by the end point temperature: the negative correlation between rephosphorization and the end point $\mathrm{P}$, the positive correlation between re-phosphorization and the end point temperature. The degree of re-phosphorization after tilting the vessel, comparing with the first and the second samples, is stably kept within $\pm 0.002 \%$ in case of elevating the lance height, while in the case of lowering the oxygen pressure the fluctuation of the end point $\mathrm{P}$ is great and the degree of re-phosphorization sometimes gets up to $0.010 \%$. This is partly because chemical composition at every part of the vessel is unhomogeneous owing to insufficient agitation of the bath. 


\section{Kazuo Wakabayashi Question to Mr. Usui)}

I am highly appreciative of your having accomplished the techniques of blowing high carbon steel, especially on the matter of dephosphorization, under the individual working conditions for a short time. I think that the important things in every steelmaking process are how to obtain the proper bath temperature, required in refining, how to make suitable slag and how to mix slag and metal sufficiently. It is considered, therefore, that the various steelmaking processes have been invented in order to solve these problems. When we investigate the dephosphorization in blowing high carbon steel, a problem of slag-formation is a matter of importance to be mainly discussed, because problems concerning the bath temperature and the agitation of the bath have been easily solved in the LD process. From this point of view, we are adopting the following methods in blowing comparatively high carbon steel: when $\mathrm{P}$ in hot metal is about $0.20 \%$ and $\mathrm{P}$ in products is admitted over $0.020 \%$, the single slag method is adopted without any problems, on the other hand, when $\mathrm{P}$ in products is required under $0.020 \%$, the double slag method is adopted to prevent re-phosphorization. The other reason for adopting the double slag method is that in order to keep $\mathrm{P}$ in products under $0.020 \%$ by the single slag method, higher basicity of slag and larger quantity of slag volume are more necessary than in the case of $\mathrm{P}$ in products being under $0.030 \%$, therefore we consider the double slag method to be better than the single slag method when producing high carbon steel which requires $\mathrm{P}$ less than $0.020 \%$.

The refining time in the LD process is so short that the slag-formation is apt to be imperfect, so various devices, such as the use of finer grain of lime, of a large quantity of fluorspar and scale or of the soft blowing method, have been adopted in blowing high carbon steel. But we, the Yawata Works, have a project of using multiple nozzle lance or the synthetic slag, which was developed in our works as slagformation material in low temperature, so as not to solely depend upon the LD-AC process. We have accomplished a method of producing "calusium ferrite" as one of the synthetic slags in operational scale and at as low a cost as producing burnt lime. We believe that blowing high carbon steel will be rather easy if we use the above-mentioned calusium ferrite, when using hot metal with low silicon content. These are the present status of blowing high carbon steel in our works.

I think that the operational conditions in Amagasaki Iron Works are being stabilized. It is mentioned that the $\mathrm{Fe}$ content in the slag increases with the elevation of the lance height and that the slag has high oxidizing power indifferent to the carbon content in the bath, even if of high carbon range, which I can well understand. However, considering the unhomogeneity of carbon in the vessel because of low oxygen pressure at the end point, and the reaction of the unhomogeneous metal and slag with high Fe content, what do you think about the probability of getting the target carbon, which is thought to be affected by unhomogeneity of the bath?

\section{Usui (Answer)}

On the unhomogeneity of chemical compositions in the bath-when tilting the vessel after having blown out, it can be seen that a large quantity of foaming slag flows out spontaneously, at the same time violent boiling occurs owing to the reaction between metal and slag. So we make it a rule to take some samples for chemical analysis after the boiling of the bath is settled. We have not investigated especially the homogeneity of the bath, but have investigated changes of chemical compositions of the bath by taking samples after a little interval after tilting the vessel. As a result, it can be seen that the changes in five minutes between the first samples and the second samples are $\mathrm{C} 0 \sim+0.01 \%, \mathrm{Mn}-0.02 \%, \mathrm{~S} \mathrm{0} \%, \mathrm{P}$ $\pm 0.002 \%$.

On getting the aimed chemical compositions-as seen in Table 2 in my lecture, at first, blowing is stopped when carbon in molten steel is by $0.05 \%$ under the middle value of the standard limits, and after receiving the results of chemical analysis at the end point from the Quant meter laboratory, the final chemical compositions are regulated both by adding alloys in the furnace or by adding coke in the ladle at tapping. Fig. 10 shows the variations of the end point carbon and

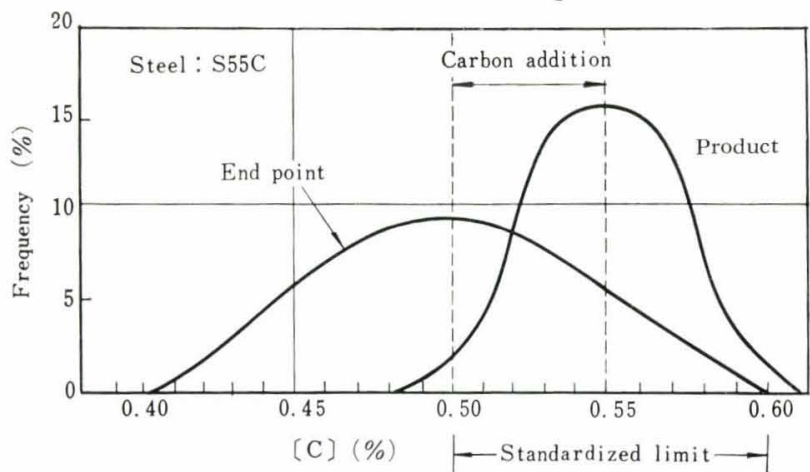

Fig. 10. Variation of $[\mathrm{C}](\%)$ at the end point and in product

carbon in products. It is shown that carbon analysis of products can be kept within the standard limits of the machine structual steel, the middle value $\pm 0.05 \%$. But in producing steel, more severe in allowable limits of chemical compositions, we must further investigate the homogeneity of chemical compositions in the vessel.

Keiichi Komoda Question to Mr. Mitsushima)

The lectures on the double slag method have just 
been announced. But in our Chiba Works, Kawasaki Steel Corporation, melting of high carbon steel by the LD process has not yet been in operation. However we, considering putting it into practice in the future, are trying some investigations on the double slag method and the relations between carbon/phosphor in molten metal and decarburization/dephosphorization.

Mr. Mitsushima explained that the primary deslagging in the double slag method should be done while the carbon content in the bath was as high as possible, because it was easy to secure the bath temperature required in the secondary blowing, and dephosphorization progressed well in the high carbon range. The results, obtained in the test blowing by a 150-ton converter in our works, are as follows. As seen in Fig. 11, which shows the change of $\mathrm{P}$ in molten metal during the blowing, it is shown that dephosphorization progresses best when decarburized weight is about $1.8 \%$. Fig. 12 shows that it is most effective in deslagging to convert the vessel as soon as the slag begins to foam. It is found that the beginning of the foaming occurs at from 8 to $10 \mathrm{~min}$. after

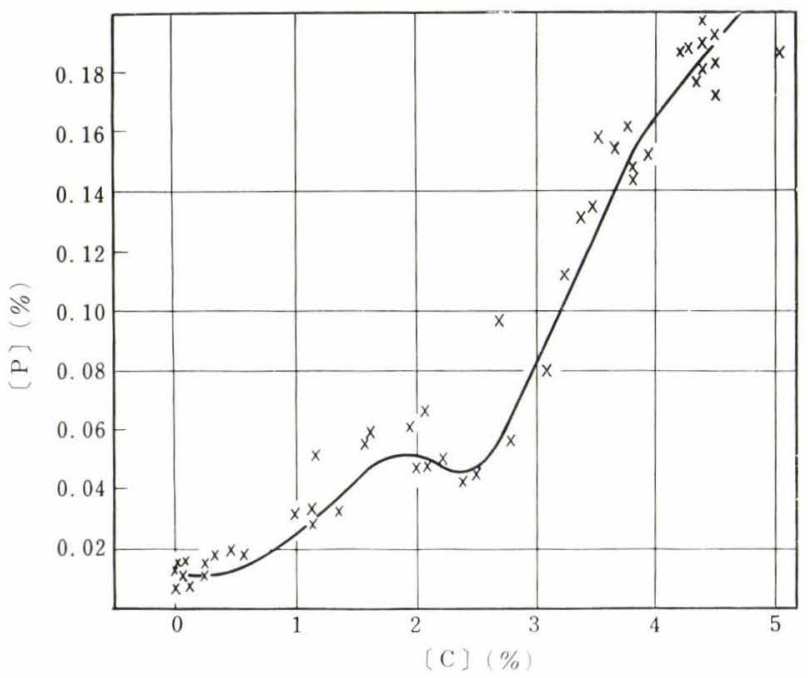

Fig. 11. Behavior of $[\mathrm{P}]$ as refered to $[\mathrm{C}]$ in a $150-\mathrm{t}$ converter

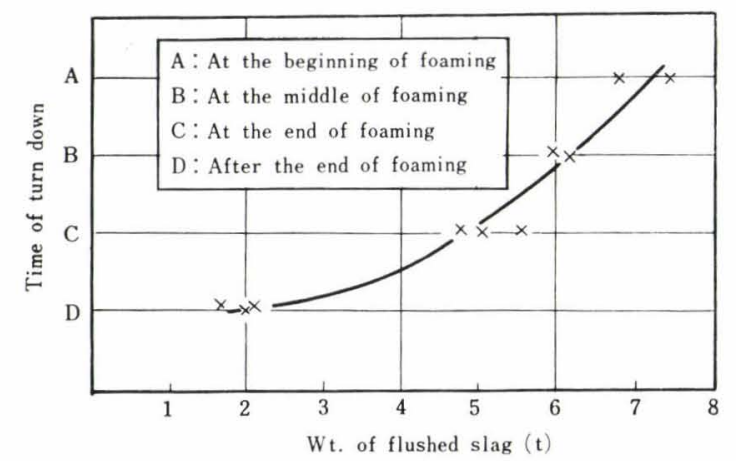

Fig. 12. Relation between weight of flushed slag and time of turn down the start of the blowing, and when decarburized weight being $1.8 \%$, therefore it is most effective to take off the first slag. But in the data of the Kobe Works, it is shown that a proper time to slag off in the double slag method corresponds to a time of decarburized weight being 0.7 to $0.9 \%$. I think these differences depend on the difference in blowing methods, hard blow or soft blow, and that in case of soft blow, the time of dephosphorization progressing well will drift to higher value of carbon content (see Fig. 11) than in case of hard blow. What do you think of the abovementioned opinion?

\section{Mitsushima (Answer)}

The most proper time to stop the first blowing varies according to the capacity of the furnace, species of steel, nature of raw materials and blowing methods. So far as our works are concerned, in melting high carbon steel by the double slag method, it is decided that the first blowing should be stopped with the carbon content as high as possible, for reasons as follows :

(1) To perform dephosphorization effectively in the first blowing.

(2) To secure time for slag-formation in the second blowing.

(3) To secure the objective tap temperature.

As seen in Fig. 13, dephosphorizationin in the first blowing does not progress so well as expected when decarburization is over $0.90 \%$, but is performed well as decarburization increases in the range of less than $0.70 \%$.

In conclusion, in melting high carbon steel by the double slag method, it may be most effective for the first blowing to be stopped when 0.70 to $0.90 \%$ of carbon in steel has been burnt, and the bath temperature is $1,350^{\circ}$ to $1,390^{\circ} \mathrm{C}$. It is considered that this period corresponds to 9 to $7 \mathrm{~min}$. after the blowing starts, and to the beginning or the middle period of foaming of slag. The easiness of slag-offing is influenced by the speed of converting the vessel and by the time when slagging materials are injected.

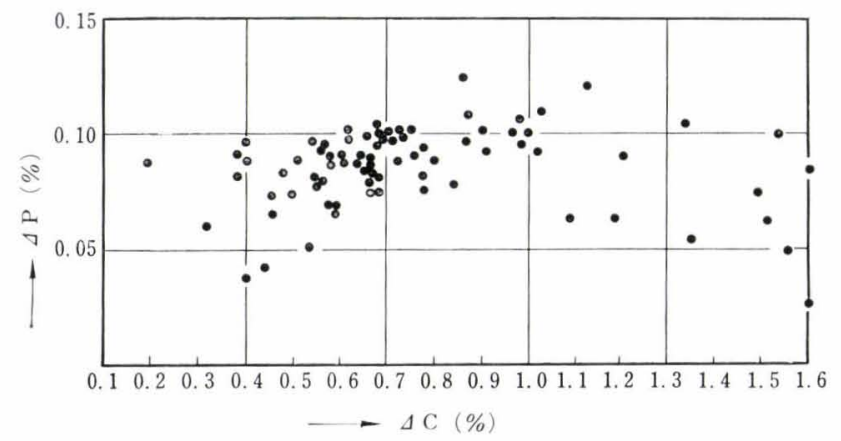

Fig. 13. Relation between $\triangle \mathrm{P}$ and $\triangle \mathrm{C}$ at the end point in 1 st blowing 


\section{Zensaku Yamamoto Question to Mr. Mitsu- shima)}

In our works, as well as Kawasaki Steel Corporation, melting of high carbon steel by the LD process is not in operation, but mainly low carbon steel and partially medium carbon steel of $0.20 \%$ of carbon. But we are now studying the technique of melting high carbon steel to put it into practice in the future. Every four lecturer mentioned a matter of dephosphorization, but I think there is another problem in actual operation on how to get the objective chemical compositions of steel. The single slag method is simpler in process and easier in applying the basic theory of metallurgical reaction to the operation than the double slag method. But we, actually operating the LD converter, think it a matter of importance, first of all, to establish a definite method of producing the objective steel stably at a low cost. We have tried the test blowing with an all hot metal charge, which may be most stable in the conditions of raw materials, to study the reaction, changes of the bath compositions and stability in melting high carbon steel.

As seen in the results of the test blowing in Fig. 14, there are no problems on dephosphorization when carbon content is $0.50 \%$, but it is seen that the carbon content at the same point fluctuates considerably, although the fluctuation decrease as carbon content in the bath decreases. I think, therefore, that in

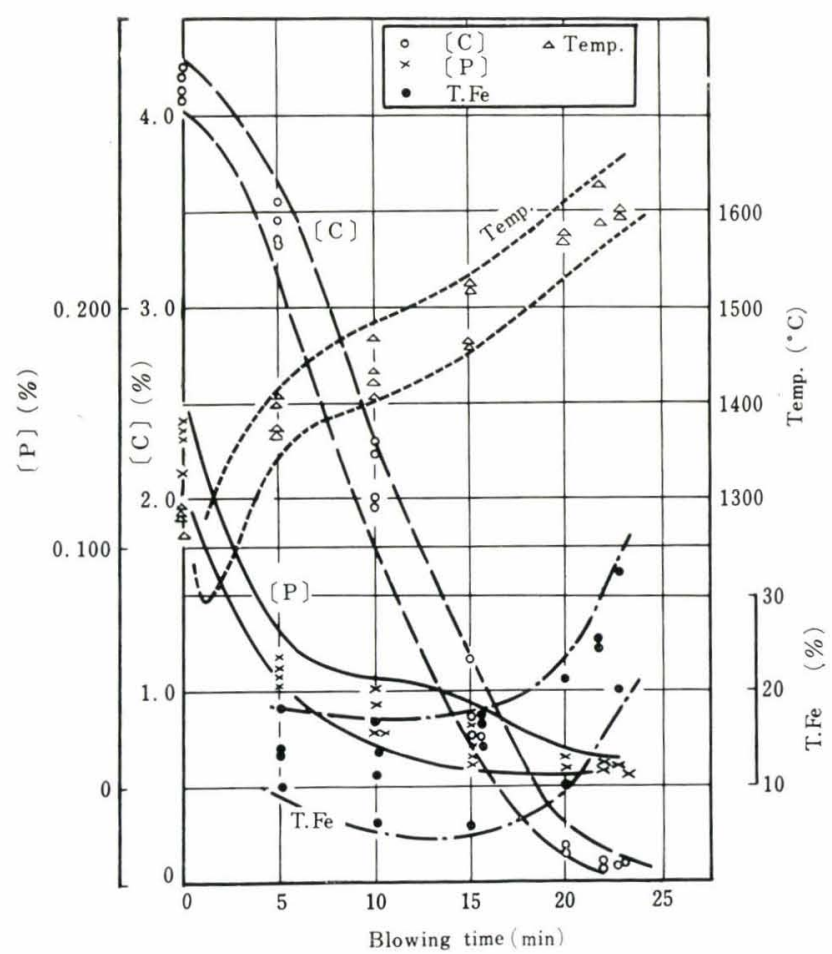

Fig. 14. Relation between bath conditions and blowing time. $\left(\mathrm{O}_{2}=12,000 \mathrm{Nm}^{3} / \mathrm{hr}, \mathrm{P} . \mathrm{R},=100 \%\right)$ melting high carbon steel by the single slag catchcarbon method, the problem of getting the target car bon content, i.e., the probability of catching the end point carbon within the limits of the standard is left still unsolved. I should like to know the way of decreasing the fluctuation of the end point carbon, which is adopted in your works.

\section{Mitsushima Answer)}

It is well-known that quality of steel and production efficiency depend upon success of deciding the end point of the blowing and catching the objective carbon content of steel. Nowadays, there are some works where fairly satisfactory results have been obtained on that point by the computer control method, but there are yet many works including our works where the end point is decided by the conventional method, that is to say, by judging the oxygen consumption, the condition of flame and the blowing time. The variation of the end point carbon in our works is shown in Fig. 15. It is shown that the target of

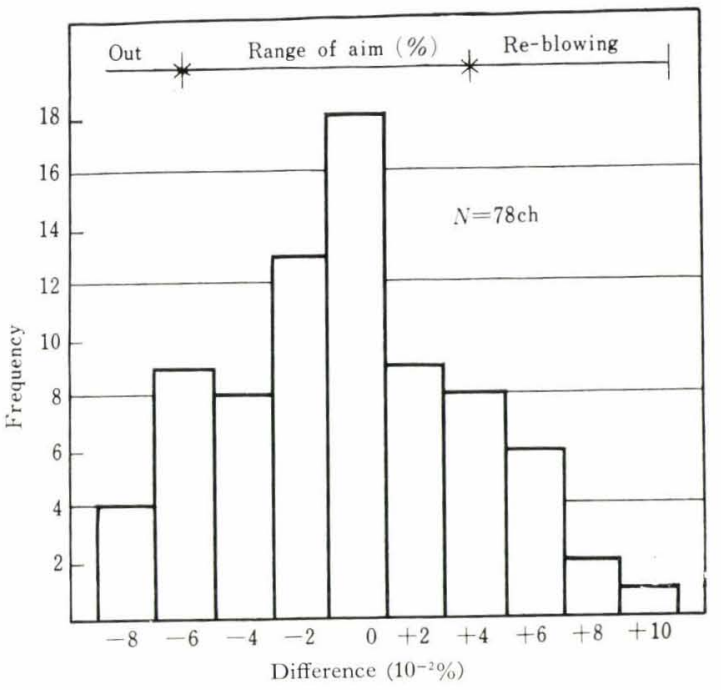

Fig. 15. Distribution of difference from target of carbon

the end point carbon is decided by $0.04 \%$ under the lower limit of the standard, and re-blowing is done in case the end point carbon is more than $0.04 \%$ over the target carbon content, and change of kind of steel in case the end point carbon is less than $0.06 \%$ under the target. Fig. 15 is the result of the recent operation.

On fluctuation of the end point carbon-we have investigated the relations between carbon contents in the bath and the oxygen consumption by stopping the blowing for sampling. The results are shown in Fig. 16. Carbon combustion weight in the figure means the value calculated by the formula: $\{$ (total charged carbon weight - the end point carbon $\%$ ) $\times$ weight of the bath\} and the solid line shows the calculated value provided that all applied oxygen is used in decarburization. In order to decrease the fluctuation of the end 


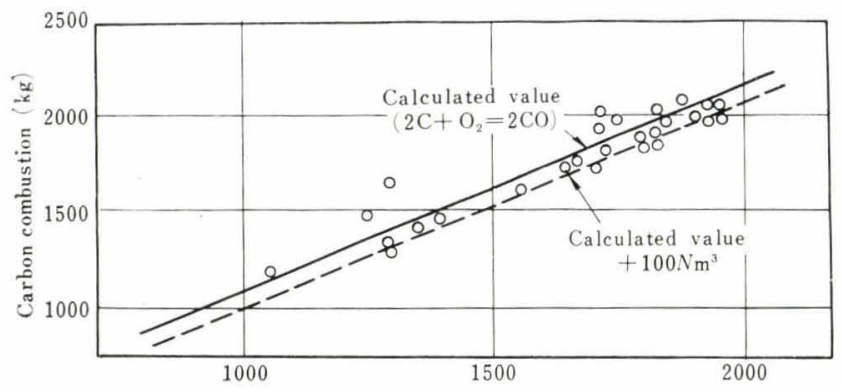

$\mathrm{O}_{2}$ flow $\left(\mathrm{Nm}^{3}\right)$

Fig. 16. Relation between carbon combustion weight in metal and $\mathrm{O}_{2}$ flow

point carbon, we try to make all conditions of steelmaking as constant and feasible as possible: the conditions of blowing, conditions of charged main raw materials, especially of scrap. So we are using mainly return scrap, of which compositions are clarified.

\section{Akira Matsunaga Question to Mr. Itaoka)}

Considering the discussions hitherto, it seems that the problems on melting high carbon steel are confined to a matter of dephosphorization, so I will ask from the viewpoint of actual operation. In your works, it is mentioned that the double slag method is adopted in case of the objective phosphor in steel less than $0.020 \%$. I should like to know, therefore, at what time of blowing the intermediate slag-off is decided to take place in your works. It is considered favorable in dephosphorization to slag-off at the early period as far as possible while the bath temperature is still low. According to our experiment, even if dephosphorization can be performed well by making foamy slag at the early period, the temperature of slag is so low that we have found it difficult to take slag off perfectly in the actual operation. It seems that it takes a fairly long time to slag-off in your works, so I should like to know the device of slag-off adopted in your works.

It is shown that the several kinds of operational standard are decided according to various preliminary conditions-phosphor in hot metal and tap temperature, etc. in the single slag method. But I think that there is not so significant a difference among these standards - the ferro-silicon heating-up method and the coke-addition method, considering the fluctuation of dephosphorization efficiency according to other conditions.

\section{Itaoka Answer)}

Table 1 shows the ways of making the first slag, adopted in our works, objecting to perform dephosphorization at the early period, the reasons of which are as follows:

(1) The reason for adopting the blowing conditions of oxygen pressure $7 \mathrm{~kg} / \mathrm{cm}^{2}$, the lance height $3 \mathrm{~m}$ is that we expect good effects of soft blowing by elevating the lance height with oxygen pressure being constant
Table 1. Operation standards of 1st blowing in the double slag method

\begin{tabular}{l|r|c|c}
\multicolumn{1}{c|}{ Fluxes $(\mathrm{kg} / \mathrm{t})$} & $\begin{array}{c}\text { Lance height } \\
(\mathrm{m})\end{array}$ & $\begin{array}{c}\mathrm{O}_{2} \text { press. } \\
\left(\mathrm{kg} / \mathrm{cm}^{2}\right)\end{array}$ \\
\hline Burnt lime & 40 & & \\
Slag of former charge & 40 & 3 & 7 \\
Scale & 6 & & \\
\end{tabular}

Table 2. Chemical composition of the bath at the end point of 1 st blowing

\begin{tabular}{c|c|c|c}
$\mathrm{C}$ & $\mathrm{Si}$ & $\mathrm{Mn}$ & $\mathrm{P}$ \\
\hline $2.0 \sim 3.0$ & $0 \sim 0.03$ & tr. $\sim 0.20$ & $0.020 \sim 0.040$
\end{tabular}

Table 3. Chemical composition of slag at the end point of 1 st blowing

\begin{tabular}{c|c|c|c|c|c}
\hline $\mathrm{CaO}$ & $\mathrm{SiO}_{2}$ & $\mathrm{~T} . \mathrm{Fe}$ & $\mathrm{MnO}$ & $\mathrm{MgO}$ & $\mathrm{P}_{2} \mathrm{O}_{5}$ \\
\hline $42 \sim 52$ & $10 \sim 15$ & $15 \sim 25$ & $4 \sim 7$ & $2 \sim 3$ & $2 \sim 3$ \\
\hline 1st end point temp.: & $1,380^{\circ} \sim 1,420^{\circ} \mathrm{C}$
\end{tabular}

in order to make foamy slag at the early period and to improve dephosphorization without lowering steelmaking efficiency.

(2) The reason for using a part of slag of the previous heat is that the formation of slag at the early period is easy and decrease of iron loss in slag can be expected.

Chemical compositions of the bath and slag at the end point are shown in Tables 2 and 3, the explanation of which is as follows:

(1) The reason for objecting the bath temperature of the end point of the first blowing $1,380^{\circ}$ to $1,420^{\circ} \mathrm{C}$ -it is generally considered that low temperature of the bath $\left(1,400^{\circ} \mathrm{C}\right)$ is rather favorable in dephosphorization judging from only the point of view of equilibrium in order to restrain the progress of decarburization, and in case of further low bath temperature, formation of foamy slag is apt to be imperfect and slagoff is not so easy.

(2) The reason why to object such bath compositions - it is seen that when decarburization further progresses and carbon content is lower than that of Table 1, occurrence of slopping becomes so violently that blowig operation becomes difficult. The blowing is continued till silicon content is decreased to trace, because dephosphorization is apt to be unsufficient when blowing is stopped with a little quantity of silicon left.

The method of slag-off is as follows. One third of total volume of slag is flowed out spontaneously after stopping the blowing, and time to slag-off is 3 to $4 \mathrm{~min}$. The rest of slag is taken off by the scrapping rod which is inserted through the shelter board. Thus it takes about $8 \mathrm{~min}$. to slag-off $90 \%$ of total slag.

Fig. 3 on page 184, being the data of low carbon steel, shows that the end point phosphor is influenced 
by the end point bath temperature. As the answer to the question whether or not there is significant difference of phosphor in steel between the normal method and the coke addition method, as seen in Fig. 10 on page 187, Table 4 is shown, which is the comparison of various methods. According to the result, we cannot find a significant difference between these methods by the T-approval of averages, because the number of data is insufficient.

Table 4. Comparison of ladle $[\mathrm{P}] \%$ in various methods

\begin{tabular}{l|c|c|c}
\hline & & $X$ & $\sigma$ \\
\hline 1 & $\begin{array}{c}\text { Catche-carbon } \\
\text { (Non-heating up) }\end{array}$ & 0.028 & 0.0034 \\
\cline { 2 - 3 } 2 & $\begin{array}{c}\text { Coke addition } \\
\text { (Non-heating up) } \\
\text { Non-heating up } \\
\text { (Coke addition) }\end{array}$ & 0.025 & 0.0038 \\
\hline $\begin{array}{c}\text { Fe-Si heating up } \\
\text { (Coke addition) }\end{array}$ & 0.025 & 0.0038 \\
\hline
\end{tabular}

In the actual operation, however, the heating-up method is adopted in melting high carbon steel which requires the high tap temperature, because the heatingup method is more profitable on dephosphorization than the normal method, especially when the end point temperature is high. The coke addition method is adopted when phosphor in hot metal is high and the end point carbon is decreased enough to promote dephosphorization.

\section{Shinkichi Koike Question to Mr. Itaoka)}

It is pointed in Fig. 3 on page 184 that degree of re-phosphorization is influenced by phosphor content in the bath and the bath temperature at the end point. It is also considered that re-phosphorization occurs to some degree owing to addition of deoxidizing ferroalloys, because $\left(3 \mathrm{CaO} \cdot \mathrm{P}_{2} \mathrm{O}_{5}\right)$ in slag becomes unstable and is dissolved by the addition of ferro-alloys. Of course, it is considered that phosphor in the bath may increase owing to phosphor contained in the ferroalloys, but its degree may be negligibly small.

I should like to know whether or not the degree of re-phosphorization is influenced by the following points besides the bath temperature, which is mentioned in your lecture:

(1) The rate of furnace addition and ladle addition of deoxidizing ferro-alloys.

(2) The basicity of slag and $\mathrm{MnO}, \mathrm{FeO}$ content in the slag at the end point.

(3) The difference of phosphor content in the slag between the single slag method and the double slag method.

(4) The influence of hardening slag by adding burnt lime before tapping.

(5) The difference of profile of the vessel or the ladle, especially from the point of the area of metal and slag contact surface.

\section{Itaoka Answer}

Concerning the influence of various conditions on re-phosphorization, we announced at the Grand Lecture Meeting of The Iron and Steel Institute of Japan, in spring, 1963. I will answer according to the papers. The regression analysis on the relation between degree of re-phosphorization $(\mathrm{P} \%$ in the ladle $-\mathrm{P} \%$ at the end point) and other steelmaking conditions, was made by means of the computer, IBM 7070, and the data used at the analysis were based on 100 charges of killed steel containing C 0.10 to $0.50 \%, \mathrm{P} 0.010$ to $0.040 \%$. The regression formula is shown in Table 5, from which the following points were clarified:

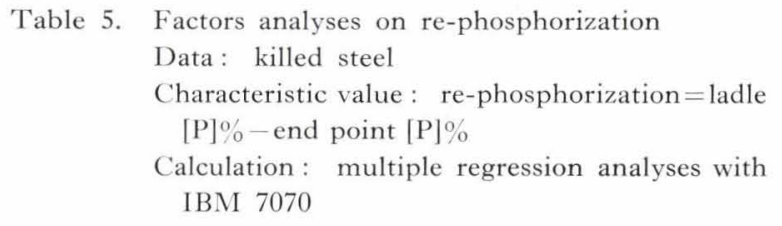
IBM 7070

\begin{tabular}{|c|c|c|c|}
\hline & Factors & Variables & $\begin{array}{c}\text { Re-phosphorization } \\
(\%)\end{array}$ \\
\hline Ferro-alloy & $\begin{array}{c}\mathrm{Fe}-\mathrm{Mn} \\
\text { (in the furnace) } \\
\mathrm{Fe}-\mathrm{Mn} \\
\text { (in the ladle) }\end{array}$ & $\begin{array}{l}100 \mathrm{~kg} / \mathrm{ch} \\
100 \mathrm{~kg} / \mathrm{ch}\end{array}$ & $\begin{array}{l}0.0011 \\
0.0008\end{array}$ \\
\hline Slag & $\begin{array}{l}\text { Basicity } \\
\left(\mathrm{CaO} / \mathrm{SiO}_{2}\right) \\
\mathrm{T} . \mathrm{Fe} \\
\mathrm{P}_{2} \mathrm{O}_{5}\end{array}$ & $\begin{array}{l}1 \% \\
1 \% \\
1 \%\end{array}$ & $\begin{array}{c}-0.0011 \\
-0.0006 \\
0.001\end{array}$ \\
\hline Notes & $\begin{array}{l}\text { Slag-hardening } \\
\text { lime } \\
\text { Shape of the } \\
\text { furnace and the } \\
\text { ladle }\end{array}$ & \multicolumn{2}{|c|}{$\begin{array}{l}\text { Without excessive re-phosphorization } \\
\text { With little effect }\end{array}$} \\
\hline \multicolumn{4}{|c|}{$\begin{array}{l}\text { Re-phosphorization formula: } \\
\text { Re-phosphorization percents }\left(\times 10^{3}\right) \\
=-78.20+5.738 \times 10^{-1} \times \text { hot metal }[\mathrm{P}] \%-1.346 \times 10^{-3} \times \text { burnt lime kg } \\
-3.878 \times 10^{-3} \mathrm{Fe} \text { ore } \mathrm{kg}+2.012 \times 10^{-4} \times \text { fluorspar } \mathrm{kg}+2.566 \times \text { end point } \\
{[\mathrm{C}] \%-5.436 \times 10^{-2} \text { end point }[\mathrm{P}] \%+6.356 \times 10^{-2} \times \text { end point temp. }+} \\
3.092 \times 10^{-1} \times \text { end point } \mathrm{O}_{2} \text { press. } \mathrm{kg} / \mathrm{cm}^{2}+1.131 \times 10^{-2} \times \mathrm{Fe}-\mathrm{Mn} \text { (in the } \\
\text { furnace) } \mathrm{kg}+8.291 \times 10^{-3} \times \mathrm{Fe}-\mathrm{Mn}\left(\mathrm{in} \text { the ladle) } \mathrm{kg}-6.865 \times 10^{-1} \times \mathrm{cam}-\right. \\
\text { paign coefficient* }+6.802 \times 10^{-2} \times \mathrm{Al} \text { (in the ladle) } \mathrm{kg}+1.121 \times\left(\mathrm{P}_{2} \mathrm{O}_{5}\right) \% \\
-5.822 \times 10^{-1} \times(\mathrm{T} \text {. Fe }) \%-1.121 \times \mathrm{CaO} / \mathrm{SiO}_{2}\end{array}$} \\
\hline
\end{tabular}

(1) The significant difference can be seen on the degree of re-phosphorization between furnace addition and ladle addition of ferro-alloys for deoxidizing: degree of re-phosphorization equivalent to furnace addition of $\mathrm{Fe}-\mathrm{Mn}$ is $0.0011 \% \mathrm{P} / 100 \mathrm{~kg}$ of $\mathrm{Fe}-\mathrm{Mn}$, and in case of ladle addition, $0.0008 \% \mathrm{P} / 100 \mathrm{~kg}$ of $\mathrm{Fe}-\mathrm{Mn}$. But the degree of re-phosphorization is influenced also by the killing time after the addition, and in case of furnace addition, the degree of re-phosphorization increased as killing time from the addition to tapping increases. The data, shown in Table 5, are that of the killing time being very short.

(2) Higher basicity $\left(\mathrm{CaO} / \mathrm{SiO}_{2}\right)$ and higher total $\mathrm{Fe}$ in slag have higher restraining power of re-phos- 
phorization, while $\mathrm{P}_{2} \mathrm{O}_{5}$ in slag has progressing effects, and no evidence on $\mathrm{MnO}$ in slag. Comparing the restraining power of re-phosphorization between total $\mathrm{Fe}$ and the basicity, $1.0 \%$ of basicity is equal to $2 \%$ of total $\mathrm{Fe}$, and decreases re-phosphorization by $0.0011 \%$.

(3) $\left(\mathrm{P}_{2} \mathrm{O}_{5}\right)$ in the slag influences re-phosphorization more than any other components in the slag, say $0.001 \% \mathrm{P} / 1.0 \%$ of $\left(\mathrm{P}_{2} \mathrm{O}_{5}\right)$. And $\left(\mathrm{P}_{2} \mathrm{O}_{5}\right)$ in the final slag in the double slag method is considerably lower than that in the single slag method, as seen in Table 6 , and it is considered that re-phosphorization from $\mathrm{P}_{2} \mathrm{O}_{5}$ in the slag is little in case of the double slag method, which is also seen in the actual operation.

Table 6. $\quad\left(\mathrm{P}_{2} \mathrm{O}_{5}\right)$ at the end point and re-phosphorization in the single slag and the double slag methods

\begin{tabular}{l|c|c|c}
\hline & $\left(\mathrm{P}_{2} \mathrm{O}_{5}\right)(\%)$ & Slag weight $(\mathrm{t})$ & $\begin{array}{c}\text { Re-phosphoriza- } \\
\text { tion }(\%)\end{array}$ \\
\hline Single slag & $2.5 \sim 2.7$ & $5.5 \sim 5.7$ & $0.003 \sim 0.004$ \\
\hline Double slag & $0.3 \sim 0.5$ & $5.0 \sim 5.5$ & None \\
\hline
\end{tabular}

(4) We have not systematically investigated the influence of using lime for hardening slag on re-phosphorization, so it is not numerically clarified, but it may well be considered from our experiment that the extreme fluctuation of degree of re-phosphorization can be lessened by using lime for the hardening of slag.

(5) As to the effect of the profile of the vessel-it has been recognized in our works that $(\mathrm{FeO})$ in the slag decreases as the furnace becomes old. It is considered, therefore, from this point of view that the tendency of re-phosphorization must decrease as the furnace becomes old. But the result of the analysis is contrary to that, the reason of which we can not understand. In any case, it is considered that there is not so evident an influence of the profile of the vessel in the actual operation, and we think the same things can be said on the shape of the ladle.

\section{-Discussion on Paper Shōzō Mitsushima Question to Mr. Itaoka)}

In the LD process, it is possible to produce low phosphor steel better than that of the basic open hearth furnace, even if the refining time is rather short; even the high carbon steel with low phosphor has been produced by this process. In melting high carbon steel, it is necessary that dephosphorization be completed at the end point and the bath temperature, required according to the pouring condition, be secured. It is considered, therefore, to be effective for dephosphorization at the early period that the bath tempera- ture be low and slag-formation be progressed at the early period and the stirring of metal and slag performed well. Otherwise it is necessary for the high oxygen pressure and high oxygen flow rate to stir the metal and slag well, which offer unfavorable conditions to dephosphorization consequently, because decarburization progresses rapidly owing to the high bath temperature caused by high oxygen pressure.

Which do you think is better the hard blowing method, in which stirring of metal and slag is put emphasis, or the soft-blowing method, in which higher oxidizing power of slag is emphasized?

\section{Itaoka Answer to Mr. Mitsushima)}

It is probable that the refining reactions, say dephosphorization and demanganization etc., are progressed by stirring the metal and slag well, if other refining conditions, such as temperature, total $\mathrm{Fe}$ and weight of slag etc., are unchanged, which has already been reported by Katō et ali.*

On the other hand, it is known that when the stirring is made violent, the relation of carbon-oxygen approaches to the equilibrium values and total $\mathrm{Fe}$ decreases because decarburization reaction progresses (see report presented at the International LD Conference, 1962 by Nippon Kokan Kabushiki Kaisha). Thus to make the stirring violent has an opposite effect on dephosphorization.

To compare the superiority of the soft blowing method and the hard blowing method is to compare these opposite effects of the stirring power on dephosphorization. So I will try to compare these two methods in the low carbon range and in the high carbon range, respectively, because there is an evident difference in the effect of the stirring on dephosphorization between low carbon and high carbon but total $\mathrm{Fe}$ in the slag considerably changes according to the carbon in the bath. In the high carbon range, clear difference of the effect of the stirring power on total Fe between hard blow and soft blow can be seen, that is to say, the effect of total Fe exceeds that of the stirring power, therefore on dephosphorization soft blow is better than hard blow.

Table 7 is an example of the results of the double slag method in our works. When the extreme soft blow, when the lance height is twice of the normal and oxygen pressure is lowered, is done, total $\mathrm{Fe}$ is 15 to $20 \%$ and phosphor in the bath is lowered to $0.030 \%$ from $0.180 \%$ of hot metal at the first end point, while in the case of normal hard blow, total $\mathrm{Fe}$ is less than $10 \%$ and phosphor is 0.070 to $0.100 \%$ at the same point. According to the results, it is seen that the soft blow is better than the hard blow when carbon

* T. Katō: "Promotion of Dephosphorization in the LD Converter", report presented at the International LD Conference in Tokyo in Nov. 1962. 
Table 7. Comparison between soft blow and hard blow

\begin{tabular}{|c|c|c|c|c|c|c|}
\hline & \multirow{2}{*}{ Lance height $(\mathrm{m})$} & \multirow{2}{*}{$\mathrm{O}_{2}$ blowing press. } & \multicolumn{4}{|c|}{ Bath and slag analysis } \\
\hline & & & Sampling & $\mathrm{C}$ & $\mathrm{P}$ & T. Fe \\
\hline Soft blow & 3.0 & 7.0 & $\begin{array}{l}\text { 1st end point } \\
\text { (double slag) }\end{array}$ & c. 2.50 & $0.020 \sim 0.040$ & $15 \sim 25$ \\
\hline Hard blow & 1.2 & 7.0 & $\begin{array}{l}\text { During blowing } \\
\text { (single slag) }\end{array}$ & c. 2.50 & $0.070 \sim 0.100$ & 10 under \\
\hline
\end{tabular}

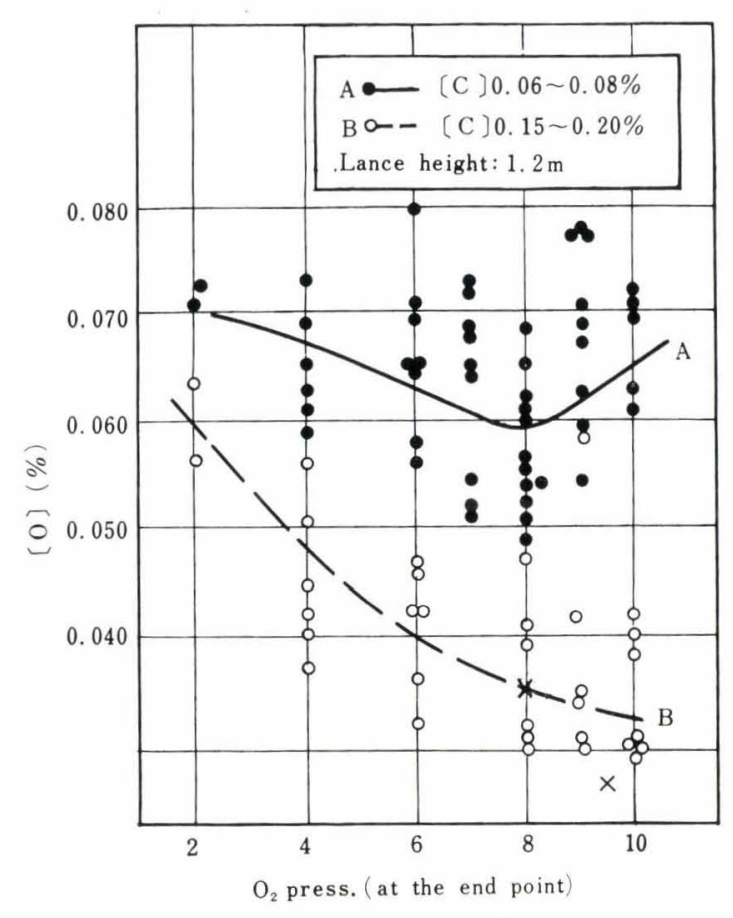

Fig. 17. Influence of the end point $\mathrm{O}_{2}$ pressure and the end point [C] on [O] $(\%)$ in the bath

is more than $0.2 \%$. While in the low carbon range, carbon less than $0.10 \%$, there is no evident difference on dephosphorization between the soft blow and the hard blow, because judging from carbon-oxygen equilibrium value, level of oxygen in steel is so high as is in total Fe in the slag, that the effect of the soft blow becomes unprominent (see Fig. 17). So in our works, oxygen pressure is unchanged regardless of the objective phosphor in steel in the case of low carbon steel melting.

\section{Motohiko Nakatani Question to Mr. Usui)}

Many investigations have been made on the relation between dephosphorization and the blowing conditions in the LD process. It is well-known that soft blow is favorable to dephosphorization and the method of elevating the lance height not lowering oxygen pressure is better than the method of lowering the oxygen pressure, one of the reasons of which is considered as the matter of stirring the bath. I think the blowing conditions in the Amagasaki Works are considerably soft compared to the normal blowing, which can be recognized from the fact that total $\mathrm{Fe}$ in the slag is
22 to $26 \%$ at the high carbon range, which is higher than that of the open hearth furnace. In those blowing condiitons, it is doubtful whether or not compositions in the bath are really homogeneous, especially in larger volume vessels. What do you think of that matter? It is considered that the bath is overoxidized when total $\mathrm{Fe}$ in the slag is high, so I should like to know what you think of the influence of such bath conditions on the quality of steel.

\section{Usui (Answer)}

A matter of homogeneity of the bath was already mentioned. We have not investigated the relations between over-oxidization and quality of steel, comparing with the normal blowing on oxygen content of the bath. But it is really considered that the oxygen distribution between slag and metal may considerably shift from the equilibrium value. As sampling at the end point is taken when the boiling of the bath is settled after converting the vessel, I do not think that oxygen in steel is expressly high in the high carbon range. This can be understood from the fact that the yield of $\mathrm{Fe}-\mathrm{Mn}$, added in the furnace, is about $80 \%$, in the case of $\mathrm{C} 0.20 \%$ steel, and about $95 \%$, in the case of high carbon steel. Therefore we do not think its influence on quality of steel so seriously.

\section{Hiroharu Usui Question to Mr. Nakatani)}

You investigated the correlation between the end point carbon and tap temperature which are the factors in controlling the dephosphorization rate. I think that these mainly influence dephosphorization, but it is premature to conclude from the correlation formula, which results from the statistical calculation, that the the condition of keeping phosphor in product under $0.030 \%$ is only that phosphor in hot metal is to be less than $0.200 \%$, because a correlation formula means an average value which is a medium value of some ranges, therefore we must consider the variation. What do you think of that point?

\section{Nakatani (Answer)}

As you mentioned, the variation must be taken into account when we consult with the correlation formula. We now considered the end point carbon and tap temperature in various conditions affecting the dephosphorization efficiency. We think it is necessary to study the other conditions. The analysis was made on the highest value of the end point carbon and on the highest value of the tap temperature in 
the actual conditions. So we think it is possible to refine hot metal of up to $0.200 \%$ phosphor. It might be considered that there be the case of missing the objective phosphor limits, when the worst conditions are piled up. But it is rare in the actual operation. In fact there have never been problems for such a thing.

\section{Itaoka Question to Mr. Nakatani)}

In the Kokura Works, a large quantity of fluorspar is used to lower the end point phosphor in the single slag method. In our works, as fluorspar consumption increases, the furnace refractory and ladle refractory consumptions are apt to increase as follows:

$\begin{array}{lll}\text { Fluorspar consumption } & 4.0 \mathrm{~kg} / \mathrm{t} & 5.0 \mathrm{~kg} / \mathrm{t} \\ \text { Ladle refractory } & 3.4 & 4.0 \\ \text { Dolomite consumption } & 6.9 & 7.5\end{array}$

Is there such a tendency in our works?

As seen in Table 3 on page 168, in your works, a considerable degree of dephosphorization has been attained by lowering the end point phosphor to $0.011 \%$, but in our works, as the end point phosphor decreases, the degree of re-phosphorization is apt to increase, as seen in Table 9. To lower the degree of re-phosphorization, we settle the lowest point of the ore consumption, say $500 \mathrm{~kg}$, calculating from statistical analysis. How much is the objective end point phosphor in your works? What sort of device do you adopt to restrain re-phosphorization?

Table 8. An example of re-phosphorization at the Kokura Works of Sumitomo Metal

\begin{tabular}{l|c|c|c|c|c} 
& $\mathrm{C}$ & $\mathrm{Si}$ & $\mathrm{Mn}$ & $\mathrm{P}$ & $\mathrm{S}$ \\
\hline Hot metal & 4.28 & 0.65 & - & 0.190 & 0.044 \\
End point & 0.42 & - & 0.25 & 0.011 & 0.016 \\
Ladle & 0.48 & 0.25 & 0.76 & 0.021 & 0.016 \\
\hline
\end{tabular}

Table 9. Effect of end point $[\mathrm{P}] \%$ and Fe ore consumption on re-phosphorization

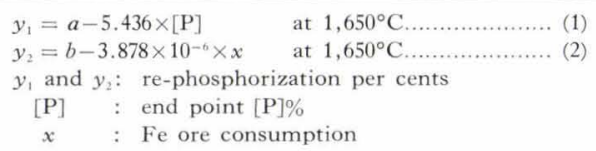

\section{Nakatani (Answer)}

In our works, in order to make slag of burnt lime at the early period and to make dephosphorization stable, a large quantity of fluorspar is used, but there is a tendency for more slopping than normal to occur. It is possible to decrease slopping by a device of shooting fluorspar and by adjusting the oxygen pressure. The yield was $90 \%$ at the first time of operation, then increased to $91.6 \%$.

The influence of fluorspar on the furnace refractory or ladle refractory, has not yet been clarified because the number of melting high carbon steel in a campaign is not sufficient. And it seems that there is no serious problems of refractory judging from observation of inner of the vessel.

According to the change of species of steel, fluorspar is increasing nowadays, and the changes of consumption in furnacere refractory and ladle refractory are shown as follows, and there is seen no evident influence of fluorspar.

$\begin{array}{lllll}\text { Fluorspar consumption } & (\mathrm{kg} / \mathrm{t}) & 1.9 & 2.2 & 3.3 \\ \text { Furnace refractory } & (\mathrm{kg} / \mathrm{t}) & 6.5 & 6.2 & 5.5 \\ \text { Ladle refractory } & (\mathrm{kg} / \mathrm{t}) & 3.6 & 3.5 & 3.2\end{array}$

On re-phosphorization - many factors can be thought. It is considered that higher $\mathrm{P}_{2} \mathrm{O}_{5}$ in the slag causes higher re-phosphorization. To prevent rephosphorization, we are adopting the method of lessening slag engulfed in the stream of tapping steel or the method to add lime in the ladle to harden the slag in the ladle, and no other special devices are adopted. Our objective end point phosphor is under $0.020 \%$.

\section{Chairman}

Listening to the lectures and discussion, I have been much impressed that the technique of melting high carbon steel by the LD process has been developed very rapidly in every works despite of being a new technique. But it is considered premature to draw a conclusion from the discussion, because of poor experience of operation. However, I think that technique of high carbon melting of our country has been developed and will be developed considerably comparing with that of foreign countries. In any way, technique being yet at the first stage, steady study and co-work of you, are by all means necessary for the further development.

I would like to thank all of you in the audience, and also express my gratitude to all who kindly extended support for the meeting. 